\title{
Quality of care and quality of life in Inflammatory Bowel Disease: A European Study
}

Citation for published version (APA):

van der Eijk, I. (2002). Quality of care and quality of life in Inflammatory Bowel Disease: A European Study. [Doctoral Thesis, Maastricht University]. Datawyse / Universitaire Pers Maastricht. https://doi.org/10.26481/dis.20020215ie

Document status and date:

Published: 01/01/2002

DOI:

10.26481/dis.20020215ie

Document Version:

Publisher's PDF, also known as Version of record

\section{Please check the document version of this publication:}

- A submitted manuscript is the version of the article upon submission and before peer-review. There can be important differences between the submitted version and the official published version of record.

People interested in the research are advised to contact the author for the final version of the publication, or visit the DOI to the publisher's website.

- The final author version and the galley proof are versions of the publication after peer review.

- The final published version features the final layout of the paper including the volume, issue and page numbers.

Link to publication

\footnotetext{
General rights rights.

- You may freely distribute the URL identifying the publication in the public portal. please follow below link for the End User Agreement:

www.umlib.nl/taverne-license

Take down policy

If you believe that this document breaches copyright please contact us at:

repository@maastrichtuniversity.nl

providing details and we will investigate your claim.
}

Copyright and moral rights for the publications made accessible in the public portal are retained by the authors and/or other copyright owners and it is a condition of accessing publications that users recognise and abide by the legal requirements associated with these

- Users may download and print one copy of any publication from the public portal for the purpose of private study or research.

- You may not further distribute the material or use it for any profit-making activity or commercial gain

If the publication is distributed under the terms of Article $25 \mathrm{fa}$ of the Dutch Copyright Act, indicated by the "Taverne" license above, 


\section{Quality of Care \& Quality of Life in Inflammatory Bowel Disease}

A European study 
${ }^{\circ}$ Ingrid van der Eijk, Maastricht 2002

ISBN 9052783365

Financial support by the European Commission (BIOMED PL963522).

Printing of this thesis was financially supported by Astra Zeneca, Byk, Maag Lever Darm Stichting, MSD and Tramedico.
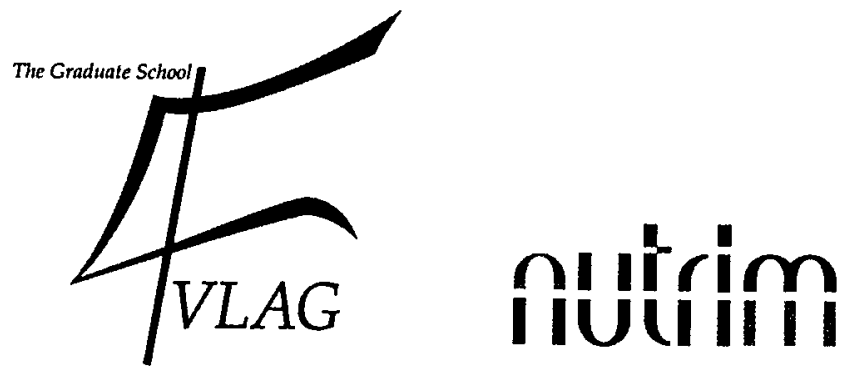

The study presented in this thesis was performed at the Nutrition and Toxicology Research Institute Maastricht (NUTRIM), which participates in the Graduate School VLAG (Food Technology, Agrobiotechnology, Nutrition and Health Sciences) accredited by the Royal Netherlands Academy of Arts and Sciences. 


\title{
Quality of Care \& Quality of Life in Inflammatory Bowel Disease
}

\author{
A European study
}

\author{
PROEFSCHRIFT \\ ter verkrijging van de graad van doctor \\ aan de Universiteit Maastricht, \\ op gezag van Prof. dr. A.C. Nieuwenhuijzen Kruseman, \\ rector magnificus, \\ volgens het besluit van het College van Decanen, \\ in het openbaar te verdedigen \\ op vrijdag 15 februari 2002 om 14.00 uur
}

door

Ingrid van der Eijk

geboren op 7 februari 1972 te Eindhoven

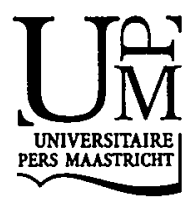




\section{Promotor}

Prof. dr. R.W. Stockbrügger

Co-promotor

Dr. M.G.V.M. Russel

Beoordelingscommissie

Prof. dr. C. Spreeuwenberg (voorzitter)

Prof. dr. C.G.M.I. Baeten

Prof. dr. R.P.T.M. Grol

Prof. dr. E.J. Irvine (Mc Master University, Hamilton, Canada)

Prof. dr. C.A. O'Morain (Adelaide \& Meath University Hospital, Dublin, Ireland) 
Voor mijn grootouders 


\section{Contents}

Chapter 1 Introduction 9

Chapter 2 Influence of quality of care on quality of life in inflammatory bowel disease (IBD): literature review and studies planned 17

Chapter 3 Quality of Health Care in IBD: development of a reliable questionnaire (QUOTE-IBD) and first results

Chapter 4 Which factors influence Quality of Life in patients with IBD: A role for Quality of Care?

Chapter 5 Quality of Care for patients with inflammatory bowel disease (IBD): opinions of physicians and patients

Chapter 6 Best practice in inflammatory bowel disease a European survey

Chapter $7 \quad$ IBD in Europe: Health care consumption and Quality of Life 93

$\begin{array}{lll}\text { Chapter } 8 & \text { General discussion and conclusions } & 107\end{array}$

Chapter 9 Summary

Chapter 10 Samenvatting

Dankwoord

Curriculum Vitae 
Chapter 1

Introduction 
$10 /$ Chapter I 


\section{Inflammatory Bowel Disease}

Crohn's disease (CD) and ulcerative colitis (UC) are chronic inflammatory disorders of unknown origin, collectively referred to as inflammatory bowel disease (IBD). The inflammation in UC is confined to the mucosal layer and affects the large bowel only, being usually superficial. CD can affect any part of the gastrointestinal tract from mouth to anus, although the most common sites to be involved are the terminal ileum and coecum. Unlike UC, the inflammation of $C D$ is not necessarily continuous and areas of ulceration may be interspersed by relatively normal mucosa. The inflammatory process can affect all layers of the gastrointestinal wall. In IBD patients, a wide spectrum of disease severity is observed, with respect to the site, nature and extent of intestinal involvement, as well as the presence or absence of extraintestinal manifestations.

\section{Descriptive epidemiology}

In Europe and in the United States, IBD appears to be more common in northern than in southern areas ${ }^{1,2}$. The European average annual incidence for the two diseases was 5.9 for $C D$ and 11.2 for $U C^{\prime}$. A recent study conducted in The Netherlands showed incidence rates of 6.9 per 100,000 and year for CD, and 10.0 for UC, respectively ${ }^{3}$. Comparison of these age and sex standardised incidence rates with those of other countries can be misleading, as different diagnostic facilities and disease definitions may have been used. The age distribution in $C D$ shows a peak incidence between 15 and 30 years of age, being higher in females than in males ${ }^{3}$. On the other hand, UC appears to be equally distributed between genders, although a male preponderance is frequently observed in the older age groups ${ }^{3.5}$. The number of newly diagnosed $C D$ patients has increased over the last decades, while the incidence of UC has shown a more constant picture ${ }^{6}$.

\section{Quality of Life}

Since the effectiveness of medical and surgical therapy remains limited in IBD, many patients pay frequent visits to their general practitioner and specialist. Some require recurrent hospitalisations for problems due to their intestinal disease. This might cause work absenteeism, as well as stress due to uncertainties about future health.

Assessment of clinical disease activity provides some indication about the impact of $\mathrm{IBD}^{7.9}$, but quality of life measures such as functional status and diseaserelated concerns have been shown to represent better the patients' perceptions 
of their health status ${ }^{10.16}$. Health-related quality of life (HRQOL) is a global concept that incorporates the patients' perceptions, attributions, and daily level of function in response to an illness. It is influenced by social, cultural, psychological, and disease-related factors ${ }^{16}$.

\section{Quality of Care}

The chronic nature of IBD usually results in long-term need for health care by these patients. Therefore, the quality of the provided health care may play a particularly important role in their lives. Few European and North American studies have been conducted in IBD patients concerning quality of care (Q०C). Issues such as providing information to patients ${ }^{17,18}$ and consumption and cost of health care ${ }^{19-21}$ have been addressed, but the total concept of QoC has never been investigated.

Donabedian has developed a model to link health care to health outcome ${ }^{22}$. The "structure-process-outcome" characterisation of this model defines structure as characteristics of the health care system, whereas process addresses the encounter between a physician or another health care professional and a patient ${ }^{23-25}$. Outcome refers to the patient's subsequent health status, which is the end result of care (e.g. quality of life). 


\section{Aims of the study and thesis outline}

This thesis attempts to provide further insights into the role of quality of care in IBD in a European context.

The following aims are addressed:

1. Developing a questionnaire to assess the patients' perspective on the quality of the provided care in a multinational setting.

2. Assessing a complete overview of the quality of care provided for IBD patients from different perspectives and in eight different countries.

3. Investigation of a possible relationship between quality of care and quality of life.

Fourteen centres of the European Collaborative study group on Inflammatory Bowel Disease (EC-IBD) in eight countries have contributed to the studies presented in this thesis. The have been collaborating in epidemiological multicentre studies in IBD since 1990, for which they have created a populationbased inception cohort of 1177 patients between 1991 and 19931,26. CD and UC were defined according to the criteria of Lennard-Jones ${ }^{27}$.

Chapter 2 of this thesis critically reviews the current knowledge about methods to study QoC in the chronically ill, focusing on those with IBD. The development and validation of an IBD-specific questionnaire to assess the patients' perspective on QoC, respectively in a European and Dutch population, is presented in Chapter 3. The role of QoC in HRQOL in IBD is described in Chapter 4. This was studied in a multi-national cross-sectional design. IBD patients diagnosed six to eight years prior to the study were included. Data on HRQoL and QoC were assessed by existing as well as specifically for this study developed patient questionnaires. Chapter 5 pays attention to a study investigating the perspective of physicians treating IBD patients in eight different countries. Comparison with patients' perspectives can be useful to determine necessary changes in practices to optimise health care for both patients and physicians. In addition, Chapter 6 discusses a survey of the available health care facilities and policies for IBD in twelve participating European hospitals. Both qualitative and quantitative observations were assessed during professional peer reviews of the centres and used to suggest best practice in IBD. Health care consumption of IBD patients in the respective hospitals, and the possible relationship of this feature with HRQoL, are described in Chapter 7. In this study, data on HRQoL and disease activity were assessed by means of a patient questionnaire, whereas health care consumption and several background variables were assessed by objective data collection from patient files.

Finally, the results of the various studies in this thesis, in relation to each other and in the light of information from current literature, are discussed in Chapter 8. 


\section{References}

1 Shivananda S, Lennard-Jones JE, Logan R, Fear N, Price A, Carpenter $L$, et al. Incidence of inflammatory bowel disease across Europe: is there a difference between north and south? Results of the European Collaborative Study on Inflammatory Bowel Disease (EC-IBD). Gut 1996;39:690-7.

2 Sonnenberg A. Geographic variation in the incidence of and mortality from inflammatory bowel disease. Dis Colon Rectum 1986;29:854-61.

3 Russel MG, Dorant E, Volovics A, Brummer R-J, Pop P, Muris JW, et al. High incidence of inflammatory bowel disease in the Netherlands. Dis Colon Rectum $1998 ; 41: 33-40$.

4 Langholz E, Munkholm P, Nielsen OH, Kreiner S, Binder V. Incidence and prevalence of ulcerative colitis in Copenhagen county from 1962 to 1987 . Scand J Gastroenterol 1991;26:1247-56.

5 Moum B, Vatn MH, Ekbom A, Aadland E, Fausa O, Lygren I, et al. Incidence of Crohn's disease in four counties in southeastern Nonway, 1990-93. Scand J Gastroenterol 1996;31:355-61.

6 Sandler RS. Epidemiology of inflammatory bowel disease. In: Targan SR, Shanahan $F$, editors. Inflammatory bowel disease; from bench to bedside. Baltimore, Maryland: Williams \& Wilkins, 1994:5-32.

7 Best WR, Becktel JM, Singleton JW, Kern F. Development of a Crohn's disease activity index. Gastroenterology 1976;70:439-44.

8 Harvey RF, Bradshaw JM. A simple index of Crohn's disease activity. Lancet 1980;1:514.

9 Lichtiger S, Present DH, Kornbluth A, Gelernt I, Bauer J, Galler G, et al. Cyclosporine in severe ulcerative colitis refractory to steroid therapy. New Engl J Med 1994;330:1841-5.

10 Drossman DA, Patrick DL, Mitchell CM, Zagami EA, Appelbaum MI. Health-related quality of life in inflammatory bowel disease. Dig Dis Sci 1989;34:1379-86.

11 Drossman DA. Measuring quality of life in inflammatory bowel disease. Pharmacoecon 1994;6:578-80.

12 Drossman DA. Quality of life issues in Crohn's disease. In: Prantera C, Korelitz Bl, editors. Crohn's disease. New York: Marcel Dekker Inc., 1996: 445-53.

13 Guyatt GH, Feeny DH, Patrick DL. Measuring health-related quality of life. Ann Int Med 1993;1 18:622-9.

14 Irvine EJ. Measuring health-related quality of life in IBD. In: Tiifgat G, Bartelsman JFW, van Deventer SJ, editors. Inflammatory Bowel Diseases, Falk Symposium 85. Dordrecht, Boston, London: Kluwer Academic Publishers, 1995:319-33.

15 Guyatt GH, Mitchell A, Irvine EJ, Singer J, Williams N, Goodacre R, et al. A new measure of health status for clinical trials in inflammatory bowel disease. Gastroenterology 1989;96:804-10.

16 Garrett JW, Drossman DA. Health status in inflammatory bowel disease. Gastroenterology 1990;99:90-6. 
17 Mayberry JF. The diagnosis of inflammatory bowel disease - What should we tell the patient? Ital J Gastroenterol Hepatol 1997;29:483-6.

18 Smart H, Mayberry JF, Calcraft B, Morris JS, Rhodes J. Effect of information booklet on patients' anxiety levels and consultation rates in Crohn's disease. Public Health 1986; 100:184-6.

19 Silverstein MD, Loftus EV, Sandborn WJ, Tremaine WJ, Feagan BG, Nietert PJ, et al. Clinical course and costs of care for Crohn's disease: Markov model analysis of a population-based cohort. Gastroenterology 1999;117:49-57.

20 Blomquist P, Ekbom A. Inflammatory Bowel Disease: Health Care and Costs in Sweden in 1994. Scand J Gastroenterol 1997;32:1134-9.

21 Hay JW, Hay AR. Inflammatory bowel disease: costs-of-illness. J Clin Gastroenterol 1992;14:309-17.

22 Donabedian A. Evaluating the quality of medical care. Milbank Mem Fund $Q$ 1966;44 (suppl):166-206.

23 van Campen C, Sixma H, Friele RD, Kerssens JJ, Peters L. Quality of care and patient satisfaction: a review of measuring instruments. Med Care Res Rev 1995;52:109-33.

24 Hall JA, Dornan MC. Meta-analysis of satisfaction with medical care: description of research domain and analysis of overall satisfaction levels. Soc Sci Med $1988 ; 27: 637-44$.

25 Pascoe GC. Patient satisfaction in primary health care: a literature review and analysis. Eval Progr Plan 1983;6:185-210.

26 Lennard-Jones JE, Shivananda S. Clinical uniformity of inflammatory bowel disease at presentation and during the first year of disease in the north and south of Europe. Eur J Gastroenter Hepatol 1997;9:353-9.

27 Lennard-Jones JE. Classification of inflammatory bowel disease. Scand J Gastroenterol 1989;24(Suppl 170):2-6. 


\section{Chapter 2}

Influence of quality of care on quality of life in inflammatory bowel disease (IBD): literature review and studies planned

I van der Eijk, R Stockbrügger, M Russel

European Journal of Internal Medicine 2000; 11:228-34 
$18 \mid$ Chapter 2

\section{Abstract}

Inflammatory bowel disease (IBD) is a chronic disorder with an early onset in life. Therefore, it is reasonable to assume that IBD patients are in considerable need of health care. The quality of life of IBD patients is reported to be impaired. Whether optimising the quality of health care for these patients may positively influence their quality of life is a question that has been raised often during recent years. This review of the literature on health care research discusses different concepts regarding the quality of care assessment in chronic disease, stresses the need to see things from the patient's perspective, and provides recommendations to optimise health care research. The two most important conclusions that can be drawn are that (1) the relationship between quality of health care and quality of life in IBD is one that is certainly worth studying and (2) when developing a means to assess patient data on quality of care, it is essential to involve patients from the very start. 


\section{Introduction}

Since inflammatory bowel disease (IBD) is a chronic disorder, health care plays an important role in the life of this patient group. The quality of the health care provided may influence the quality of life of patients with such a chronic disease. This review focuses on methods to study the quality of health care in the chronically ill, concentrating on those with IBD. The protocol used by the European Collaborative Study Group on Inflammatory Bowel Disease to study the relationship between quality of care and quality of life in IBD patients will be discussed.

\section{Inflammatory bowel disease}

Crohn's disease (CD) and ulcerative colitis (UC) are chronic inflammatory disorders of the gut. They are collectively described as inflammatory bowel disease (IBD). IBD can commence at any time during life, but it primarily affects young people (the highest incidence rate observed is between the age of 20 and 40 years). The incidence of IBD in Europe is around 16 new patients per 100,000 inhabitants per year, and the prevalence is $160-320$ per 100,000 inhabitants ${ }^{1,2}$.

UC is primarily a mucosal inflammation involving the rectum and colon. In a number of patients it is characterised by complaints of abdominal cramps, rectal bleeding, diarrhoea, urgency, weight loss, and systemic signs of inflammation. $C D$ is a transmural inflammation and can occur in any part of the gastrointestinal tract, but it is mainly localized in the terminal ileum and colon. Disease characteristics are diarrhoea, abdominal pain, anorexia, weight loss, fever, nausea, and fatigue. Other clinical features of $C D$ include narrowing and obstruction of the bowel, abscess and fistula formation and, on rare occasions, perforation. Unlike UC, the inflammation in $C D$ is not necessarily continuous. Areas of ulceration can be interspersed with normal mucosa.

Exacerbations of varying acuity and severity occur intermittently. Extra-intestinal complaints involving the eyes, joints, skin, and hepatobiliary system may also be associated with both $C D$ and UC. Most patients need continuous medication and are at an increased risk of undergoing abdominal surgery. Current therapy is not curative but palliative, mainly supportive or immunosuppressive. Obviously, all complaints can have profound effects on everyday activities. The cause of IBD is not known, but both genetic and environmental factors may play a role ${ }^{3,4}$. 


\section{Health care use in IBD}

\section{Utilisation}

Chronically ill patients are consistently high users of health care services, especially those with a normal life expectancy, as IBD patients ${ }^{5}$. The early onset and sometimes intensive course of IBD can result in a considerable need for health care. Quite often exacerbations can only be treated with the patient admitted to the hospital, whereas outpatient visits are common in order to monitor medication ${ }^{6}$. Although IBD patients use certain health care services more often than other patients, they seem to know precisely what type of care they are looking for and do not use the health care system indiscriminately. They first turn for help to their own gastroenterologist or internist because of his/her expertise in IBD. When they are in need of a second opinion, they consult another gastroenterologist, not another specialist $t^{5}$. Generally known predisposing factors such as age, sex, race, education, and marital status do not seem to predict health care utilisation in IBD ${ }^{7,8}$.

\section{Health care system}

The health care system can be defined as a complex network of relationships among individuals and organisations pursuing their respective goals and interests in the delivery or financing of health services and the use of these services. Exchanges occur between organisational purchasers and providers, and between providers and patients ${ }^{9}$. Relatively little research exists on the ideal mix, organisation, or orientation of providers to effectively satisfy the needs of the chronically ill patient. Patients, providers, and purchasers must be able to integrate, access, respond to, and modify health and health care mechanisms ${ }^{10}$. It is essential to identify, develop, and implement a system of care that is unique to those with specific, long-term health concerns.

\section{Costs}

Most of the money available for health care is spent on chronic illnesses and their associated complications. In terms of societal costs, IBD is less costly than, for example, rheumatic and coronary diseases, since disability and early death are less common and disease prevalence is lower. However, in terms of medical costs per patient lifetime, IBD costs can be higher than those for most other diseases, depending on the age at onset and the severity of the illness ${ }^{11,12}$. As the population of a country increases and ages, the prevalence of chronic illnesses will continue to rise, resulting in an increasing demand for a health care delivery system unique to the needs and resources of this population ${ }^{13}$. 


\section{Quality of care in relation to quality of life in IBD}

\section{Quality of life}

Quality of life is now firmly established as an important endpoint in medical care, especially for chronic diseases for which a cure is unlikely. The term "quality of life" stands for the subjective perception of objective circumstances. In relation to a chronic illness like IBD, quality of life is preferably referred to as health-related quality of life, which can be defined as "the value assigned to duration of life, modified by the impairments, functional states, perceptions, and social opportunities that are influenced by disease, injury, treatment, or policy". Essentially, health and quality of life outcomes involve a trade-off between how long an individual or population lives and how well they live ${ }^{14}$. When patients are diagnosed as having a chronic disease, they are immediately forced to make major lifestyle changes and to add various care-related tasks to their daily activities. These behavioural changes are requested by the health care professionals. Many of these changes are without any immediate reward or recognition for the patient ${ }^{13}$. From both an ethical and a financial point of view, it is desirable to minimise the negative effects of IBD on everyday activities and, thus, to maintain or enhance the quality of life of patients suffering from this disease. An improvement in quality of life may be induced by optimising the quality of health care ${ }^{7,9}$.

\section{Assessing quality of life in IBD}

It has been shown that quality of life is a multidimensional concept ${ }^{15-17}$. Therefore, it needs to be measured from multiple perspectives. It has been stated that only those components of quality of life that can reasonably be expected to be affected by the illness should be measured ${ }^{18,19}$. An extensive literature search produced four variables that have indisputably been proven to affect quality of life in IBD patients. In addition to disease activity, these are perceived adequacy of social support, psychological status, and coping strategies ${ }^{20-27}$. Controversial literature exists on the influence of stressful life events, indicating that this variable should not be discarded in the assessment of quality of life ${ }^{23,28-31}$.

\section{Quality of care}

Quality of care has become a key issue in health care. An increasing number of activities have been performed in order to assure and, wherever possible, to improve the quality of care. Experts have tried for decades to formulate a concise, meaningful, and generally applicable definition of the quality of health care. One of the most widely cited definitions, formulated by the Institute of Medicine in 1990, holds that quality of care consists of the "degree to which health services for individuals and populations increase the likelihood of desired health outcomes and are consistent with current professional knowledge ${ }^{\prime \prime 32,33}$. Good care is certainly not only the absence of bad events. Different perspectives 
and definitions of quality will logically call for different approaches to its measurement and management ${ }^{34,35}$.

\section{Quality of care in IBD}

Only a few aspects of quality of care have been studied in IBD. One of these is the amount of information IBD patients receive. It was demonstrated that most IBD patients reported a lack of information concerning various aspects of their disease ${ }^{36 \cdot 38}$. Lower information level scores were associated with more severe worries and concerns of the patients and, accordingly, with decreased quality of life in IBD ${ }^{21}$. Another aspect of health care that has been studied is the possibility of obtaining life insurance, a financial aspect that is of great importance to the patient. Several population-based studies have found that the mortality of IBD patients differs little from that of the general population ${ }^{39.44}$. Despite these relatively recent data, it has been shown that patients with IBD continue to have difficulty obtaining life insurance because insurance companies often use outdated mortality tables ${ }^{45}$. It was also found that insurance companies use mean data about the course of IBD to determine individual premium loads, while the severity of symptoms is known to vary considerably between patients ${ }^{46,47}$.

These studies imply that these aspects of quality of care need to be improved. They also indicate the need to investigate all aspects of quality of care in IBD. A conceptual construct for studying the relationship between quality of health care and quality of life in IBD is represented in Figure 2.1.

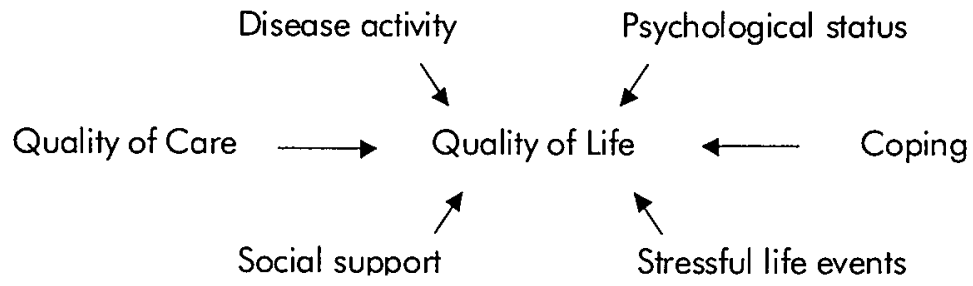

Figure 2.1: Variables influencing quality of life in IBD

Quality of care and health outcomes

To link components of health care with health outcomes, Donabedian introduced the structure-process-outcome characterisation ${ }^{48}$. This conceptual framework defines structure as characteristics of the health care system, such as the individuals and institutions providing care. Structure can be subdivided into four dimensions: accessibility, costs, accommodation, and continuity of care. Process encompasses the components of the actual encounter between a physician or other health care professional and a patient. Process can be subdivided into: courtesy, information, competence, and autonomy ${ }^{49,50}$. 
Outcome refers to the patient's subsequent health status, the end result of care (e.g., population health status, life expectancy, and quality of life $)^{9,48,51}$. Process data are usually more sensitive measures of quality than outcome data, as a poor outcome does not occur every time there is an error in the provision of care. The assessment of quality of care should depend more on process data than on outcome data ${ }^{52}$.

It has been said that satisfaction with care is predictive of whether or not a person seeks medical advice, complies with treatment, and maintains a continuing relationship with a physician ${ }^{53,54}$. This is particularly true in long-term care. When an individual is subject to long-term care, the perceived quality of care can become synonymous with the subjective quality of life. It is, therefore, worthwhile investigating the patient's view of high quality care. Care assumed to be of high quality according to provider-defined criteria is far from ideal if, as a result of that care, the patient is unhappy or dissatisfied. There is, then, a sound rationale for making the organisation and delivery of health care responsive to consumer opinion ${ }^{54}$.

\section{Quality of care research: the patient's view}

\section{Provider versus patient}

The provider's perspective, which is reflected the most in the majority of existing instruments, differs substantially from that of the user of health care facilities ${ }^{51,55}$. 58. Each patient comes to the physician's office with a unique set of vulnerabilities, past experiences, and stores of knowledge. These variables influence the physician's interpretation of symptoms and lead the patient to expect a certain response from the physician. The physician's actual response is then evaluated in light of the patient's expectations. It has been observed that patient reports lead to positive changes in the behaviour of clinicians and health care delivery organisations, so that not only does patient satisfaction improve, but unfulfilled expectations are also reduced ${ }^{59,60}$.

In early studies of the patient's perspective on quality of care, it was found that the opinion of patients resulted in higher scores than the opinion of physicians, indicating the need for both the patient's opinion and other evaluations of the care situation in order to create a complete view of the care provided. Comparisons should be made across types of care, facilities, and physicians to gain insight into what the patient regards as important in care and how he/she feels about the care he/she receives ${ }^{61}$.

\section{The patient's opinion}

The technical medical record contains little or no information about interpersonal quality of care. A key reason for this information gap is the lack of a standardized tool for measuring patient perceptions and their opinion of health care $^{62}$. Health care professionals have often neglected the importance of 
patient's perspectives in the belief that patients have very limited knowledge of what constitutes quality, and because of the difficulty of measuring patient's views accurately and reliably. An inaccurate reflection of the patient's real opinions can occur due to changes in response because the subject knows he/she is being evaluated, as well as to difficulties with recall of events concerning care during a certain period of time ${ }^{35,55,61}$. On the other hand, patients tend to believe that their physicians determine the quality of care they receive. They may find it difficult to appreciate technical measures of quality and may place greater weight than their physicians on measures of convenience for patients, such as physician's availability and waiting time for appointments ${ }^{63}$.

More and more attention is being paid to the contribution that patients can make to improve the quality of their care ${ }^{64}$. Increasing competition has made providers of care more sensitive to notions of customer service. The criteria for optimal care are changing ${ }^{65}$. Changes in medical practice call for new methods to measure and improve quality.

\section{Satisfaction with care}

Patient views on the quality of health care have often been assessed by means of patient satisfaction questionnaires. Patient satisfaction is regarded to be of paramount importance with respect to quality assurance and the expected outcome of care. Typically, 70\% of patients report "being satisfied" with care; similarly, fewer than $10 \%$ of patients report any specific dissatisfaction ${ }^{66,67}$. Satisfaction has been found to be related to improvement in condition, personal interest of the staff in the patient, and information received about their condition $^{61,68}$. However, the relevance and uniformity of patient satisfaction studies with respect to quality management in the health care sector is offen questioned because of conceptual and operational problems. A theoretical framework is missing for most instruments developed in this area of health care research. Theory and methodology in this field seem to have developed separately from each other, and a well-defined socio-psychological theory of patient satisfaction has not yef been developed ${ }^{51,62}$.

\section{Perception of care}

During recent years, a new conceptual framework for measuring quality of care from the patients' perspective, based on delivered and perceived service, has been developed. Good performance is associated with good quality of care, and vice versa. Although the frequency of poor performance, as perceived by the patient, is highly relevant in quality assessment programs, some problems are more important to patients than others, both on the population level and on the level of the individual patient. Importance is defined as the "degree to which performance is related to satisfaction ${ }^{167}$. Quality judgments of patients can be derived from importance and performance scores of different health care aspects $^{51}$. This concept of patient perceptions differs from the concept of patient satisfaction, in that perceptions measure whether a patient's expectations are met, in addition to satisfaction. Valid and reliable patient survey data can enable 
physicians to identify areas for improvement and demonstrate to external reviewers the quality of care they provide to their patients ${ }^{69}$. Questions that ask for "reports" about events that did or did not happen during a clinical encounter (compared to satisfaction questions) tend to better reflect the quality of care and are both easier to interpret and to implement for quality improvement purposes ${ }^{70,71}$. It has been stated that patients' perception of their care is, in itself, the most important outcome of care ${ }^{69}$.

\section{Global assessment of health care impact}

Chronically ill patients cannot be ignored when assessing health care quality, since this group may be particularly vulnerable to undertreatment as a means of cost containment. As a result, developing standardised, sound, quality assessment tools for chronically ill patients should become an important priority ${ }^{72}$. One of the principal advantages of a standardised instrument is the possibility of comparison with data produced in other research. This is dependent, in part, on the instrument's reliability, but also on the stability of the population from which samples are drawn ${ }^{73}$.

It has been shown that the opinions of patients who have multiple contacts with the health care system (elderly patients, those with multiple hospitalisations, and patients with chronic diseases) with regard to the care they receive score higher than the opinions of other patients ${ }^{68,70}$. This implies that separate measures are needed in order to be able to distinguish differences in perceptions within these groups.

Studies that explicitly link delivery systems to patient-reported quality of life outcomes seldom demonstrate differences in care delivery systems. New models of research are needed to advance our understanding of the relationships between organisational arrangements, the processes of health care, and health outcomes?.

An overview of the most important steps in the development of an instrument to assess health care data in a chronically ill patient group, is given in Table 2.1A. The challenge is to identify the variations that produce the best outcomes and for which general guidelines can be developed ${ }^{77,78}$. The ideal health care system is impossible, not only because medical possibilities, cultural values, and environmental conditions are constantly changing, but also because the ideal situation presupposes an unlimited supply of resources. Guidelines for the improvement of a health care system can only be developed within the context and culture of a particular population ${ }^{80}$. The most important steps to improve the quality of health care are summarised in Table 2.1B. 
Table 2.1 Health care assessment and improvement in the chronically ill

\begin{tabular}{|c|c|}
\hline \multicolumn{2}{|c|}{ A. Health care assessment } \\
\hline $\begin{array}{l}\text { Step } 1 \\
\text { Step } 2 \\
\text { Step } 3\end{array}$ & $\begin{array}{l}\text { Define patient group } \\
\text { Randomise patients across severity of symptoms } s^{61} \\
\text { Collaborate with patients from the start in the development of a } \\
\text { questionnaire to obtain items that: } \\
\text { 1) are formulated in collaboration with patients } \\
\text { 2) produce data that are related to the patients' needs and expectations }{ }^{74-76} \\
\text { Isolate process and structure dimensions in the questionnaire } \\
\text { Isolate doctor and hospital characteristics in the questionnaire }\end{array}$ \\
\hline \multicolumn{2}{|c|}{ B. Health care improvement } \\
\hline $\begin{array}{l}\text { Step } 6 \\
\text { Step } 7 \\
\text { Step } 8\end{array}$ & $\begin{array}{l}\text { Study the influence of health care on health outcomes } \\
\text { Generate guidelines in consensus of all participants in health care } \\
\text { Implement and continually evaluate guidelines at a local level }\end{array}$ \\
\hline
\end{tabular}

\section{Influence of quality of care on quality of life in IBD - the EC-IBD study}

The European Collaborative Study Group on Inflammatory Bowel Disease (ECIBD) consists of 20 centres in 12 countries. They have been collaborating in epidemiological multi-centre studies in IBD since 1990, for which they created a population-based inception cohort of 2201 patients between 1991 and $1993^{2,81}$.

Because the quality of health care may influence the quality of life in chronic diseases, 14 centres of the EC-IBD study group in eight countries decided to conduct an extensive study on this relationship in IBD $(n=1177)$. The schematic construct, as presented in Figure 2.1, is used as the study concept for collecting data from IBD patients. Suitable scales are available from previous studies to determine the magnitude of all variables in this schematic construct, except for quality of care. Subsequently, the first step in the EC-IBD study is to develop an instrument that represents the opinion of IBD patients in Europe on quality of care. Patients in different countries (not from the inception cohort) need to be involved in the creation of a scale that produces data on all described dimensions of quality of care ${ }^{48.50}$. Once developed, the questionnaire will be administered to the patient cohort, simultaneously with those for the other variables in the conceptual construct.

In addition, data will be assessed concerning individual health care consumption since diagnosis in order to be able to correct for any possible influence on the patient's opinion of quality of care ${ }^{68,70}$.

To draw the correct conclusions concerning the influence of quality of care on quality of life, all data need to be placed in the light of the local health care systems. Therefore, the local procedures for providing health care in IBD will be studied and described in all participating centres. The perspective of the treating 
physicians on quality of care will also be assessed, as it has been proven that this differs from the patient's view ${ }^{51,55.58}$. Background variables regarding the professional life of the treating physicians will be described as well for a complete, objective estimate of the quality of care provided.

Guidelines to optimise quality of health care in IBD cannot be developed before data from these sources are collected, analysed, and combined. 


\section{References}

1 Russel MG, Dorant $E$, Volovics $A$, et al. High incidence of inflammatory bowel disease in the Netherlands. Dis Colon Rectum 1998;41:33-40.

2 Shivananda S, Lennard Jones J, Logan $R$, et al. Incidence of inflammatory bowel disease across Europe: is there a difference between north and south? Results of the European Collaborative Study on Inflammatory Bowel Disease (EC-IBD). Gut 1996;39:690-7.

3 Lochs $\mathrm{H}$. Consequences of aetiological hypotheses for the treatment of IBD. In: Scholmerich J, Kruis W, eds. IBD, pathophysiology as a basis for treatment. Dordrecht: Kluwer Academic Publishers, 1993;30-5.

4 Russel MGVM, Stockbrugger RW. Review: Epidemiology of inflammatory bowel disease: an update. Scand J Gastroenterol 1996;31:417-27.

5 Verhoef MJ, Sutherland L. Outpatient health care utilisation of patients with inflammatory bowel disease. Dig Dis Sci 1990;35:1276-80.

6 Blomquist P, Ekbom A. Inflammatory Bowel Disease: Health Care and Costs in Sweden in 1994. Scand J Gastroenterol 1997;32:1134-9.

7 de Boer AGEM, Sprangers MAG, Bartelsman JFW, de Haes JCJM. Predictors of health care utilization in patients with inflammatory bowel disease: a longitudinal study. Eur J Gastroenter Hepatol 1998; 10:783-9.

8 de Boer AGEM, Wiiker W, de Haes JCJM. Predictors of health care utilization in the chronically ill: a review of the literature. Health Policy 1997;42:101-15.

9 Patrick DL. Finding health-related quality of life outcomes sensitive to health-care organization and delivery. Med Care 1997;35:NS49-NS57.

10 Grazier KL. The chronically ill and managed care. J Healthcare Managem 1998;43:477-9.

11 Silverstein MD, Loftus EV, Sandborn WJ, et al. Clinical course and costs of care for Crohn's disease: Markor model analysis of a population-based cohort. Gastroenterology 1999;117:49-57.

12 Hay JW, Hay AR. Inflammatory bowel disease: costs-of-illness. J Clin Gastroenterol 1992;14:309-17.

13 Etzwiler DD. Chronic care: a need in search of a system. Diab Educ 1997;23:56973.

14 Smith KW, Avis NE, Assmann SF. Distinguishing between quality of life and health status in quality of life research: A meta-analysis. Qual Life Res 1999;8:447-59.

15 Love JR, Irvine EJ, Fedorak RN. Quality of life in inflammatory bowel disease. J Clin Gastroenterol 1992;14:15-9.

16 Mitchell A, Guyatt GH, Singer J, Irvine EJ, Goodacre R, Tompkins C, et al. Quality of life in patients with inflammatory bowel disease. J Clin Gastroenterol 1988;10:30610.

17 Ware JE, Sherbourne CD. The MOS 36-item short-form health survey (SF-36). Med Care 1992;30:473-81. 
18 Aaronson NK. Quality of life: what is it? How should it be measured? Oncology 1988;2:69-74.

19 Jalowiec A. Issues in using multiple measures of quality of life. Sem Onc Nurs $1990 ; 6: 271-7$.

20 Turnbull GK, Vallis TM. Quality of life in inflammatory bowel disease: the interaction of disease activity with psychosocial function. Am J Gastroenterol 1995;90: 1450-4.

21 Moser G, Tillinger W, Sachs G, Genser D, Maier-Dobersberger T, Spiess K, et al. Disease-related worries and concerns: a study on out-patients with inflammatory bowel disease. Eur J Gastroenterol Hepatol 1995; 7:853-8.

22 McColl MA, Skinner H. Assessing inter- and intrapersonal resources: social support and coping among adults with a disability. Dis Rehab 1995;17:24-34.

23 Sherbourne CD, Meredith LS, Rogers W, Ware JE. Social support and stressful life events: age differences in their effects on health-related quality of life among the chronically ill. Qual Life Res 1992;1:235-46.

24 Drossman DA, Patrick DL, Mitchell CM, Zagami EA, Appelbaum MI. Health-related quality of life in inflammatory bowel disease. Dig Dis Sci 1989;34:1379-86.

25 Drossman DA, Leserman J, Mitchell M, Li Z, Zagami EA, Patrick DL. Health status and health care use in persons with inflammatory bowel disease. Dig Dis Sci $1991 ; 36: 1746-55$.

26 Kinash RG, Fischer DG, Lukie BE, Carr TL. Coping patterns and related characteristics in patients with IBD. Rehabil Nurs 1993;18:12-9.

27 Lazarus RS. Coping theory and research: past, present, and future. Psychosom Med $1993 ; 55: 234$.

28 Duffy LC, Zielezny MA, Marshall JR, et al. Relevance of major stress events as an indicator of disease activity prevalence in inflammatory bowel disease. Behav Med $1991 ; 101-10$.

29 Levenstein S, Prantera C, Varvo V, et al. Life stresses and effects on ulcerative colitis. Am J Gastroenterol 1994;87:1219-25.

30 North CS, Alpers DH, Helzer JE, Spitznagel EL, Clouse RE. Do life events or depression exacerbate inflammatory bowel disease? Ann Int Med 991;1 14:381-6.

31 von Wietersheim J, Kohler T, Feiereis H. Relapse-precipitating life events and feelings in patients with inflammatory bowel disease. Psychother Psychosom 1992;58:103-12.

32 Lohr KN, Donaldson MS, Harris-Wehling J. Medicare: a strategy for quality assurance. V. Quality of care in a changing health care environment. Qual Rev Bull 1992;18:120-6.

33 Lohr KN. Medicare: a strategy for quality assurance. Washington DC: National Academy Press, 1990.

34 Rosen AK, Berlowitz DR, Anderson JJ, Ash AS, Kazis LE, Moskowitz MA. Functional status outcomes for assessment of quality in long-term care. Int I Qual Health Care $1999 ; 11: 37-46$.

35 Blumenthal D. Quality of health care. Quality of care - what is it? New Engl J Med 1996;335:891-4.

36 Mayberry JF. The diagnosis of inflammatory bowel disease - What should we tell the patient? Ital J Gastroenterol Hepatol 1997;29:483-6. 
37 Smart H, Mayberry JF, Calcraft B, Morris JS, Rhodes J. Effect of information booklet on patients' anxiety levels and consultation rates in Crohn's disease. Public Health 1986;100:184-6.

38 Jones SC, Gallacher B, Lobo AJ, Axon AT. A patient knowledge questionnaire in inflammatory bowel disease. J Clin Gastroenterol 1993;17:21-4.

39 Langholz $E$, Munkholm $P$, Davidsen $M$, Binder V. Colorectal cancer risk and mortality in patients with ulcerative colitis. Gastroenterology 1992;103:1444-51.

40 Munkholm P, Langholz $E$, Davidsen $M$, Binder $V$. Intestinal cancer risk and mortality in patients with Crohn's disease. Gastroenterology 1993; 105:1716-23.

41 Persson PG, Bernell O, Leijonmarck CE, Farahmand BY, Hellers G, Ahibom A. Survival and cause-specific mortality in inflammatory bowel disease: a populationbased cohort study. Gastroenterology 1996;110:1339-45.

42 Ekbom A, Helmick CG, Zack M, Holmberg L, Adami HO. Survival and causes of death in patients with inflammatory bowel disease: a population-based study. Gastroenterology 1992;103:954-60.

43 Probert CS, Jayanthi V, Wicks AC, Mayberry JF. Mortality from Crohn's disease in Leicestershire, 1972-1989: an epidemiological community-based study. Gut 1992;33:1226-8.

44 Probert CS, Jayanthi V, Wicks AC, Mayberry JF. Mortality in patients with ulcerative colitis in Leicestershire, 1972-1989. An epidemiological study. Dig Dis Sci 1993;38:538-41.

45 Moody GA, Mayberry JF. Life insurance and inflammatory bowel disease: is there a discrimination against patients? Int J Colorect Dis 1996;11:276-8.

46 Travis SPL. Review article: insurance risks for patients with ulcerative colitis or Crohn's disease. Aliment Pharmacol Ther 1997;11:51-9.

47 Beck IT, Leddin DJ, Lemire SE, et al. Insurance rating of patients with inflammatory bowel disease: report of a conference on morbidity and mortality. Can $J$ Gastroenterol 1994;8:438-45 .

48 Donabedian A. Evaluating the quality of medical care. Milbank Mem Fund $Q$ 1966;44 (suppl): 166-206.

49 Hall JA, Dornan MC. Meta-analysis of satisfaction with medical care: description of research domain and analysis of overall. Soc Sci Med 1988;27:637-44.

50 van Campen C, Sixma H, Friele RD, Kerssens JJ, Peters L. Quality of care and patient satisfaction: a review of measuring instruments. Med Care Res Rev 1995;52:109-33.

51 Sixma H, Kerssens JJ, van Campen C, Peters L. Quality of care from the patients' perspective: from theoretical concept to a new measuring instrument. Health Expectations 1998; 1:82-95.

52 Brook RH, McGlynn EA, Cleary PD. Quality of health care. Measuring quality of care. New Engl J Med 1996;335:966-70.

53 Al Qatari G, Haran D. Determinants of users' satisfaction with primary health care settings and services in Saudi Arabia. Int J Qual Health Care 1999;1 1:523-31.

54 Locker D, Dunt D. Theoretical and methodological issues in sociological studies of consumer satisfaction with medical care. Soc Sci Med 1978;12:283-92.

55 Borgiel A, O'Neil JJS. Assessing quality in primary care. Can we ask the right questions? Can Fam Phys 1997;43:1699-1700. 
56 Riggs JE. Assessing quality of care. The limitation imposed by condorcet paradox. Arch Neurol 1997;54:1351-2.

57 Jun M, Peterson RT, Zsidisin GA. The identification and measurement of quality dimensions in health care: focus group interview results. Health Care Manag Rev $1998 ; 23: 81-96$.

58 Fagerstrom L, Bergbom Engberg l, Erikkson K. A comparison between patients' experiences of how their caring needs have been met and the nurses' patient classification - an explorative study. J Nurs Manag 1998;6:369-77.

59 Longo DR, Land G, Schramm W, Fraas J, Hoskins B, Howell V. Consumer reports in health care. Do they make a difference in patient care? JAMA 1997;278:1579-84.

60 Kravitz RL, Callahan EJ, Paterniti D, Antonius D, Dunham M, Lewis CE. Prevalence and sources of patients' unmet expectations for care. Ann Int Med 1996; 125:730-7.

61 Lebow JL. Consumer assessments of the quality of medical care. Med Care $1974 ; 12: 328-37$.

62 Meterko M, Nelson EC, Rubin HR, et al. Patients' judgments of hospital quality: report of a pilot study. Med Care 1990;28:S1-S56.

63 Meredith P. But was the operation worth it? The limitations of quality of life and patient satisfaction research in health-care outcome assessment. J Qual Clin Pract 1996; 16:75-85.

64 Casparie AF, van der Waal MAE. Differences in preferences between diabetic patients and diabetologists regarding quality of care: a matter of continuity and efficiency of care? Diab Med 1995; 12:828-32.

65 Larrabee JH, Engle VF, Tolley EA. Predictors of patient-preceived quality. Scand J Caring Sci 1995;9:153-64.

66 Zastowny TR, Stratmann WC, Adams EH, Fox ML. Patient satisfaction and experience with health services and quality of care. Qual Man Health Care 1995;3:50-61.

67 Pascoe GC. Patient satisfaction in primary health care: a literature review and analysis. Eval Progr Plan 1983;6:185-210.

68 Hall JA, Dornan MC. Patient sociodemographic characteristics as predictors of satisfaction with medical care: a meta-analysis. Soc Sci Med 1990;30:81 1-8.

69 Epstein KR, Laine C, Farber NJ, Nelson EC, Davidoff F. Patients' perceptions of office medical practice: judging quality through the patients' eyes. Am J Med Qual $1996 ; 11: 73-80$.

70 Salomon L, Gasquet I, Mesbah M, Ravaud P. Construction of a scale measuring inpatients' opinion on quality of care. Int J Qual Health Care 1999;1 1:507-16.

71 Cleary PD, Edgman-Levitan S. Health care quality. Incorporating consumer perspectives. JAMA 1997;278:1608-12.

72 Smith MA, Atherly AJ, Kane RL, Pacala JT. Peer review of the quality of care. Reliability and sources of variability for outcome and process assessments. JAMA 1997;278:1573-8.

73 Lewis JR, Williamson V. Examining patient perceptions of quality care in general practice: comparison of quantitative and qualitative methods. Brit J General Pract 1995;45:249-53.

74 Lindberg $M$, Ahlner J, Ekstrom T, Moller M. Patient questionnaires in primary health care. Validation of items used in asthma care. Int J Qual Health Care 2000;12:1924. 
75 Trochim WMK. An introduction to concept mapping for planning and evaluation. Eval Progr Plan 1989;12:1-16.

76 van Campen C, Sixma $H$, Kerssens JJ, Peters L. Assessing noninstitutionalized asthma and COPD patients' priorities and perceptions of quality of health care: the development of the QUOTE-CNSLD instrument. J Asthma 1997;34:531-38.

77 Brook RH. Managed care is not the problem, quality is. JAMA 1997;278:1612-4.

78 Blumenthal D. Quality of health care. The origins of the quality-of-care debate. New Engl J Med 1996;335:1146-9.

79 Kassirer JP. The quality of care and the quality of measuring it. New Engl J Med 1993;329:1263-5.

80 Loewy EH. Justice and health care systems: what would an ideal health care system look like? Health Care Anal 1998;6:185-92.

81 Lennard-Jones JE, Shivananda S. Clinical uniformity of inflammatory bowel disease at presentation and during the first year of disease in the north and south of Europe. Eur J Gastroenter Hepatol 1997;9:353-9. 


\section{Chapter 3}

Quality of Health Care in IBD:

development of a reliable questionnaire (QUOTE-IBD) and first results

I van der Eijk, H Sixma, T Smeets, F Tavarela Veloso, S Odes, S Montague, $G$ Fornaciari, B Moum, R Stockbrügger, and $M$ Russel, on behalf of the ECIBD Study Group

American Journal of Gastroenterology: in press 


\section{Abstract}

\section{Objectives}

As inflammatory bowel disease is a chronic disorder with usually an early onset in life, quality of care plays an important role for patients. The aim of this study was to develop a questionnaire to measure quality of care through the eyes of patients with inflammatory bowel disease.

\section{Methods}

Ten generic questions were already available since the questionnaire is based on an existing instrument. Patients with inflammatory bowel disease in seven countries were involved in the development of additional disease-specific items. Validation and first fieldtesting of the total questionnaire - QUOTE-IBD - was performed in the Netherlands.

\section{Results}

In total 380 patients co-operated in the development of 13 disease-specific items, with high internal reliability (Cronbach's alpha $=0.83$ ). Another 162 patients were involved in validating and testing of the QUOTE-IBD, which consists of 23 items in total. Pearson's correlation coefficient between QUOTE-IBD and Visual Analogue Scale scores of health care items was 0.55 . Intra-class correlation coefficient of two assessments was 0.64 . First testing showed that patients gave relatively poor marks to some part of health care services, such as providing information about extraintestinal complaints and psychological besides physical approach of complaints.

\section{Conclusions}

A short, valid, and reliable questionnaire was developed to measure the opinion of patients with inflammatory bowel disease on quality of health care. The QUOTE-IBD can be used for identification of areas for improvement, with the aim of optimising health care in inflammatory bowel disease. 


\section{Introduction}

Inflammatory Bowel Disease (IBD) comprises several disease entities, the most common being ulcerative colitis (UC) and Crohn's disease (CD). Since IBD is a chronic continuous or recurrent disorder, health care plays an important role in the life of this patient group. The early onset, chronic nature, and sometimes intensive course of IBD can result in a considerable need for health care. Frequently exacerbations have to be treated with the patient admitted to the hospital. In order to monitor medication regular outpatient visits are required ${ }^{1,2}$. Therefore, in addition to medical and surgical therapy, health care workers should focus on a high standard of the care provided. Generally, health care is worth studying as a dependent variable, but also as a predictor variable for e.g. compliance to therapy, quality of life, and health status. In IBD, until today some selected aspects of quality of care have been studied (e.g. regarding patient information $)^{3.5}$. However, so far no study has been conducted to assess the total concept of quality of care in this group of disorders.

During the last decade, increasing attention has been paid to measuring quality of health care. The health care provider's perspective, which is reflected in most of the existing instruments for measuring quality of health care, differs substantially from that of the user of health care facilities, i.e. the patient ${ }^{6}$. To our knowledge, no instrument exists for measuring the IBD patient's perspective of the health care provided.

The aim of the present study was to develop a questionnaire that represents the opinion of IBD patients on the provided quality of health care, to be used in national or international comparisons. Therefore patients in seven countries were involved in the development. To evaluate whether the questionnaire achieved its purpose, we administered it to a group of IBD patients who have had experience of the disease for many years.

\section{Patients and methods}

\section{Patients}

In the present study the participants for the development of a questionnaire that measures quality of care from the patients' perspective were IBD patients from six European countries (Norway, Ireland, The Netherlands, Portugal, Italy, Greece) and Israel. All patients were randomly selected from registration files in the participating hospitals. They were asked to indicate on a short questionnaire which specific care aspects they considered being important. The structuring for similarity and importance of the items mentioned, the reduction of the number of items, and the validation of the questionnaire were conducted in the Netherlands, involving only Dutch patients. 
The treating physicians of all patients gave their permission to approach their patients for this study.

Centres in the above-mentioned countries participate in a study on quality of health care in IBD in the context of the European Collaborative Study Group on Inflammatory Bowel Disease $(E C-\mid B D)^{7}$. Where needed, the Medical Ethics Committees of the centres involved gave their approval for this study.

IBD was uniformly defined by using the classification criteria of Lennard-Jones, used in a large previous survey of IBD by the same working group ${ }^{8-10}$.

\section{Methods}

The Netherlands Institute for Health Services Research (NIVEL) has developed a series of questionnaires that measure Quality of Care Through the Patient's Eyes (QUOTE) and can be completed anonymously by patients". The QUOTE instruments are developed particularly for chronically ill patients, elderly people, disabled persons, and persons who use specific health care services. They address health care provided by general practitioners, specialists, or other services as applicable. In the QUOTE-instruments Donabedian's "structureprocess-outcome" characterisation of quality of health care is incorporated ${ }^{12}$. This model defines structure as characteristics of the health care system, whereas process addresses the encounter between a physician or another health care professional and a patient ${ }^{13-15}$. Outcome refers to the patient's subsequent health status, which is the end result of care (e.g. quality of life) and is incorporated in the QUOTE-instruments when this is suggested by patients, which is rarely the case in chronic diseases.

In the QUOTE instruments three features are explored: 1) the weight that patients give to various care aspects ("importance"), 2) the experiences concerning the functioning of medical practices and health care workers for each care aspect ("performance"), and 3) the combined effect of importance and performance ("quality impact"). The scoring system is explained in the Appendix.

The QUOTE instruments consist of both generic and disease-specific questions concerning health care provided during the past year. The NIVEL has developed ten generic questions that are similar for all QUOTE questionnaires for different patient groups ${ }^{16.18}$. The focus of the present study was to develop diseasespecific questions of a QUOTE instrument for IBD patients and to test the complete instrument in a realistic situation. In the following paragraphs the resulting questionnaire will be referred to as the QUOTE-IBD including the ten generic questions. The health care providers that are predominantly involved in the treatment of IBD are specialists and general practitioners. Therefore the questions of the QUOTE-IBD address these two professional categories by repeating all questions for either of them.

When developing a questionnaire to assess quality of care from the patient's perspective, it is essential to involve patients ${ }^{19}$. For this purpose in the present study the procedure of "concept mapping", a structured, participant-orientated process, was used ${ }^{20}$. It allows all of the participants (patients) to have an equal say in the final assessment (questionnaire). It is a so-called "bottom-up" process 
as it starts with multiple specific ideas from brainstorms before it moves to more general concepts. In this procedure patients are involved during three stages: 1) to generate a list of relevant care aspects; 2) to structure these aspects for similarity and importance; and 3) to reduce the number of aspects to be included in the questionnaire.

\section{Validity and reproducibility of QUOTE-IBD}

To guarantee correct measurement of the concept (quality of health care from the patient's view), construct and content validity were measured for the QUOTE-IBD. Since no gold standard is available to determine construct validity (the degree to which an instrument measures the theoretical construct it is intended to measure ${ }^{21}$ ), in this study Visual Analogue Scales (VAS scales) were used as proxy measures to assess the patient's opinion of the provided care both as a total and as separate care dimensions. The VAS scales consisted of horizontal lines with at both ends a statement, in which the left represented the worst, and the right of the line represented the best possible experience. Scores were calculated as percentages of the scale, $0 \%$ indicating the worst experience to $100 \%$ indicating the best experience with provided health care. However, for two dimensions ("autonomy" and "costs") no VAS scales were included as they contributed one single question each to the QUOTE-IBD.

To investigate content validity with regard to the QUOTE-IBD, the patients were asked to indicate which other care aspects should be included to give a more complete representation of health care in IBD.

The reproducibility of the QUOTE-IBD was determined by asking participants to complete the QUOTE-IBD twice, at an interval of four weeks. They were also asked to mark their experience with the provided care on the VAS scales both initially and at follow-up.

\section{Applicability of the QUOTE-IBD}

Since it has been stated that in general $90 \%$ of a population are satisfied with the quality of care provided, we decided to use this information for our QUOTE$\mathrm{IBD}^{13}$. When $90 \%$ of the population give a good evaluation - and thus $10 \%$ give a poor evaluation - on a particular aspect or care dimension, the corresponding performance score in the population for this aspect will be 0.1 . This score combined with extreme importance (score $=10$ ) of the aspect leads to a quality impact score of 9.0 (quality impact $=10$ - (importance $\times$ performance)). An average quality impact score smaller than 9.0 indicates that more than the regular $10 \%$ of the population give a poor evaluation of the certain care aspect; in other words: there is room for improvement concerning that particular item. 


\section{Statistics}

Statistical analyses were performed with SPSS package 8.0 for Windows (SPSS Inc., Chicago, IL). Identification of the optimal set of aspects describing the quality of care in IBD was conducted using Principal Component Factor Analysis. Items with factor loadings greater than 0.5 were preserved. Internal reliability of the questionnaire was evaluated by means of testing internal consistency expressed as Cronbach's alpha. Mann-Whitney tests were performed to investigate differences in importance, performance, and quality impact scores for patients with $C D$ compared to UC and for males versus females. Pearson's correlation coefficients between VAS scales and quality impact scores, and between VAS scales and performance scores of the QUOTE-IBD, were calculated per dimension and for the total care received. Reproducibility of the QUOTE-IBD was determined by calculating Pearson's correlation coefficient between quality impact as well as performance scores of the two assessments. Cohen's Kappa (intra-class correlation coefficient) was calculated for quality impact and performance scores to examine the degree of agreement between the two assessments.

\section{Results}

The process of development and testing of an instrument concerning quality of health care and characteristics of all patients involved is represented in Table 3.1.

\section{Concept mapping}

A total of 267 European (107 Norwegian, 30 Irish, 47 Dutch, 24 Portuguese, and 59 Italian) and 19 Israeli IBD patients indicated 54 different aspects of care that they considered of the highest importance for good quality of care. In all co-operating countries similar aspects were mentioned; however, cost and hygiene aspects appeared to be mentioned more in southern than in northern countries.

Of 53 Dutch IBD patients invited to sort the aspects for similarity, 30 patients responded positively (response rate $=57 \%$ ). Cluster analysis assigned all aspects to eight generally accepted care dimensions as to be found in the literature ${ }^{13.15}$.

One-factor analysis of importance ratings of the 54 IBD-specific aspects resulted in 21 aspects with factor loadings greater than 0.5. These 21 aspects were sent to a separate group of 97 Dutch IBD patients to further reduce the number of disease-specific items. Again the patients were asked to rate the aspects for importance. Sixty-four patients $(66 \%)$ responded to our request. The data were subjected to explorative factor analysis, using Principal Component Analysis (PCA). Out of 21 items, 12 items finally received factor loadings greater than 0.5 . 


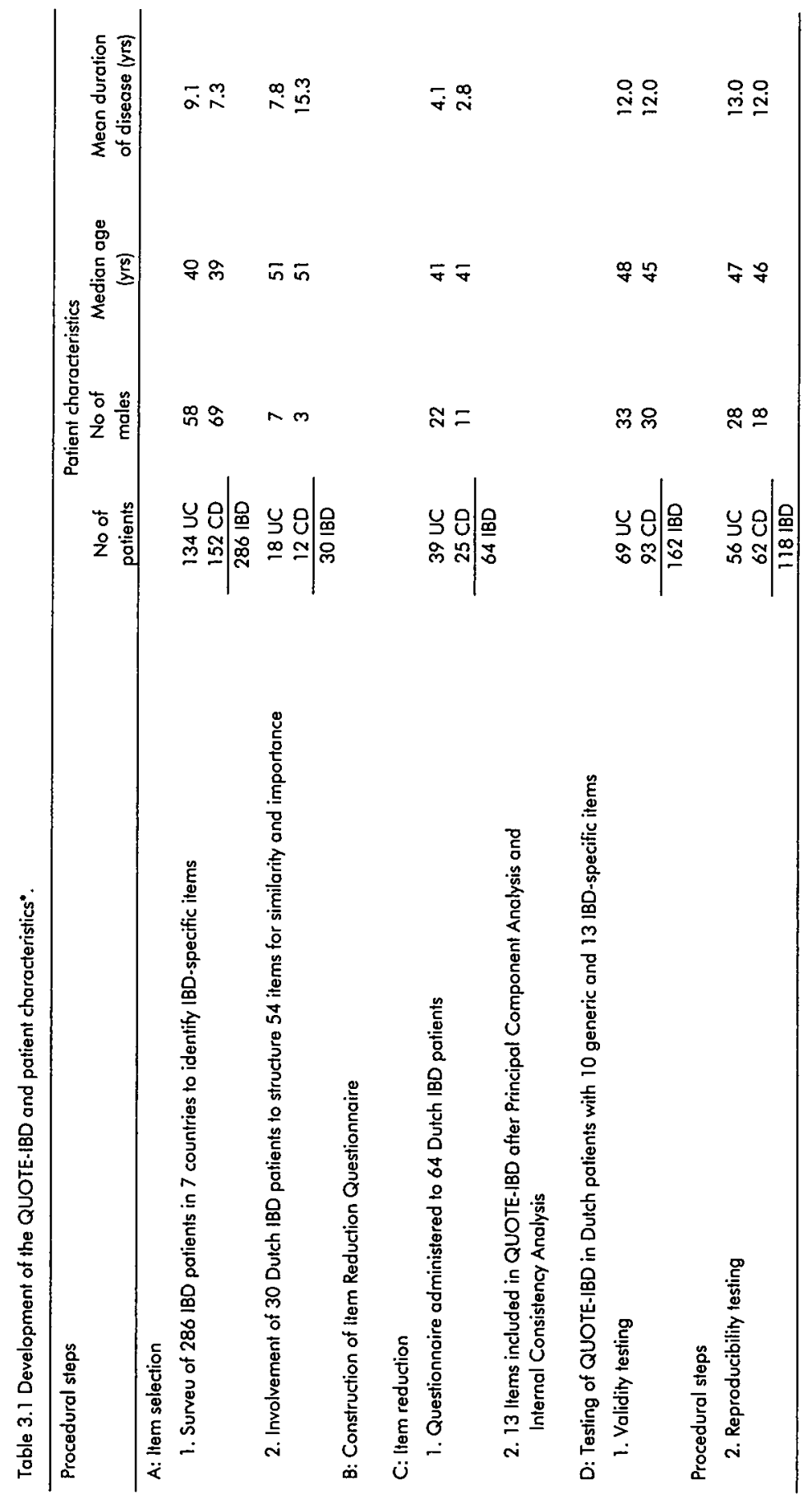


Inclusion of care aspects in the questionnaire

Eventually three other disease-specific aspects were included in the questionnaire despite exclusion according to PCA. Reasons for inclusion were: 1) highest total importance score (liem 21: In case of acute problems a doctor should be available within 24 hours), 2) particularly mentioned during the concept mapping procedure in countries other than The Netherlands (Item 17: Hospitals and medical practice rooms should have good toilet facilities), and 3) the investigators themselves highly valued the IBD-specific item (Item 16: Nurses at the endoscopy department should have specific expertise in (BD).

On the other hand, two aspects with factor loadings greater than 0.5 in PCA were excluded from the final questionnaire after all. One was excluded because a very low correlation was observed with other items in the dimension, and the other was excluded because a similar generic item was already available. Cronbach's alpha of the remaining 13 IBD-specific aspects was 0.83 .

In Table 3.2 all items included in the QUOTE-IBD are shown.

\section{Validation of the Dutch QUOTE-IBD}

For validation of the QUOTE-IBD, a group of 231 Dutch IBD patients outside the EC-IBD cohort were sent the questionnaire. Of those approached, 162 patients completed the QUOTE-IBD and the included VAS scales (response rate $=70 \%$ ). Mann-Whitney tests did not show any differences in importance, performance, and quality impact scores for patients with $C D$ compared to UC. Between males and females differences were observed for several scores regarding quality impact, importance and performance (Table 3.3).

Pearson's correlation coefficients were calculated for performance as well as quality impact scores. As illustrated in Table 3.4, correlations between the VAS and the total QUOTE-IBD performance and quality impact scores were 0.56 and 0.55 respectively.

No new aspects to be included in the QUOTE-IBD were suggested by this group of patients. 


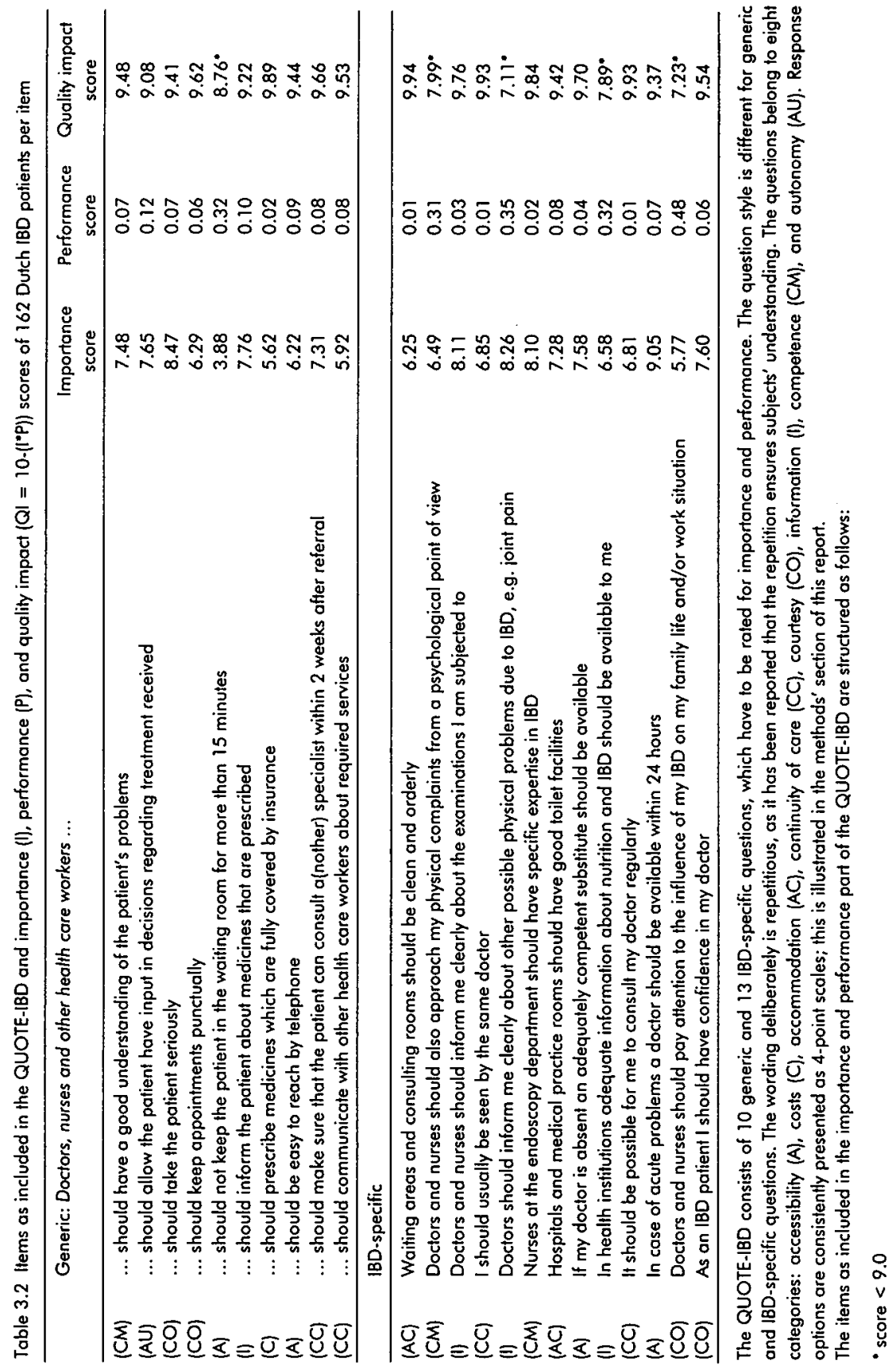


Table 3.3 Total and dimensional importance $\left(\mathrm{I}^{\dagger}{ }^{\dagger}\right.$, performance $(\mathrm{P})^{\dagger}$, and quality impact $\left(Q^{\dagger}\right.$ scores for males $(\mathrm{m})$ and females $(f)$ of 162 Dutch IBD patients.

\begin{tabular}{lcccccc}
\hline & $I(\mathrm{~m})$ & $\mathrm{I}(\mathrm{f})$ & $\mathrm{P}(\mathrm{m})$ & $\mathrm{P}(\mathrm{f})$ & $\mathrm{Q}(\mathrm{m})$ & $\mathrm{QI}(\mathrm{f})$ \\
\hline Total care & 6.82 & 7.05 & 0.09 & $0.15^{*}$ & 9.51 & $9.04^{*}$ \\
Competence & 6.88 & 7.05 & 0.11 & $0.25^{*}$ & 9.44 & $8.41^{*}$ \\
Courtesy & 6.92 & 7.14 & 0.13 & 0.18 & 9.31 & 8.84 \\
Accessibility & 6.78 & 6.64 & 0.10 & 0.16 & 9.45 & 9.25 \\
Information & 7.34 & $7.87^{*}$ & 0.15 & 0.23 & 9.03 & $8.22^{*}$ \\
Continuity of care & 6.51 & 6.82 & 0.01 & $0.06^{*}$ & 9.94 & 9.66 \\
Accommodation & 6.58 & 6.88 & 0.02 & 0.06 & 9.82 & 9.52 \\
Autonomy & 7.34 & 7.73 & 0.07 & 0.15 & 9.75 & 9.04 \\
Costs & 5.51 & 5.72 & 0.03 & 0.01 & 9.81 & 9.94 \\
\hline
\end{tabular}

† I ranges from 0 (least important) to 10 (most important); $P$ ranges from 0 (best performance) to 1 (poor performance); QI ranges from 0 (poor) to 10 (best)

${ }^{*} p<0.05$

Table 3.4 Construct validity of the QUOTE-IBD: correlation coefficients between the total score as well as the dimensional scores of the QUOTE-IBD and the Visual Analogue Scales for Quality Impact and Performance scores in 162 Dutch IBD patients

\begin{tabular}{lcc}
\hline Care dimensions & Quality impact & Performance \\
\hline Total care & $0.55^{*}$ & $0.56^{*}$ \\
Information & $0.55^{*}$ & $0.60^{*}$ \\
Courtesy & $0.56^{*}$ & $0.60^{*}$ \\
Competence & $0.31^{*}$ & $0.40^{*}$ \\
Accessibility & $0.51^{*}$ & $0.57^{*}$ \\
Accommodation & $0.23^{\dagger}$ & $0.47^{*}$ \\
Continuity of care & $0.28^{\dagger}$ & $0.36^{*}$ \\
\hline
\end{tabular}

${ }^{*} p<0.001 ;{ }^{\dagger} p<0.01$

\section{Reproducibility}

Of 162 patients approached, 148 patients agreed to a test-retest assessment. Data of 118 patients (response rate was $80 \%$ ) were used for statistical analysis, as they had indicated that the time in-between the two assessments had been stable; no specific event had occurred concerning the health care provided. Pearson's correlation coefficients between the two assessments are shown in Table 3.5, resulting in coefficients for total performance and quality impact scores of 0.80 and 0.76 , respectively. Intra-class correlation coefficients for total performance and quality impact scores were 0.63 and 0.64 respectively. 
Table 3.5 Reproducibility of the QUOTE-IBD: agreement between two sets of measurements, expressed by the correlation coefficients $(R)$ and intra-class correlation coefficients (ICC) between Quality Impact as well as Performance scores, for the total score and dimensional scores of the QUOTE-IBD in 118 Dutch IBD patients

\begin{tabular}{lcccc}
\hline $\begin{array}{l}\text { QUOTE-IBD } \\
\text { dimensions }\end{array}$ & $\begin{array}{c}\mathrm{R} \\
\text { Quality Impact }\end{array}$ & $\begin{array}{c}\mathrm{ICC} \\
\text { Quality Impact }\end{array}$ & $\begin{array}{c}\mathrm{R} \\
\text { Performance }\end{array}$ & $\begin{array}{c}\mathrm{ICC} \\
\text { Performance }\end{array}$ \\
\hline Total care & $0.76^{*}$ & $0.64^{*}$ & $0.80^{*}$ & $0.63^{*}$ \\
Information & $0.70^{*}$ & $0.58^{*}$ & $0.81^{*}$ & $0.50^{*}$ \\
Courtesy & $0.66^{*}$ & $0.53^{*}$ & $0.76^{*}$ & $0.56^{*}$ \\
Competence & $0.56^{*}$ & $0.42^{*}$ & $0.71^{*}$ & $0.67^{*}$ \\
Accessibility & $0.60^{*}$ & $0.57^{*}$ & $0.57^{*}$ & $0.32^{\dagger}$ \\
Accommodation & $0.59^{*}$ & $0.47^{*}$ & $0.53^{*}$ & $0.23^{\dagger}$ \\
Continuity of care & $0.33^{\dagger}$ & $0.26^{\dagger}$ & $0.39^{*}$ & $0.26^{\dagger}$ \\
Autonomy & $0.50^{*}$ & $0.59^{*}$ & $0.69^{*}$ & $0.60^{*}$ \\
Costs & $0.86^{*}$ & $0.66^{*}$ & $0.43^{*}$ & $0.66^{*}$ \\
\hline
\end{tabular}

${ }^{*} p<0.001 ;{ }^{\dagger} p<0.01$

Applicability

As the number of patients who had consulted a general practitioner during the last year was too small, only the data for the specialist are shown here.

In Table 3.2 the importance, performance, and quality impact scores of the 162 Dutch IBD patients who participated in the validation of the QUOTE-IBD are presented for each question. It is shown that the average group quality impact scores of "waiting time in waiting room", "psychological approach", "information about extraintestinal complaints", "information about nutrition", and "attention to IBD and family/work" were lower than 9.0. The total and dimensional quality impact scores of the entire patient group and the differences between male and female patients are represented in Figure 3.1. In this figure a line is displayed delimiting a quality impact score of 9.0. Quality impact scores of the total group were below this level for the dimensions "competence" and "information". In addition, females scored "courtesy" lower than 9.0. 


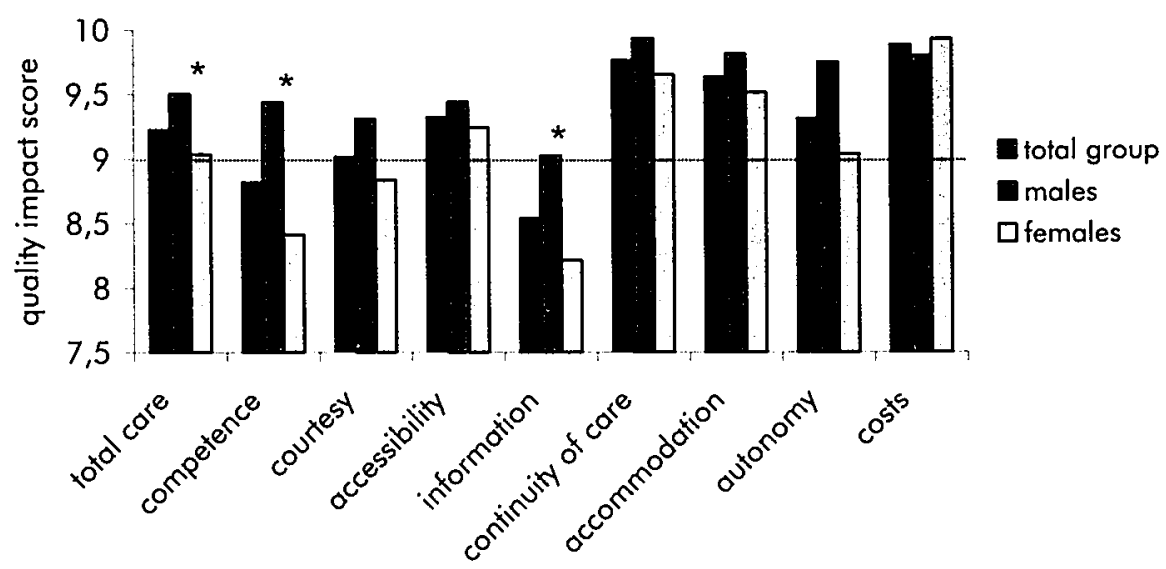

Figure 3.1 Total care score and dimensional Quality Impact (QI) scores for the total group $(n=162)$, male $(n=63)$ and female $(n=99)$ Dutch patients * $p<0.05$ (males versus females)

\section{Discussion}

IBD is a relatively common, chronic, benign inflammatory disease that affects mostly young people ${ }^{22}$. Mortality rates are similar to the background population ${ }^{23-26}$. The disease can have many medical and, in particular, social consequences, and is therefore an excellent example to show that wellorganised health care could give good results. To study the hypothesis that quality of health care influences quality of life of IBD patients, for the latter (QOL) a valid questionnaire (e.g. the IBDQ) exists, whereas for the assessment of the quality of care (QoC) no evaluated instrument has been available ${ }^{27}$.

In this study we have developed a valid and reliable questionnaire to assess quality of care through the patients' eyes (QUOTE-IBD). This was conducted in a multinational setting in co-operation with a large number of IBD patients. The result is an easy-to-complete, anonymous, self-administered instrument, all of which are important features to prevent bias that could be expected when patients were interviewed by representatives of a hospital or other medical organisation. The questionnaire covers the health care provided in the past year as it has been shown that patients, especially those with complicated conditions, do not describe their experiences in terms of single visits, but rather in terms of periods of disease and/or care $^{28}$.

The QUOTE-IBD consists of ten generic and 13 IBD-specific items and combines both importance and performance evaluations. The 23 items are in agreement with the literature, since eight generally accepted care dimensions - accessibility, costs, accommodation, continuity of care, courtesy, information, competence, 
and autonomy - are represented by at least one item in our concept ${ }^{13.15}$. The ten generic questions included in the QUOTE-IBD also constitute part of similar QUOTE instruments for other chronic illnesses, like rheumatic diseases and COPD, and can therefore serve as material for comparison between different diseases ${ }^{17,18}$. One might expect that the disease-specific items would hold more "process of care" aspects, such as frequency of monitoring and adequate symptomatic therapy, but those items were not mentioned frequently nor given much importance by the patients. Therefore the current items in the QUOTE-IBD should be considered to give a correct representation of the patient's perspective on quality of health care.

As is shown in detail in this study, measurement of the construct validity of the QUOTE-IBD, using proxy measures, was good. The observed correlation coefficients between VAS and QUOTE-IBD scores were moderately high, except for three dimensions (competence, accommodation, and continuity of care). Reasons for this could be: 1) as the QUOTE-IBD is a newly developed questionnaire, based on a new conceptual theory (i.e. quality of care from the patient's opinion, in which importance is incorporated in addition to satisfaction), no gold standard and not even a comparable instrument is available, which would be optimal for validation; 2) some patients seemed to find it difficult to use the VAS scales; 3) the QUOTE-IBD specifies a number of events whereas the VAS scales ask for general evaluations. In spite of these limitations, the results raise positive expectations concerning the construct validity of the QUOTE-IBD in Dutch patients. Additionally, according to the patients, the items as included in the questionnaire completely represented their ideas of health care in IBD. This indicates that the content of the questionnaire is valid in The Netherlands. Further validation of the QUOTE-IBD in other countries is required.

The QUOTE-IBD has proven apt to reproduce similar results at an interval of four weeks. Pearson's correlation coefficients between the two assessments of performance and quality impact scores were high ${ }^{29}$. Intra-class correlation coefficients can be considered moderately high, except for the quality impact score of "continuity of care", and the performance scores for "accessibility", "accommodation" and "continuity of care" ${ }^{\text {"21 }}$. This may be explained by the fact that the median duration of disease of the patients who completed the questionnaire was twelve years. It is likely that most of these patients are in stable condition and therefore had only little or no experience with these particular care aspects during the past year. On these grounds, and taking the high internal consistency of the IBD-specific questions into consideration, the QUOTE-IBD can be regarded as a reliable measure.

It might be seen as a disadvantage that the QUOTE-IBD has been developed in a multinational setting and thus does not provide specificity for each country. On the other hand, this can be regarded as an advantage as it creates the possibility of international comparisons. 
Although applicability of the QUOTE-IBD is only tested in a limited number of patients in one nation, some very informative results already emerged. First of all, it is not needed to distinguish between $C D$ and $U C$ when assessing the patient's view on the quality of the provided health care, since statistical analyses did not show differences between these disease entities in QUOTE-IBD scores. Secondly, female patients appeared to give poorer evaluations of the provided care than male patients, reflected by significantly lower quality impact scores for competence, courtesy, and information. The literature reports inconsistent findings regarding male and female patients' views on quality of health care ${ }^{30}$. 32. This inconsistency might be due to the use of different instruments for data assessment; however, the possibility of a real difference between males and females should not be neglected. Until these issues are better understood, no gender-specific recommendations for the organisation of health care can be made.

Furthermore, during this first use of the QUOTE-IBD we could identify health care areas that might need improvement, both on the level of individual care items (e.g. information about nutrition) and of care dimensions (e.g. competence). These preliminary results have encouraged our plans to use the QUOTE-IBD on a large scale in the ongoing EC-IBD study in 1177 patients concerning the influence of quality of care on quality of life ${ }^{33}$.

In conclusion, assessing IBD patients' experiences of health care has resulted in a short and self-administered instrument that was shown to be valid and reliable. The QUOTE-IBD appeared to be easy to use when studying quality of health care for patients with IBD and can enable researchers to identify targets for improvement both in hospital settings and in general practices. When arrangements have been made to improve a certain health care aspect, the QUOTE-IBD measurement should be repeated to confirm whether the improvement has taken place. As good quality of care appears to be essential in chronic diseases, the QUOTE-IBD should become an important tool in addition to traditional methods to optimise health care for IBD patients. 


\section{Appendix}

Scoring system of the QUOTE-IBD

With regard to the importance part of the QUOTE-instruments, responses to the statements mentioned are graded on a 4-point Likert scale, in which " 0 " represents "not important", " 3 " represents "fairly important", "6" represents "important", and "10" represents "extremely important". Population importance scores range between 0 and 10.

\section{Example}

Doctors and nurses should inform me clearly about the examinations I am subjected to.

\begin{tabular}{lll}
$\square \quad$ Not important & answer represents "0" \\
$\square \quad \begin{array}{l}\text { Fairly important } \\
\text { Important }\end{array}$ & $\begin{array}{l}\text { answer represents " } 3 \text { " } \\
\text { answer represents "6" }\end{array}$ \\
\hline$\square \quad$ Extremely important & answer represents "10"
\end{tabular}

Performance responses to the same statements are scored on a 4-point scale as well: "no" and "not really" are represented by "1", and "on the whole, yes" and "yes" are represented by " 0 ". Average population performance scores range between 0 and 1 .

\section{Example}

The specialist I have seen during the past year, has informed me adequately about the examinations I am subjected to.

$\begin{array}{ll}\text { No } & \text { answer represents "1" } \\ \square & \begin{array}{l}\text { Not really } \\ \text { On the whole, yes }\end{array} \\ \text { Yes } & \begin{array}{l}\text { answer represents "1" } \\ \text { answer represents "0" }\end{array}\end{array}$

Quality impact scores of patients concerning a health care aspect can be derived from importance and performance scores as follows: Quality Impact $=10$ - (Importance $\mathrm{x}$ Performance) $)^{12}$.

\section{Example}

When a patient rates a certain aspect as extremely important, and has had a good experience with the performance of this aspect, the individual quality impact score will be: $10-(10 \times 0)=10$.

When a patient rates another aspect as fairly important, but has no good experience, the score will be: $10-(3 \times 1)=7$. Average quality impact (QI) scores range from 0 (worst) to 10 (best). 


\section{References}

1 Blomqvist P, Ekbom A. Inflammatory Bowel Disease: Health Care and Costs in Sweden in 1994. Scand J Gastroenterol 1997;32:1134-9.

2 Eckardt VF, Lesshaff C, Kanzler G, et al. Disability and health care use in patients with Crohn's disease: a spouse control study. Am J Gastroenterol 1994;89:2157. 62.

3 Mayberry JF. The diagnosis of inflammatory bowel disease - What should we tell the patient? Ital J Gastroenterol Hepatol 1997;29:483-6.

4 Lange $A$, Haslbeck $E$, Andus $T$, et al. Ambulatory education of patient with Crohn disease/ulcerative colitis. Z Gastroenterol 1996;34:411-5.

5 Smart H, Mayberry JF, Calcraft B, et al. Effect of information booklet on patients' anxiety levels and consultation rates in Crohn's disease. Public Health 1986;100:184-6.

6 Lebow JL. Consumer assessments of the quality of medical care. Med Care 1974;12:328-37.

7 Stockbrügger RW, Russel MGVM, van Blankenstein $M$, et al. EC-IBD: a European effort in inflammatory bowel disease. Eur J Int Med 2000;1 1:187-90.

8 Lennard-Jones JE. Classification of inflammatory bowel disease. Scand J Gastroenterol Suppl 1989;24:2-6.

9 Lennard-Jones JE, Shivananda S. Clinical uniformity of inflammatory bowel disease at presentation and during the first year of disease in the north and south of Europe. Eur J Gastroenter Hepatol 1997;9:353-9.

10 Shivananda S, Lennard-Jones JE, Logan R, ef al. Incidence of inflammatory bowel disease across Europe: is there a difference between north and south? Results of the European Collaborative Study on Inflammatory Bowel Disease (EC-IBD). Gut 1996;39:690-7.

11 Sixma H, van Campen C, Kerssens JJ, et al. De QUOTE-vragenlijsten. Utrecht: NIVEL, 1998.

12 Donabedian A. Evaluating the quality of medical care. Milbank Mem Fund $Q$ 1966;44 (suppl): 166-206.

13 van Campen C, Sixma H, Friele RD, et al. Quality of care and patient satisfaction: a review of measuring instruments. Med Care Res Rev 1995;52:109-33.

14 Hall JA, Dornan MC. Meta-analysis of satisfaction with medical care: description of research domain and analysis of overall satisfaction levels. Soc Sci Med 1988;27:637-44.

15 Pascoe GC. Patient satisfaction in primary health care: a literafure review and analysis. Eval Progr Plan 1983;6:185-210.

16 Sixma H, Kerssens JJ, van Campen $C$, ef al. Quality of care from the patients' perspective: from theoretical concept to a new measuring instrument. Health Expectations 1998; $1: 82-95$. 
17 van Campen $\mathrm{C}$, Sixma $\mathrm{H}$, Kerssens JJ, et al. Assessing noninstitutionalized asthma and COPD patients' priorities and perceptions of quality of health care: the development of the QUOTE-CNSLD instrument. J Asthma 1997;34:531-8.

18 van Campen $C$, Sixma $H$, Kerssens JJ, ef al. Assessing patients' priorities and perceptions of the quality of health care: The development of the quote-rheumaticpatients instrument. Brit J Rheumat 1998;37:362-8.

19 Meterko M, Nelson EC, Rubin HR, et al. Patients' judgments of hospital quality: report of a pilot study. Med Care 1990;28:S1-S56.

20 Trochim WMK. An introduction to concept mapping for planning and evaluation. Eval Progr Plan 1989;12:1-16.

21 Bouter LM, van Dongen MCJM. Epidemiologisch onderzoek, opzet en interpretatie 2nd ed. Houten/Antwerpen: Bohn, Stafleu, Van Loghum, 1991.

22 Russel MG, Dorant $E$, Volovics $A$, ef al. High incidence of inflammatory bowel disease in the Netherlands. Dis Colon Rectum 1998;41:33-40.

23 Langholz E, Munkholm P, Davidsen $M$, ef al. Colorectal cancer risk and mortality in patients with ulcerative colitis. Gastroenterology 1992;103:1444-51.

24 Munkholm P, Langholz E, Davidsen $M$, et al. Intestinal cancer risk and mortality in patients with Crohn's disease. Gastroenterology 1993;105:1716-23.

25 Persson PG, Bernell O, Leijonmarck CE, et al. Survival and cause-specific mortality in inflammatory bowel disease: a population-based cohort study. Gastroenterology 1996;110:1339-45.

26 Ekbom A, Helmick CG, Zack M, et al. Survival and causes of death in patients with inflammatory bowel disease: a population-based study. Gastroenterology 1992;103:954-60.

27 Guyatt GH, Mitchell A, Irvine EJ, et al. A new measure of health status for clinical trials in inflammatory bowel disease. Gastroenterology 1989;96:804-10.

28 Cleary PD, Edgman-Levitan S. Health care quality. Incorporating consumer perspectives. JAMA 1997;278:1608-12.

29 de Boer AGEM, Sprangers MAG, Bartelsman JFW, et al. Predictors of health care utilization in patients with inflammatory bowel disease: a longitudinal study. Eur $\mathrm{J}$ Gastroenter Hepatol 1998; 10:783-9.

30 Ayanian JZ, Weissman JS, Chasan-Taber SC, ef al. Quality of care by race and gender for congestive heart failure and pneumonia. Med Care 1999;37:1260-9.

31 Wilde Larsson B, Larsson G, Starrin B. Patients' views on quality of care: a comparison of men and women. J Nurs Manag 1999;7:133-9.

32 Weisman CS, Rich DE, Rogers J, et al. Gender and patient satisfaction with primary care: funing in to women in quality measurement. J Women Health Gend Based Med 2000;9:657-65.

33 van der Eijk I, Stockbrügger RW, Russel MG. Influence of quality of care on quality of life in inflammatory bowel disease (IBD): literature review and studies planned. Eur J Int Med 2000;1 1:228-34. 


\section{Chapter 4}

Which factors influence Health-Related

Quality of Life in patients with IBD:

A role for Quality of Care?

I van der Eijk, I Vlachonikolis, P Munkholm, J Niiman, T Bernklev, P Politi, $S$ Odes, E Tsianos, R Stockbrügger, M Russel, on behalf of the EC-IBD Study Group

Submitted for publication 


\section{Abstract}

\section{Background}

In the literature there are indications of associations between health-related quality of life in inflammatory bowel disease (IBD) and disease activity, psychological status, coping, stressful life events, and social support. The aim of this study was to examine whether a relation exists between quality of health care and health-related quality of life, taking possible confounding variables into account.

\section{Methods}

For this purpose one single questionnaire was compiled from existing validated questionnaires to assess information on all these variables. A population-based inception cohort of 1056 patients with IBD in eight countries, diagnosed 6-8 years prior to the study, was approached to participate.

\section{Results}

In total 824 patients responded (78\%). Of those, $36 \%$ did not receive health care from their specialist during the past year. They were excluded from quality of care assessment. It was shown that in IBD health-related quality of life was indeed influenced by quality of care, and "providing information" in particular, as well as by disease activity, psychological status, type of hospital, social support, stressful life events, and way of administration of the questionnaire. Patients with active disease had depressed healthrelated quality of life compared to those with inactive disease. Crohn's disease (CD) patients scored the care dimension "costs" lower than ulcerative colitis (UC) patients. For CD patients the care dimension "continuity of care" and for UC patients "courtesy of the attending medical personnel" appeared to be important for health-related quality of life.

\section{Conclusions}

It is shown here, for the first time, that in IBD quality of health care has a pivotal role in determining health-related quality of life, particularly with regard to the parameters of "costs", "providing information", "continuity of care", and "courtesy". 


\section{Introduction}

Quality of health care (Q०C) is important for efficient disease monitoring and healing, as well as for prevention of disease exacerbation and death. Until a few years ago, QoC was considered to be a narrow concept only second to direct medical treatment, hospitals routinely monitored poor outcomes such as morbidity and mortality, but no other aspects or results of QoC. More recently, interest has been raised regarding the importance of high standards of care as a broad issue ${ }^{1-6}$. Since chronically ill patients are usually in continuous need for health care, QoC may play a particularly important role in their lives.

Inflammatory bowel diseases (IBD) are chronic diseases which affect many people (prevalence approximately 300 per 100,000 in the Western world ${ }^{7}$ ) predominantly at a young age ${ }^{8}$. The main disease entities of IBD are Crohn's disease (CD) an ulcerative colitis (UC). The efficacy of medical and surgical therapy still remains limited in these disorders, resulting in recurrent or even continuous life-long complaints of abdominal discomfort, diarrhoea, malabsorption, and malaise. These symptoms may have profound effects on the activities of daily life, reducing the health-related quality of life (HRQoL) $)^{9.14}$. Few studies have been conducted in IBD patients concerning QoC. Issues such as providing information to patients ${ }^{15,16}$ and consumption and cost of health care ${ }^{17 .}$ 19 have been addressed, but the total concept of QoC has never been investigated.

Optimisation of QoC may induce improvement in $\mathrm{HRQ}^{20} \mathrm{~L}^{20}$, however, many factors need to be taken into account when the influence of QOC on HRQOL in $I B D$ is to be investigated ${ }^{21,22}$. Five different factors have been described to be associated with HRQOL in IBD: disease activity ${ }^{23,24}$, psychological status ${ }^{25.27}$, coping patterns $s^{24,28-30}$, social support ${ }^{31,32}$. Controversial literature exists on the influence of stressful life events ${ }^{33 \cdot 38}$, suggesting that this variable should not be discarded in the assessment of HRQoL. The aim of the present study was to investigate the relationship between QOC and HRQOL in IBD, adjusted for those factors (Figure 4.1).

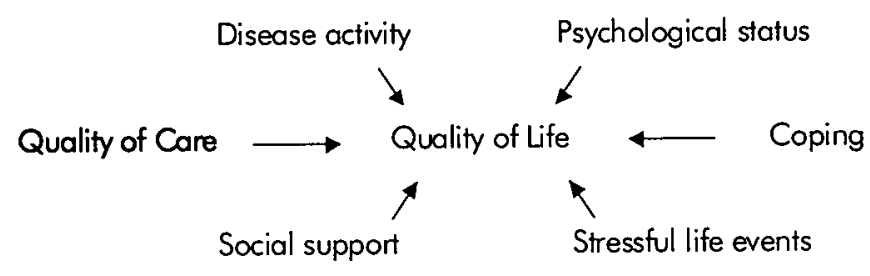

Figure 4.1 Conceptual model of variables influencing quality of life in IBD. 


\section{Methods}

\section{Survey sample}

Fourteen centres in eight countries (Table 4.1) participated in the current project to study the relationship between quality of health care and health-related quality of life in a cross-sectional study design. Between October 1991 and September 1993, they established a population-based inception cohort of IBD $(n=1177)$ with the European Collaborative study group on Inflammatory Bowel Disease (EC-IBD) in order to investigate the incidence of IBD in Europe ${ }^{39}$. The current sfudy was performed in 1999, indicating that the participating patients had been diagnosed with IBD 6-8 years. Of the 1177 original patients, 1056 were approached for participation in the current study. The reasons for exclusion of the remaining 121 patients were: patient deceased (44), moved away from the study area (16), untraceable address (28), no IBD after all (13), lost-tofollow-up (17), and mental disorder (3).

Table 4.1 Centres participating in the EC-IBD study to quality of health care and quality of life in IBD.

\begin{tabular}{lllc}
\hline Centre & Country & $\begin{array}{c}\text { Number of patients } \\
\text { approached from } \\
\text { original cohort }\end{array}$ \\
\hline North & Oslo & Norway & $131 / 137$ \\
& Copenhagen & Denmark & $129 / 155$ \\
Dublin & Ireland & $100 / 127$ \\
& South Limburg & The Netherlands & $211 / 215$ \\
& Almada & Portugal & $14 / 21$ \\
& Braga & Portugal & $22 / 38$ \\
& Milan & Italy & $44 / 45$ \\
& Cremona & Italy & $40 / 49$ \\
& Reggio Emilia & Italy & $74 / 76$ \\
& Firenze & Italy & $105 / 106$ \\
& Palermo & Italy & $31 / 32$ \\
& Heraklion & Greece & $64 / 71$ \\
Epirus & Greece & $36 / 41$ \\
Beer Sheva & Israel & $55 / 64$ \\
& & \\
Total & & $1056 / 1177$ \\
\hline
\end{tabular}

Survey questionnaire

A single questionnaire was designed based on the conceptual model in Figure 4. 1 to assess the influence of all related variables on HRQoL. Thus, it comprised eight existing questionnaires to include all six variables influencing HRQoL in the 
conceptual model. For disease activity the Harvey-Bradshaw Index $(\mathrm{HBI})^{40}$ was chosen for $C D$, because completion of the $\mathrm{HBI}$ does not require a consultation of the patient with a physician, in contrast to the Crohn's Disease Activity Index $(\mathrm{CDAl})^{41}$. Active disease was determined at a score $\geq 4$ by corresponding the cutoff point of the CDAl (score $\geq 150^{41}$ ) to the $\mathrm{HBI}$ score in the figure in Harvey and Bradshaw's publication. Likewise, the Colitis Activity Index (CAl) was selected to assess disease activity for $\mathrm{UC}^{42}$. CAl scores greater than 10 were considered to indicate active disease in UC patients.

The Mental Health Inventory-5 (MHI-5) was selected to score psychological status ${ }^{43}$. To assess information on coping strategies (avoidance, emotion, and problem-focused), the Coping Inventory of Stressful Situations (CISS) was included $^{44}$. Sherbourne \& Stewart's 20-item MOS Social Support Survey was chosen to grade the degree of patient's received social support ${ }^{45}$. A list of 16 major stressful life events was extracted from the Social Readjustment Rating Questionnaire $^{46}$. The patient's perspective on quality of care was assessed with the Quality of Care through the IBD patients' eyes (QUOTE-IBD), a diseasespecific questionnaire that was originally developed for the purpose of this study ${ }^{47}$. With the QUOTE-IBD data can be assessed of eight care dimensions: competence, courtesy, accessibility, information, continuity of care, accommodation, autonomy, and costs. The disease-specific short Inflammatory Bowel Disease Questionnaire (SIBDQ) was included to assess HRQoL ${ }^{48}$.

If a version of one of the eight questionnaires was already available and validated in the requested language (Danish, Dutch, English, Greek, Hebrew, Italian, Norwegian, and Portuguese), then it was used. Where not, the English version was translated into the required language by a professional translation agency, in collaboration with the local EC-IBD participants, when needed. For each language, questionnaires were compiled into one single questionnaire, which was sent to the local researchers for distribution to patients. This questionnaire consisted of 167 items that took 30 to 45 minutes to complete.

\section{Statistical Analysis}

\section{Group differences}

Differences between groups of respondents were examined using unpaired ttests for: age, HRQoL, psychological status, coping strategies, and social support. Pearson's chi-square tests for contingency tables were performed for: gender, marital status, and smoking status (yes or no). Differences in QoC scores and stressful life events were analysed with Mann-Whitney $U$ tests.

\section{Conceptual model}

Other factors, not included in the conceptual framework (Figure 4.1), could also possibly influence HRQoL. For example, demographic aspects (age, gender) and centre-specific conditions (hospital type: university versus regional), way of 
administration of the questionnaire (postal versus interview), occupation of the patient, disease entity $(C D$ versus $U C)$, smoking, marital status, and geographical location (South versus North Europe)). These variables were included together with the conceptual model variables in multiple regression analyses, with HRQoL as dependent variable. The analyses were performed for the total patient group as well as for $C D$ and $U C$ patients separately using the total care score (Model A), as well as the scores for the single care dimensions (Model B). The data however, did not satisfy the standard conditions of ordinary regression (uncorrelated observations with constant variance across all individuals) for either model: the estimation of "between-centres" variance to its standard error (2.269 and 2.282, respectively) as well as the "intra-centre" correlation (0.224 and 0.237 , respectively) were significant. These results confirmed the existence of a hierarchical or multi-level structure, meaning that patients (level 1 units) were clustered within centres (level 2 units) ${ }^{49-51}$. Indeed, centres were different in patient composition $(C D$ versus $U C$, males versus females) and it had to be expected that they were different in other aspects (cultural factors, health care systems, etc). Therefore, the independent influences of the above mentioned variables were studied using multi-level regression models. The latter were applied using iterative generalised least squares (IGLS) methods; selection of variables was carried out by backward elimination based on the log-likelihood ratio test ${ }^{49-51}$.

All statistical analyses were carried out using SPSS package 10.0 for Windows (SPSS Inc., Chicago, IL) and MLNwiN version 1.10.0006 (Institute of Education, London, United Kingdom).

\section{Results}

The compiled questionnaire was sent to 835 patients $(79.1 \%)$ for self-reporting, and 90 patients $(8.5 \%)$ were personally interviewed. One hundred and thirtyone patients $(12.4 \%)$ were interviewed on parts of the questionnaire only, whereas the other questionnaire items were self-reported. The way of administration of the questionnaire was chosen by the local researchers, based on their estimation of the balance between the largest response and the lowest information bias. Overall response rate to the questionnaire was $78 \%(n=824)$. The response rates of individual hospitals ranged from 57 to $100 \%$. Ten patients were diagnosed with indeterminate colitis and were therefore excluded from further analyses.

Two hundred ninety-seven patients (36\%) had not received health care from their specialist during the last year. They were excluded from QoC assessment. With respect to HRQoL and psychological status the two groups of responders (the group that did receive health care during the past year versus the group that did not) differed significantly $(p<0.05)$ from each other: the group that received care had lower scores on both features. Current disease activity was found to be significantly higher $(p<0.001)$ in the group that had received health care. 
Patients who did not receive health care during the past year were excluded from statistical analyses with regard to the conceptual model of the relation between quality of health care and quality of life (Figure 4.1). Of the 517 patients who did receive health care, 322 had UC and 195 had CD, 270 were female and 247 male, and the median age was 42.0 years $\left(34.0-56.0\right.$ yrs $\left(25^{\text {th }}\right.$ $75^{\text {th }}$ percentiles)). In Table 4.2 mean scores per variable of the conceptual model are shown separately for CD and UC patients. Significantly lower scores in HRQoL were observed for patients with CD. Of all patients, $15.5 \%(n=80)$ had active disease at the time of completion of the questionnaire, most of these were $C D$ patients. These patients showed significantly lower psychological status and HRQoL compared to the group that had no active disease. No differences in HRQOL scores could be observed between CD and UC patients without active disease. Between patients with and without active disease no differences in total QoC scores were observed. However, CD patients scored the care dimension "costs" significantly lower (worse) than patients with UC.

Table 4.2 Scores per variable of the conceptual model for patients with Crohn's disease (CD) and ulcerative colitis (UC).

\begin{tabular}{lrrrr}
\hline & \multicolumn{2}{c}{ CD patients } & \multicolumn{2}{c}{ UC patients } \\
& mean & (SD) & mean & (SD) \\
\hline Quality of Life $\left(7-70^{\dagger}\right)$ & 48.5 & $(12.4)$ & 52.1 & $(11.6)^{*}$ \\
Quality of Care $\left(0-10^{\dagger}\right)$ & 8.9 & $(1.2)$ & 8.9 & $(1.2)$ \\
$\quad$ Competence & 9.1 & $(1.9)$ & 9.3 & $(1.6)$ \\
Courtesy & 9.2 & $(1.4)$ & 9.3 & $(1.5)$ \\
Accessibility & 8.7 & $(1.7)$ & 8.7 & $(1.8)$ \\
Information & 8.4 & $(2.4)$ & 8.5 & $(2.1)$ \\
Continuity of care & 9.0 & $(1.6)$ & 8.9 & $(1.7)$ \\
Accommodation & 9.6 & $(1.5)$ & 9.6 & $(1.4)$ \\
Autonomy & 9.1 & $(2.7)$ & 9.2 & $(2.5)$ \\
Costs & 8.6 & $(3.0)$ & 9.1 & $(2.5)$ \\
Disease activity & & & & \\
Harvey-Bradshaw Index $\left(>0^{\dagger}\right)$ & 3.8 & $(3.3)$ & - & \\
CAI (0-21 & - & & 3.6 & $(2.9)$ \\
Psychological status $\left(0-100^{\dagger}\right)$ & 67.0 & $(20.6)$ & 69.0 & $(20.2)$ \\
Coping (25-75 & & & & \\
$\quad$ Task & 46.1 & 11.5 & 47.3 & 11.6 \\
$\quad$ Avoidance & 49.8 & 12.9 & 51.5 & 12.5 \\
$\quad$ Emotion & 52.6 & 11.2 & 52.4 & 11.8 \\
Stressful life events $\left(0-16^{\dagger}\right)$ & 1.3 & $(1.2)$ & 1.0 & $(1.1)^{*}$ \\
Social support $\left(0-100^{\dagger}\right)$ & 78.3 & $(21.2)$ & 78.4 & $(21.1)$ \\
\hline
\end{tabular}

${ }^{\dagger}$ possible range; ${ }^{*} p<0.05$

Data of all variables were included in multivariate regression analyses for the total group as well as for $C D$ and UC patients separately. Table $4.3 \mathrm{~A}$ shows the results of the final (optimal) model. The variables with a positive significant influence on HRQoL were: QoC $(p=0.016)$, psychological status $(p<0.001)$, 
$58 \mid$ Chapter 4

and attendance to a university hospital rather than a regional hospital $(p=0.049)$. Social support had a similar influence, just failing to reach statistical significance $(p=0.058)$. In contrast, the variables with a negative marked or significant influence on HRQoL were disease activity $(p<0.001)$, the number of stressful life events $(p=0.058)$, and the way of administration of the questionnaire $(p=0.061)$ (interview appeared to result in better HRQoL scores than self-report). Among the variables with a non-significant or marked influence were gender, age, smoking, living with partner, occupation, disease entity (UC or CD), geographic location (South versus North) and all three coping strategies. Exclusion of these variables from the model did not significantly influence the results $\left(\chi^{2}=19.142 ;\right.$ d.f. $\left.=12 ; p=0.085\right)$.

Analysing the separate care dimensions (excluding the total care score), gave comparable results, showing a significant positive influence of "providing information" (Table 4.3B). As in the first analysis, the exclusion of the other variables did not significantly influence the results $\left(\chi^{2}=26.646\right.$; d.f. $=19$; $p=0.113)$.

The analyses for $C D$ and UC patients separately showed similar results, although in UC patients the total score of QOC did not contribute to HRQoL. The following exceptions however relating to further care dimensions, were found to have marked or significant positive influence on HRQOL: in CD patients the care dimension "continuity of care" $(p=0.060)$, and in UC patients the care dimension "courtesy" ( $p=0.017)$.

Table 4.3 Optimal models of quality of life in IBD influenced by fixed and random parameters using multi-level multivariate regression analysis

\begin{tabular}{lccc}
\hline & Beta & (s.e.) & p-value \\
\hline A: QoL model including QoC as a total score & & & \\
Constant $\left(\alpha_{0}\right)$ & 12.538 & $(3.829)$ & 0.001 \\
QoC - Total score & 0.799 & $(0.331)$ & 0.016 \\
Disease activity & -6.547 & $(1.074)$ & $<0.001$ \\
Psychological status & 1.296 & $(0.086)$ & $<0.001$ \\
Stressful life events & -0.634 & $(0.354)$ & 0.073 \\
Social support & 0.036 & $(0.019)$ & 0.058 \\
Type of hospital & 2.136 & $(1.084)$ & 0.049 \\
Way of administration on the questionnaire & -3.326 & $(1.772)$ & 0.061 \\
B: QoL model including QoC with the dimensional scores & & & \\
Constant ( $\left.\alpha_{0}\right)$ & 15.473 & $(3.035)$ & $<0.001$ \\
QoC - Information & 0.462 & $(0.176)$ & 0.009 \\
Disease activity & -6.664 & $(1.075)$ & $<0.001$ \\
Psychological status & 1.305 & $(0.086)$ & $<0.001$ \\
Stressful life events & -0.692 & $(0.353)$ & 0.051 \\
Social support & 0.037 & $(0.019)$ & 0.051 \\
Type of hospital & 2.085 & $(1.086)$ & 0.055 \\
Way of administration of the questionnaire & -3.153 & $(1.853)$ & 0.089 \\
\hline
\end{tabular}

* s.e. $=$ standard error 


\section{Discussion}

In previous years several factors have been described that influence HRQoL in IBD: disease activity, psychological status, coping strategies, social support, and stressful life events ${ }^{23,24,24-38}$. In the present study a new feature, namely QoC, was investigated in addition to these already known factors. Taking possible interrelations and confounding factors into consideration, it was found that HRQoL was influenced by QoC as a whole and by all other factors in the conceptual model except for "coping". The influence of QoC concerned particularly the QOC aspect of "providing information". These findings open opportunities for improving HRQOL in IBD as QoC can probably be optimised in contrast to most of the other contributing factors.

The finding that $C D$ patients suffered from the cost aspect more than UC patients might be caused by the generally more difficult disease course of $C D$. Treatment of $C D$ patients is more complex and implicates the need for more expensive medication (e.g. anti-TNF $\alpha$ ) and nutritional support, which may not be refunded by insurance companies or national health care systems. Increasing the accessibility to the necessary treatment (i.e. decreasing the costs) would suppress disease activity and thus increase HRQoL for CD patients.

For CD patients, in addition to $Q \circ C$ as a total score, the care dimension of "continuity of care" contribute to the HRQoL, whereas for UC patients "courtesy" is of special importance.

From this particular choice by the patients, it can be concluded that in the care process the combination of medical treatment and psychological approach is needed for improvement of HRQOL in IBD patients. This confirms Blumenthal's hypothesis that patient-centred care is needed when studying the patients' perspective on health care and health outcome ${ }^{2}$.

To date, many health outcome assessment studies have not demonstrated an association between the processes and outcomes of care. For those studies that did show such a relationship, a criticism could be that their conceptual framework did not include sufficient variables that might also have significant influence on the outcome measured ${ }^{52,53}$. In the present study, these considerations were taken into account in the conceptual model. Moreover, the study was conducted in a multinational setting (for the first time to our knowledge), and provides results for a large European area.

The high response rate to the patient questionnaire seems to indicate that IBD patients are greatly interested in this topic. This is underlines the statement by Cleary et al. that patients' involvement in the care process is likely to improve compliance, return for follow-up care, and outcomes ${ }^{54}$.

Irvine has suggested that HRQoL is linked to non-disease elements e.g., gender, age, cultural factors and coping skills, besides disease elements ${ }^{55}$. Our results support this assumption with regard to the direct relationship of each of the individual variables with HRQoL, but when adjusting for them in a multivariate regression analysis, the majority of these associations disappeared, apparently due to interrelation of these parameters in daily life. However, disease activity 
remains as a factor of influence ${ }^{56}$, and to a minor degree also the type of disease (CD or $U C)^{13}$.

The present study used the SIBDQ ${ }^{48}$ to determine HRQoL in UC and $C D$ patients. This was adopted for logistic reasons to keep the total length of the questionnaire acceptable to the patients. In the meantime, the groups led by Hjortswang et al., Han et al., and Cheung et al. have criticised the number and content of dimensions for UC patients in the original SIBDQ, as this questionnaire was developed and validated in CD patients only ${ }^{57.59}$. Therefore, the multivariate analyses in the present study were performed not only for the patient group as a total, but also separately for the CD and UC subgroups. The results of these analyses were comparable.

Although our study was carried out in seven countries in Europe and one in the Near East, straightforward extrapolation of the results to a European or even global level must be done with caution. Further investigation of the observed correlations in other countries will be most informative. Another note of prudence concerns the fact that the participating patients might have received above average care, since they are part of a study cohort and attend hospital departments that have been collaborating in clinical epidemiological research for several years. The fact, however, that differences could be observed between countries despite this uniform background, reinforces our premise about the impact of the care determining factors identified in this study. Nevertheless, repeating this study in a longitudinal setting will be helpful to prove causality of the found relationship. Performance of this study in different settings, e.g. per country or area, could give additional results in terms of the particular local care aspects that influence HRQoL. Local health care policies could then be adapted and improved into detail, optimising IBD patients' HRQOL even further.

Unfortunately, many new research findings resulting in guidelines do not reach the target group, and if they do, they may not be translated into daily clinical practice 6,60 . Several years ago, guidelines on quality of health care were discussed by Kassirer ${ }^{61}$ and Greco \& Eisenberg ${ }^{62}$, who stressed the following points: practice guidelines are a response to the perception of unwarranted variations in practice between physicians; some of the high cost of medical care can be explained by inappropriate care; standards are needed to bring outliers into compliance; most studies conducted to investigate these perceptions exclude the actual physician-patient encounter, which represents the most frequent mode of contact for the patient in the care system ${ }^{61,62}$.

It is our hope that the design of the present study, which thoroughly studied the determinants of the care process and disease outcome in IBD, will convince health policy makers of the importance of patient judgements on quality of health care and of the existing relationship between QOC and HRQoL. Therefore we would like our findings and recommendations to be used for the development of guidelines for optimising the health-related quality of life in IBD, in addition to health economic purposes. The recommendations emerging from 
this study, for the improvement of QoC, should now be implemented and feedback should be gained by repeating data collection on Q०C in a prospective way. 


\section{References}

1 Berwick DM. Quality of health care part 5: Payment by capitation and the quality of care. New Engl J Med 1996;335:1227-31.

2 Blumenthal D. Quality of health care part 1: Quality of care - what is it? New Engl J Med 1996;335:891-4.

3 Blumenthal D, Epstein AM. Quality of health care part 6: The role of physicians in the future of quality management. New Engl J Med 1996;335:1328-31.

4 Blumenthal D. Quality of health care part 4: The origins of the quality-of-care debate. New Engl J Med 1996;335:1146-9.

5 Brook RH, McGlynn EA, Cleary PD. Quality of health care part 2: Measuring quality of care. New Engl J Med 1996;335:966-70.

6 Chassin MR. Quality of health care part 3: Improving the quality of care. New Engl J Med 1996;335:1060-3.

7 Shivananda S, Lennard-Jones JE, Logan R, Fear N, Price A, Carpenter L, et al. Incidence of inflammatory bowel disease across Europe: is there a difference between north and south? Results of the European Collaborative Study on Inflammatory Bowel Disease (EC-IBD). Gut 1996;39:690-7.

8 Russel MG, Dorant E, Volovics A, Brummer R-J, Pop P, Muris JW, et al. High incidence of inflammatory bowel disease in the Netherlands. Dis Colon Rectum 1998;41:33-40.

9 Drossman DA, Patrick DL, Mitchell CM, Zagami EA, Appelbaum MI. Health-related quality of life in inflammatory bowel disease. Dig Dis Sci 1989;34:1379-86.

10 Drossman DA. Measuring quality of life in inflammatory bowel disease. Pharmacoecon 1994;6:578-80.

11 Eckardt VF, Lesshafft C, Kanzler G, Bernhard G. Disability and health care use in patients with Crohn's disease: a spouse control study. Am J Gastroenterol 1994;89:2157-62.

12 Love JR, Irvine EJ, Fedorak RN. Quality of life in inflammatory bowel disease. J Clin Gastroenterol 1992;14:15-9.

13 Mitchell A, Guyatt GH, Singer J, Irvine EJ, Goodacre R, Tompkins C, et al. Quality of life in patients with inflammatory bowel disease. J Clin Gastroenterol 1988;10:30610.

14 Sorensen VZ, Olsen BG, Binder V. Life prospects and quality of life in patients with Crohn's disease. Gut 1987;28:382-5.

15 Mayberry JF. The diagnosis of inflammatory bowel disease - What should we tell the patient? Ital J Gastroenterol Hepatol 1997;29:483-6.

16 Smart H, Mayberry JF, Calcraft B, Morris JS, Rhodes J. Effect of information booklet on patients' anxiety levels and consultation rates in Crohn's disease. Public Health 1986;100:184-6.

17 Silverstein MD, Loftus EV, Sandborn WJ, Tremaine WJ, Feagan BG, Nietert PJ, et al. Clinical course and costs of care for Crohn's disease: Markov model analysis of a population-based cohort. Gastroenterology 1999;117:49-57. 
18 Blomqvist $P$, Ekbom A. Inflammatory Bowel Disease: Health Care and Costs in Sweden in 1994. Scand J Gastroenterol 1997;32:1134-9.

19 Hay JW, Hay AR. Inflammatory bowel disease: costs-of-illness. J Clin Gastroenterol 1992;14:309-17.

20 de Boer AGEM, Sprangers MAG, Bartelsman JFW, de Haes JCJM. Predictors of health care utilization in patients with inflammatory bowel disease: a longitudinal study. Eur J Gastroenter Hepatol 1998; 10:783-9.

21 van der Eijk I, Stockbrügger RW, Russel MG. Influence of quality of care on quality of life in inflammatory bowel disease (IBD): literature review and studies planned. Eur J Int Med 2000;1 1:228-34.

22 Drossman DA, Leserman J, Mitchell M, Li Z, Zagami EA, Patrick DL. Health status and health care use in persons with inflammatory bowel disease. Dig Dis Sci 1991;36:1746-55.

23 Turnbull GK, Vallis TM. Quality of life in inflammatory bowel disease: the interaction of disease activity with psychosocial function. Am J Gastroenterol 1995;90:1450-4.

24 MacPhee M, Hoffenberg EJ, Feranchak A. Quality-of-life factors in adolescent inflammatory bowel disease. Inflam Bowel Dis 1998;4:6-11.

25 Porcelli P, Leoci C, Guerra V. A prospective study of the relationship between disease activity and psychologic distress in patients with inflammatory bowel disease. Scand J Gastroenterol 1996;31:792-6.

26 Helzer JE, Chammas S, Norland CC, Stillings WA, Alpers DH. A study of the association between Crohn's disease and psychiatric illness. Gastroenterology 1984;86:324-30.

27 Moser G, Tillinger W, Sachs G, Genser D, Maier Dobersberger T, Spiess K, et al. Disease-related worries and concerns: a study on out-patients with inflammatory bowel disease. Eur J Gastroenterol Hepatol 1995;7:853-8.

28 Lazarus RS. Coping theory and research: past, present, and future. Psychosom Med 1993;55:234.

29 Wahl A, Hanestad BR, Wiklund I, Moum T. Coping and quality of life in patients with psoriasis. Qual Life Res 1999;8:427-33.

30 Kinash RG, Fischer DG, Lukie BE, Carr TL. Coping patterns and related characteristics in patients with IBD. Rehabil Nurs 1993; 18:12-9.

31 McColl MA, Skinner $H$. Assessing inter- and intrapersonal resources: social support and coping among adults with a disability. Dis Rehab 1995;17:24-34.

32 Sherbourne CD, Meredith LS, Rogers W, Ware JE. Social support and stressful life events: age differences in their effects on health-related quality of life among the chronically ill. Qual Life Res 1992;1:235-46.

33 von Wietersheim J, Kohler T, Feiereis H. Relapse-precipitating life events and feelings in patients with inflammatory bowel disease. Psychother Psychosom 1992;58:103-12.

34 North CS, Alpers DH, Helzer JE, Spitznagel EL, Clouse RE. Do life events or depression exacerbate inflammatory bowel disease? Ann Int Med 1991;1 14:381-6.

35 Drossman DA. Life stresses and effects on ulcerative colitis, selected summaries. Inflam Bowel Dis 1995; 1:86-9.

36 Porcelli P, Zaka S, Centonze S, Sisto G. Psychological distress and levels of diease activity in inflammatory bowel disease. Ital J Gastroenterol 1994;26:111-5. 
64 Chapter 4

37 Levenstein S, Prantera C, Varvo V, Scribano ML, Berto E, Andreoli A ef al. Psychological stress and disease activity in ulcerative colitis: a multidimensional cross-sectional study. Am J Gastroenterol 1994;89:1219-25.

38 Duffy LC, Zielezny MA, Marshall JR, Byers TE, Weiser MM, Phillips JF, ef al. Relevance of major stress events as an indicator of disease activity prevalence in inflammatory bowel disease. Behar Med 1991;17:101-10.

39 Stockbrügger RW, Russel MGVM, van Blankenstein M, Shivananda S. EC-IBD: a European effort in inflammatory bowel disease. Eur J Int Med 2000;1 1:187-90.

40 Harvey RF, Bradshaw JM. A simple index of Crohn's disease activity. Lancet $1980 ; 1: 514$.

41 Best WR, Becktel JM, Singleton JW, Kern F. Development of a Crohn's disease activity index. Gastroenterology 1976;70:439-44.

42 Lichtiger S, Present DH, Kornbluth A, Gelernt I, Baver J, Galler G, et al. Cyclosporine in severe ulcerative colitis refractory to steroid therapy. New Engl J Med 1994;330:1841-5.

43 Berwick DM, Murphy JM, Goldman PA, Ware JE, Barskey AJ, Weinstein MC. Performance of a five-item mental health screening test. Med Care 1991;29:16976.

44 Endler NS, Parker JDA. Multidimensional assessment of coping: a critical evaluation. J Pers Soc Psychol 1989;58:844-54.

45 Sherbourne CD, Stewart AL. The MOS Social Support Survey. Soc Sci Med 1991;32:705-14.

46 Holmes $\mathrm{TH}$, Rahe $\mathrm{RH}$. The social readjustment rating scale. J Psychosom Res 1967;11:213-8.

47 van der Eijk 1, Sixma H, Smeets T, Tavarela Veloso F, Odes S, Montague S, et al. Assessing IBD patients' priorities and perceptions on quality of health care: development of the QUOTE-IBD. Am J Gastroenterol, in press.

48 Irvine EJ, Zhou Q, Thompson AK, CCRPT Investigators. The Short Inflammatory Bowel Disease Questionnaire: a quality of life instrument for community physicians managing inflammatory bowel disease. Am J Gastroenterol 1996;91:1571-8.

49 Longford NT. Random coefficient models. Oxford: Clarendon Press, 1993.

50 Goldstein H. Multilevel statistical models. 2nd ed. London: Edward Arnold, 1995.

51 Langford IH, Bentham G, MCDonald A. Multilevel modelling of geographically aggregated health data: a case study on malignant melanoma mortality and UV exposure in the European Community. Stat Med 1998;17:41-58.

52 Coyle YM, Battles JB. Using antecendents of medical care to develop valid quality of care measures. Int J Qual Health Care 1999; 1 1:5-12.

53 Cleary PD, McNeil BJ. Patient satisfaction as an indicator of quality care. Inquiry 1988;25:25-36.

54 Cleary PD, Edgman-Levitan S, Roberts M, Moloney TW, McMullen W, Walker JD, et al. Patients evaluate their hospital care: a national survey. Health Affairs 1991;10:254-67.

55 Irvine EJ. Quality of life in inflammatory bowel disease: biases and other factors affecting scores. Scand J Gastroenterol 1995;30:136-40. 
56 Irvine EJ, Feagan B, Rochon J, Archambault A, Fedorak RN, Groll A, et al. Quality of life: a valid and reliable measure of therapeutic efficacy in the treatment of inflammatory bowel disease. Canadian Crohn's Relapse Prevention Trial Study Group. Gastroenterology 1994;106:287-96.

57 Hjortswang H, Järnerot G, Curman B, Sandberg-Gertzén H, Tysk C, Blomberg B, et al. Validation of the Inflammatory Bowel Disease Questionnaire in Swedish patients with ulcerative colitis. Scand J Gastroenterol 2001;36:77-85.

58 Han S-W, Gregory W, Nylander D, Tanner A, Trewby P, Barton R, et al. The SIBDQ: Further validation in ulcerative colitis patients. Am J Gastroenterol 2000;95:145-51.

59 Cheung W, Garratt AM, Russell IT, Williams JG. The UK IBDQ - A British version of the inflammatory bowel disease questionnaire: development and validation. J Clin Epidem 2000;53:297-306.

60 Grol R. Implementation of evidence and guidelines in clinical practice: a new field of research? Int J Qual Health Care 2000;12:455-6.

61 Kassirer JP. The quality of care and the quality of measuring it. New Engl J Med 1993;329:1263-5.

62 Greco PJ, Eisenberg JM. Changing physicians' practices. New Engl J Med $1993 ; 329: 1271-4$. 


\section{Chapter 5}

Quality of Care for patients with inflammatory bowel disease (IBD): opinions of physicians and patients

I van der Eijk, J Freitas, C O'Morain, P Munkholm, G d'Albasio,

$C$ van Deursen, $R$ Stockbrügger, and $M$ Russel, on behalf of the EC-IBD Study Group

Submitted for publication 


\section{Abstract}

\section{Objectives}

The aims of this study were to investigate the physicians' perspective on the quality of care provided for patients with inflammatory bowel disease (IBD), and to compare this with the perception of the care-receiving patient in a multi-national setting.

\section{Methods}

A questionnaire to assess the physicians' perspective was developed involving physicians treating IBD patients. The scoring system combined importance and performance ratings. The questionnaire was administered to 129 physicians treating IBD patients in eight countries. Simultaneously, a patient questionnaire that was developed for the purpose of this study, was administered to 1056 IBD patients in these countries.

\section{Results}

Ninety-eight physicians responded and indicated care aspects that could be improved, specifically regarding costs of health care. In total 824 patients responded, of whom 517 received health care during the past year. The perspectives of patients and physicians differed markedly. For example, patients had a better opinion of the cost aspect of IBD, whereas physicians scored the provision of information about the disease better.

\section{Conclusions}

Most of the observed differences between the perceptions of patients and physicians might have emerged from the fact that the latter are restricted to work in predetermined health care structures unknown by the patients. This might explain the different perception of costs of IBD. With regard to providing information, physicians should be aware of the growing demand of patients for more detailed information about the nature of their disease, its clinical management, social consequences and prognosis. The results of this study, representing both the physicians' and the patients' perspectives, contribute to develop guidelines for changing practice in order to optimise quality of care for IBD. 


\section{Introduction}

Since chronically ill patients are usually in continuous need for health care, quality of health care (QoC) may play a particularly important role in their lives. Several studies have been conducted to examine the role of patients in the optimisation of QoC 1.9 . The physician's part in improving health care is however little discussed. Changing physicians' practice in order to optimise health care cannot simply be achieved by only providing evidence-based guidelines. Physicians frequently rely on their own experience or colleagues' recommendations in deciding whether to adopt new attitudes, techniques or interventions ${ }^{10}$. The goal of the present study was twofold; first to investigate the perception of the treating physicians on QOC in IBD, and second to compare it with the perception of patients receiving the care.

\section{Methods}

\section{Participants}

Centres in seven European countries (Norway, Denmark, Ireland, Netherlands, Portugal, Italy, Greece) and Israel participated in this study on quality of health care in IBD in the context of the European Collaborative Study Group on IBD $(\mathrm{EC}-\mathrm{IBD})^{1 !}$.

A questionnaire for physicians treating IBD patients, with the purpose to investigate the physicians' perspective on the QoC provided, was developed by asking 24 Dutch physicians to indicate which specific care aspects they considered of importance. The response rate to this request was $66.7 \%(n=16)$; ten physicians were gastroenterologists, four were internists, and two were surgeons. Seven out of eight generally accepted care dimensions (courtesy, accessibility, continuity of care, accommodation, providing information, costs, patient autonomy, and competence of the physician ${ }^{12.14}$ ), were addressed in the questionnaire. The dimension "accommodation" was excluded, as it was not proposed by the physicians. The scoring system of the questionnaire combined "importance" and "performance" perspectives. Scores could range from 0 to 10 (best), scores below 9.0 indicate that the care aspect could be improved in the doctors' opinion. The developed questionnaire with the calculation of the score is presented in the Appendix.

For the purpose of the above-mentioned study a similar patient questionnaire (QUOTE-IBD) had been developed to assess the perspective of IBD patients on $Q_{0}{ }^{15}$ (Chapter 3). In this questionnaire all eight care dimensions were addressed. In order to compare the perspective of treating physicians with that of the patients, data on "accommodation" were omitted for the present study. 
One thousand fifty-six patients, all diagnosed with IBD between six to eight years ago, were approached to complete the QUOTE-IBD. Concomitant to the administration of the QUOTE-IBD, the physicians' questionnaire also was completed. In addition, the physicians $(n=129)$ were asked their opinion regarding the extent to which they could provide optimal health care.

In this study, the diagnosis IBD had been uniformly defined by the classification criteria of Lennard-Jones, used in a large previous survey of IBD by the same working group ${ }^{16-18}$. The main disease entities of IBD are Crohn's disease (CD) and ulcerative colitis (UC).

\section{Statistical analyses}

Non-parametric chi-square tests were performed to compare male and female physicians with regard to their professional characteristics. To further differentiate the physicians' opinion, Mann-Whitney tests were conducted to compare perspectives of physicians for total care scores and scores per dimension between age groups younger and older than 46.0 years (which was the median age of the total group), between males and females, between northern and southern countries, and between patients and physicians. To examine physicians' perspectives regarding total and dimensional care scores between the different countries, Kruskal-Wallis tests were performed.

Statistical analyses were carried out using SPSS package 8.5 for Windows (SPSS Inc., Chicago, IL). For all analyses $p$-values smaller than 0.05 were considered significant.

\section{Results}

Of the 129 physicians approached, 98 responded to the questionnaire $(76 \%)$. Characteristics of the participating physicians are presented in Table 5.1. No significant differences could be observed between males and females concerning geographic location (north compared to south Europe), age, years of experience with IBD patients, yearly hours of postgraduate training, and number of IBD patient consultations each month.

In Table 5.2 the physicians' perspectives on QoC is shown per country. It is demonstrated that the physicians scored most care dimensions below 9.0. Comparison between northern and southern countries indicated that with regard to the different aspects of care provided, physicians in southern countries generally gave lower scores.

In addition to "total quality of care", male physicians scored the dimensions "accessibility", "continuity of care", "competence", and "costs" significantly better than female physicians. Of the total group, physicians aged less than 46 years (median age of the total group) rated the "total care", "accessibility" and "continuity of care" significantly lower than older physicians. 
Table 5.1 Characteristics of 98 physicians treating IBD patients of the EC-IBD cohort

\begin{tabular}{|c|c|c|c|}
\hline & & Males & Females \\
\hline Numbe & & 82 & 16 \\
\hline Median & (range) & $48(32-63)$ & $42(31-65)$ \\
\hline Countri & & & \\
\hline North & Norway & 4 & 0 \\
\hline & Denmark & 11 & 4 \\
\hline & Ireland & 8 & 0 \\
\hline & Netherlands & 12 & 0 \\
\hline South & Portugal & 7 & 3 \\
\hline & Italy & 18 & 4 \\
\hline & Greece & 13 & 2 \\
\hline & Israel & 9 & 3 \\
\hline Medical & cialty & & \\
\hline & Gastroenterology & 70 & 13 \\
\hline & Internal Medicine & 6 & 2 \\
\hline & Surgery & 4 & 1 \\
\hline & Paediatrics & 2 & 0 \\
\hline Mean $n$ & er of years working with IBD (range) & $12.8(1-30)$ & $8.8(3-20)$ \\
\hline $\begin{array}{r}\text { Mean } n \\
\text { for po }\end{array}$ & $\begin{array}{l}\text { er of hours per year } \\
\text { duate training (range) }\end{array}$ & $81(3-415)$ & $65(15-150)$ \\
\hline $\begin{array}{l}\text { Mean } n \\
\text { of IBD } \\
\end{array}$ & $\begin{array}{l}\text { er of outpatient consultations } \\
\text { ents per month (range) }\end{array}$ & $32(2-150)$ & $22(2-56)$ \\
\hline
\end{tabular}

Of the 824/1056 responding patients of the EC-IBD cohort (78\%), 517 had received health care $(62.7 \%)$ during the past year and were subsequently included in the analyses. Patient characteristics are shown in Table 5.3. According to their treating physicians, optimal health care could be provided for 423 patients $(81.8 \%)$. Of the remaining 94 patients, receiving less than optimal health care in their doctor's view, requisite facilities were not available in $7.4 \%$ $(n=7)$, in a further $21.2 \%$ the patient did not agree with the treatment offered $(n=20)$, and in $6.4 \%$ optimal health care could not be provided because of financial reasons $(n=6)$. For the remaining $65 \%$ of patients $(n=61)$ no specified reason was given.

Table 5.4 presents the care scores given by patients and physicians, respectively. The total care was scored significantly higher by patients than by physicians. The care sub-dimensions "competence", "continuity of care", and "costs" were scored significantly higher by patients, whereas the sub-dimensions "accessibility" and "providing information" were scored significantly higher by the physicians. 
$72 \mid$ Chapter 5

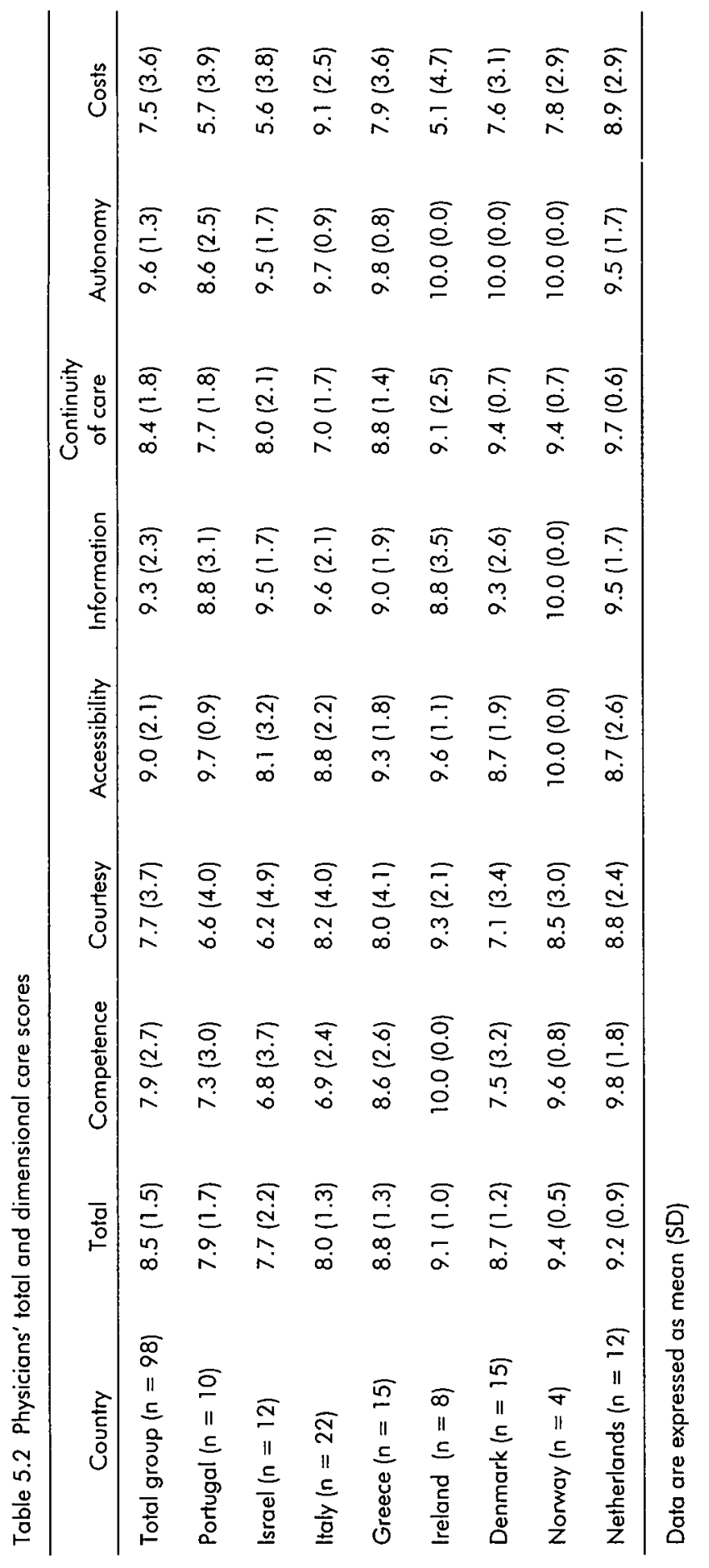


Table 5.3 Characteristics of 517 responding IBD patients who had received health care during the past year

\begin{tabular}{llll}
\hline & CD & UC \\
\hline Number & 195 & 322 \\
Males & 76 & 171 \\
Females & 119 & 151 \\
Mean age (range) & $42.6(22-84)$ & $47.6(19-85)$ \\
Number of patients per country & & \\
North Norway & 20 & 36 \\
& Denmark & 28 & 50 \\
& Ireland & 16 & 16 \\
& Netherlands & 58 & 67 \\
South & Portugal & 13 & 11 \\
& !faly & 39 & 73 \\
& Greece & 10 & 50 \\
& Israel & 11 & 19 \\
\hline
\end{tabular}

Table 5.4 Care scores of IBD patients and their treating physicians

\begin{tabular}{llll}
\hline & Patients & Physicians & $\mathrm{p}^{*}$ \\
\hline Total score & $8.9(1.3)$ & $8.5(1.5)$ & 0.001 \\
$\begin{array}{l}\text { Dimensional scores } \\
\text { Competence }\end{array}$ & $9.2(1.5)$ & $7.9(2.7)$ & $<0.001$ \\
Courtesy & $9.3(1.5)$ & $7.7(3.7)$ & $\mathrm{ns}$ \\
Accessibility & $8.7(1.8)$ & $9.0(2.1)$ & $<0.001$ \\
Information & $8.4(2.2)$ & $9.3(2.3)$ & $<0.001$ \\
Continuity of care & $8.9(1.7)$ & $8.4(1.8)$ & 0.001 \\
Autonomy & $9.1(2.6)$ & $9.6(1.3)$ & $\mathrm{ns}$ \\
Costs & $8.9(2.7)$ & $7.5(3.6)$ & $<0.001$ \\
\hline
\end{tabular}

* Non-parametric Mann-Whitney test

\section{Discussion}

In concordance with earlier findings ${ }^{19-23}$, the present study shows that perceptions of IBD patients and their treating physicians differed markedly with regard to most aspects of health care. Physicians rated the provided accessibility to care and information offered more positively, whereas patients were more content than their treating physicians with the competence of the physician, the continuity of care and cost aspects. In addition, it was found that physicians treating $I B D$ patients in Europe had the opinion that several aspects of care could be improved. Cost aspects of medical management of IBD were specifically deemed problematic in most countries. The available time to spend 
per patient was considered too short, and continuous postgraduate training was perceived to be insufficient according to physicians in most countries.

Furthermore, a number of differences between groups of physicians treating IBD patients were observed. Male physicians were more positive regarding the QoC that they were able to provide than their female colleagues. Older physicians were more positive with regard to structural aspects of the care system ("accessibility" and "continuity of care"). Generally, physicians in the north rated the QoC provided to IBD patients better than those in the south.

Most of the observed differences between the perceptions of patients and physicians might be explained by the fact that the latter are restricted to work in predetermined health care structures unknown by the patients. For example, they may have to choose certain disease management strategies taking cost aspects into consideration. As a result a less expensive, but also less efficient diagnostic procedure or treatment might be proposed to a patient, who is not aware of this choice. A further explanation is that physicians have better opportunities than patients to compare possibilities to provide QoC in different centres. They may be aware of certain aspects that have been organised better or worse in another hospital setting, thus resulting in opinions divergent from those of the patients.

With regard to provision of information, it has been shown that patients with chronic diseases specifically have a growing demand for more detailed information about the nature of their disease, its clinical management, social consequences and prognosis ${ }^{24}$. This might reflect better education and social maturity, but probably also more widespread health information by media, patient organisations and also the Internet.

The fact that female physicians rated the quality of the care they provided lower than males, may be caused by the fact that in general females are more prone to admit negative feelings and criticism to themselves and their environment ${ }^{25}$. An alternative explanation is that females generally hold less prestigious job positions in health care compared to males, causing them to be less satisfied. In this study, they also tended to be younger than their male colleagues.

Older physicians probably perceived the quality of the provided care better since they usually are more experienced than younger doctors, resulting in less need for expensive diagnostic procedures and other costly interventions. They may rely more on their own accumulated experiences and privileged job positions to provide good care.

The observation that doctors in northern Europe rated the provided care better compared to those in the south is difficult to explain. Perhaps differences in health care funding could play a role, besides differences in health care structures, and demographic, geographic and cultural features.

Physicians indicated the lack of patient's consent to the treatment proposed as the most common reason for the failure to provide optimal health care to particular patients. This suggests that physicians respect the patient's opinion, 
regardless of the clinical implications. This factor is reflected in the care dimension "autonomy of the patient", which was rated similarly good by both patients and physicians. In a few cases the requisite facilities for optimal treatment were not available. Unfortunately, reasons for this were not recorded in the present study.

Financial reasons (e.g. costs for medical treatment that are not refunded by national health systems or insurance companies) were also a factor for regarding the provided health care less than optimal. With regard to the cost aspect, the results from the doctor's questionnaire confirm this observation and stress the impact of financial budgets on the provision and perception of QoC. A note should be made to the large number of unspecified reasons of providing sub-optimal care; it is possible that in this study physicians were reluctant to come forward with information that might present a negative view on the hospital where they are employed.

To our knowledge this study is the first that both investigates and compares the perspectives of chronically ill patients and their treating physicians regarding the provided QoC. Since all diseases have individual characteristics, studying health care in chronic disorders should start by investigating patients' and doctors' views on provided health care per specific disease. Eventually, combining the results of these surveys could be of value for European harmonisation and contribute to high standard health care for chronically ill patients.

In conclusion, in IBD physicians' perspectives differ from patients' perspectives with regard to QoC. It is obvious that physicians' practices are influenced by QoC factors, in addition to guidelines based on scientific research and published by "national experts" doctors' perspectives on the provided QoC in a scientifically sound way, could help policy makers in recognizing and solving practical bottlenecks in providing good health care for the chronically $i l^{26}$. In IBD, but possibly in all chronic diseases, such developments could ultimately result in improved quality of life for the patients. 


\section{References}

1 Cleary PD, Edgman-Levitan S. Health care quality. Incorporating consumer perspectives. JAMA 1997;278:1608-12.

2 Kirsner RS, Federman DG. Patient satisfaction. Quality of care from the patients' perspective. Arch Dermatol 1997;133:1427-31.

3 Longo DR, Land G, Schramm W, ef al. Consumer reports in health care. Do they make a difference in patient care? JAMA 1997;278:1579-84.

4 Richards T. Partnership with patients. BMJ 1998;316:85-6.

5 Zastowny TR, Stratmann WC, Adams EH, et al. Patient satisfaction and experience with health services and quality of care. Qual Man Health Care 1995;3:50-61.

6 Brink-Muinen A, Verhaak PF, Bensing JM, et al. Doctor-patient communication in different European health care systems: relevance and performance from the patients' perspective. Patient Educ Couns 2000;39:115-27.

7 Brody DS, Miller SM, Lerman CE, et al. The relationship between patients' satisfaction with their physicians and perceptions about interventions they desired and received. Med Care 1989;27:1027-35.

8 Epstein KR, Laine C, Farber NJ, et al. Patients' perceptions of office medical practice: judging quality through the patients' eyes. Am J Med Qual 1996;1 1:73-80.

9 Casparie AF, van der Waal MAE. Differences in preferences between diabetic patients and diabetologists regarding quality of care: a matter of continuity and efficiency of care? Diab Med 1995; 12:828-32.

10 Greco PJ, Eisenberg JM. Changing physicians' practices. New Engl J Med 1993;329:1271-4.

11 Stockbrügger RW, Russel MGVM, van Blankenstein $M$, et al. EC-IBD: a European effort in inflammatory bowel disease. Eur J Int Med 2000;1 1:187-90.

12 Hall JA, Dornan MC. Meta-analysis of satisfaction with medical care: description of research domain and analysis of overall satisfaction levels. Soc Sci Med $1988 ; 27: 637-44$.

13 Pascoe GC. Patient satisfaction in primary health care: a literature review and analysis. Eval Progr Plan 1983;6:185-210.

14 van Campen C, Sixma H, Friele RD, ef al. Quality of care and patient satisfaction: a review of measuring instruments. Med Care Res Rev 1995;52:109-33.

15 van der Eijk I, Sixma H, Smeets T, et al. Assessing IBD patients' priorities and perceptions on quality of health care: development of the QUOTE-IBD. Am J Gastroenterol, in press.

16 Lennard-Jones JE. Classification of inflammatory bowel disease. Scand J Gastroenterol 1989;24(Suppl 170):2-6.

17 Lennard-Jones JE, Shivananda S. Clinical uniformity of inflammatory bowel disease at presentation and during the first year of disease in the north and south of Europe. Eur J Gastroenter Hepatol 1997;9:353-9. 
18 Shivananda S, Lennard-Jones JE, Logan $R$, et al. Incidence of inflammatory bowel disease across Europe: is there a difference between north and south? Results of the European Collaborative Study on Inflammatory Bowel Disease (EC-IBD). Gut 1996;39:690-7.

19 Sixma H, Kerssens JJ, van Campen C, et al. Quality of care from the patients' perspective: from theoretical concept to a new measuring instrument. Health Expectations 1998;1:82-95.

20 Borgiel A, O'Neil JJS. Assessing quality in primary care. Can we ask the right questions? Can Fam Phys 1997;43:1699-700.

21 Riggs JE. Assessing quality of care. The limitation imposed by Condorcet paradox. Arch Neurol 1997;54:1351-2.

22 Jun M, Peterson RT, Zsidisin GA. The identification and measurement of quality dimensions in health care: focus group interview results. Health Care Manag Rev 1998;23:81-96.

23 Fagerstrom L, Bergbom Engberg I, Eriksson KA. comparison between patients' experiences of how their caring needs have been met and the nurses' patient classification - an explorative study. J Nurs Manag 1998;6:369-77.

24 Mayberry JF. The diagnosis of inflammatory bowel disease - What should we tell the patient? Ital J Gastroenterol Hepatol 1997;29:483-6.

25 Streiner DL, Norman GR. Health measurement scales. A practical guide to their development and use. Oxford University Press, New York, 1995.

26 Blumenthal D, Epstein AM. Quality of health care part 6: The role of physicians in the future of quality management. New Engl J Med 1996;335:1328-31. 


\section{Chapter 6}

Best practice in inflammatory bowel disease: a European survey

I van der Eijk, J Freitas, C O'Morain, P Munkholm, G d'Albasio, $C$ van Deursen, $R$ Stockbrügger, and $M$ Russel, on behalf of the EC-IBD Study Group

Submitted for publication 


\section{Abstract}

\section{Objectives}

To compare European health care facilities and to define "best practice" with regard to inflammatory bowel disease (IBD).

\section{Design}

Observational study in eight university and four general hospitals in eight countries collaborating in clinical and epidemiological research in IBD.

\section{Methods}

The approach of this multi-national survey was unique. Existing quality norms, developed for total hospital care by a specified organisation, were restricted to IBD-specific care and adapted to the frame of reference of the study group. In each centre these norms were surveyed by means of questionnaires. The data collected were used as a basis for professional audits in all participating centres. Each centre was visited by two auditors, using a uniform approach for the site visits.

\section{Results}

The observations in each centre can be categorised into patient-oriented processes, technical and patient safety, and quality of the medical standard. Several findings can be considered as "benchmarks" (positive care aspects that can directly be implemented for improvement of IBD care in another hospital). They concern confidential relationship between health care worker(s) and patient, good accessibility to health care, availability of patient data, and continuous training and updating of health care workers with regard to care for IBD patients.

\section{Conclusions}

The observed benchmarks, in combination with other important positive observations, have been deduced to "best practice" in IBD. "Best practice" can be summarised as practical guidelines towards optimal quality of care in IBD. 


\section{Introduction}

International comparisons of health care systems are difficult to make for a variety of reasons, such as differences in geographical, demographic and cultural features, political and economic structures, including social care systems. Although the structural characteristics of health care systems differ, every country attempts to provide optimal medical services in a cost-effective manner'. The most frequently used basis for comparing international health care resources is health care expenditure, measured either as a fraction of gross domestic product or per capita. However, comparisons based on measures of actual resources can be more useful and lead to important insights for the future organisation of health care ${ }^{2}$, which was the first objective of the present study.

The second objective of the present study was to define "best practice" in the special case of inflammatory bowel disease (IBD) in seven European countries and Israel, in order to assist health care policy makers and clinicians to provide optimal health services for this group of patients with a chronic disease. The Member States of the European Union (EU) are facing the challenge to unify their health care services at the best possible level and to an affordable cost. "Best practice" can be considered as a way to identify, collect, evaluate, disseminate, and implement information about a disorder and to monitor the outcomes of subsequent interventions ${ }^{3}$. Therefore, information is required on the best available evidence on safety, efficacy, (cost)effectiveness, appropriateness, social and ethical value and subjectively experienced quality of health care interventions.

The reason for studying health care provided for IBD patients in particular, is that IBD is a chronic disease, usually diagnosed at young age ${ }^{4}$, which affects many people (prevalence approximately 300 per 100,000 of populations in the Western world $d^{5}$ ). The efficacy of medical and surgical therapy still remains limited in these patients, resulting in chronically recurrent or even continuous life-long complaints of, amongst others, abdominal discomfort, diarrhoea, and decreased quality of life. These features of IBD may result in a considerable need for health care $^{6}$.

\section{Methods}

\section{Study group}

In the present study physicians and other health care workers of eight countries participated: Norway, Denmark, The Netherlands, Ireland, Portugal, Italy, Greece, and Israel. Since 1989, representatives of these countries have been collaborating in epidemiological and clinical IBD research (European Collaborative study group on $\mid \mathrm{BD}$; EC-IBD) ${ }^{7}$. 


\section{Approach}

Several methods of surveying and improving health care organisation can be applied, for example accreditation ${ }^{8}$, those established by the International Organisation for Standardisation $9000^{\circ}$, or European Foundation of Quality Management ${ }^{10}$.

For the present study, we decided to set up an organisational audit by means of professional peer review, as it appeared to be closer to actual clinical performance than other models with regard to Donabedian's model of improvement that is focused on structure, process, and outcome of health care $^{10,11}$. This feature had already been implemented in one of the participating countries (i.e. the Netherlands ${ }^{12}$ ), and is organised per specialty. It is a physician-led quality assurance and quality improvement program, meaning that physicians set the standards, conduct the surveys, formulate the recommendations for improvement, and decide on sanctions or corrective actions $^{13}$.

The quality norms of the Netherlands Institute of Accreditation of Hospitals (NIAZ) were used as a frame of reference to assess a solid impression of the provided health care for IBD patients. The Plan-Do-Check-Act (PDCA) cycle forms the core of the NIAZ accreditation system $(\text { Box 6.1 })^{8}$.

1. not planned

2. P: planned, not arranged (Plan)

3. D: planned, arranged (Do), but not evaluated

4. C: planned, arranged, evaluated (Check), but not improved

5. A: the cycle is completed (Act) and this can be shown by means of an audit

Box 6.1 The plan-Do-Check-Act cycle in which the surveyed organisation can indicate the status of a certain care aspect

For the purpose of the present study, the NIAZ norms had to be specified and restricted to specific features of IBD, centre-related organisational aspects, and to hospital units that are involved in providing health care for IBD patients. In collaboration with all participating centres, the norms and clinical indicators in the questionnaires for the survey were slightly adapted to fit within the clinical practice references of EC-IBD. Questionnaires were developed separately inquiring the outpatient department, the clinical ward, and the endoscopy unit. The items in the questionnaires concerned the topics as presented in Box 6.2.

The questionnaires were distributed to collaborating doctors in the participating centres (eight university and four general hospitals) in the eight countries, who then completed and returned them to the co-ordinating centre. 
- department / unit characteristics

- management and personnel

- request and consultation

- examination and treatment

- reporting, registration and filing
- maintenance of equipment

- collaboration with other health care workers

- knowledge and skills

- quality evaluation

Box 6.2 Health care topics addressed in questionnaires concerning organisational health care structure

Subsequently, the data were used to prepare audits of the specific centres. Of each topic of the questionnaire (Box 6.2) representative aspects were selected for all audits in order to have a standard, uniform basis. In case of unclear or paradoxical answers in the individual questionnaires, these were selected to be further addressed during the local audit (site visit) as well. The results of the questionnaires, using the PDCA cycle, are not shown here, as they were only used for the planning of the individual audits. The total preparation time prior to the actual site visits took one year.

\section{Site visit/organisational audit}

During the preparation stage and the very first audit the Dutch Institute for Health Care Improvement ( $\mathrm{CBO}$ ) was involved in developing peer review activities. The $\mathrm{CBO}$ supports and co-ordinates the peer review activities of all scientific clinical societies in the Netherlands.

The participating hospitals in the present study were visited by one EC-IBD auditor who was trained by a professional agency for this purpose (lvdE). In each country this auditor was accompanied by a collaborating physician from a different country, resulting in a total of nine auditors reviewing in teams of two. During these peer review surveys, lasting one day per centre, the circumstances were evaluated under which clinical practice took place (Box 6.3).

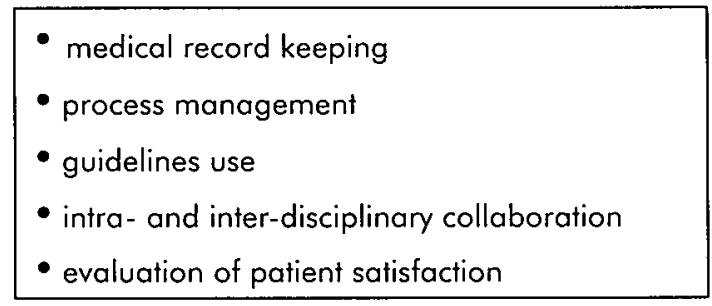

Box 6.3 Items from clinical practice that were evaluated during the site visits

The individual site visit started with an introduction, during which the two auditors explained to all health care workers involved the reason why the audit was to be performed and what could be expected regarding questions and requests of the auditors. Subsequently, the three gastroenterology units involved 
$84 \mid$ Chapter 6

in IBD care (outpatient, inpatient, endoscopy) were visited separately, on which occasion doctors and nurses were interviewed. At the end of the day the auditors evaluated their observations in a preliminary way and gave verbal feedback to all persons involved during the audit day. A written report with the observations and recommendations was prepared for each centre after all audits had been conducted. This was sent to the persons involved in the respective centres three months after the last site visit was performed. These reports were not made available to the public ${ }^{14}$.

\section{Results}

The characteristics of the participating hospitals are represented in Table 6.1. The data show differences in size of hospital population, as well as differences in practice norms in terms of health care consumption.

Table 6.1 Characteristics of the outpatient, endoscopy and clinical wards of the participating hospitals in 1998

\begin{tabular}{clccccc}
\hline Country & Hospital & $\begin{array}{c}N^{\circ} \text { of } \\
\text { admissions } \\
\text { to } I \mathrm{M}^{\ddagger} \text { and } \\
\text { GE }\end{array}$ & $\begin{array}{c}N^{\ddagger} \text { wards } \\
\text { in } 1 \mathrm{M}^{\ddagger} \text { and } \\
\mathrm{GE}^{\ddagger} \text { wards }\end{array}$ & $\begin{array}{c}\text { Mean in- } \\
\text { hospital } \\
\text { time (days) }\end{array}$ & $\begin{array}{c}N^{\circ} \text { of } \\
\text { admitted } \\
\text { IBD } \\
\text { patients }\end{array}$ \\
\hline North & Norway & University & 1153 & 24 & 8.4 & 60 \\
& Denmark & General & 1277 & 26 & 7 & 12 \\
& Iniversity & 1314 & $20^{\dagger}$ & 6.5 & 220 \\
& Ireland & University & 850 & $\S$ & 8 & 95 \\
& Netherlands & University & $338^{\dagger}$ & $13^{\dagger}$ & 7 & 83 \\
& Pouth & General & 1036 & 32 & 14 & 50 \\
& Portugal & University & 1009 & 65 & 8.7 & 190 \\
& Italy & General & 2076 & 68 & 10.3 & 32 \\
& University & $664^{\dagger}$ & $24^{\dagger}$ & 9 & 67 \\
& Greece & General & 1829 & 60 & 10.1 & 91 \\
& Israel & University & 3200 & 68 & 13 & 140 \\
& University & 17343 & 200 & 4.1 & 100 \\
\hline
\end{tabular}

${ }^{\ddagger} I M=$ internal medicine, $G E$ = gastroenterology; ${ }^{\S}$ not defined for $I M \&$ GE dept, all beds are pooled throughout the hospital; ${ }^{\dagger} G E$ department only

In Table 6.2 the main observations of the actual audits are presented for all centres. Endoscopy service 24 hours a day was not provided in all centres, but relatively more university than general hospitals provided this service. 
Best practice in IBD

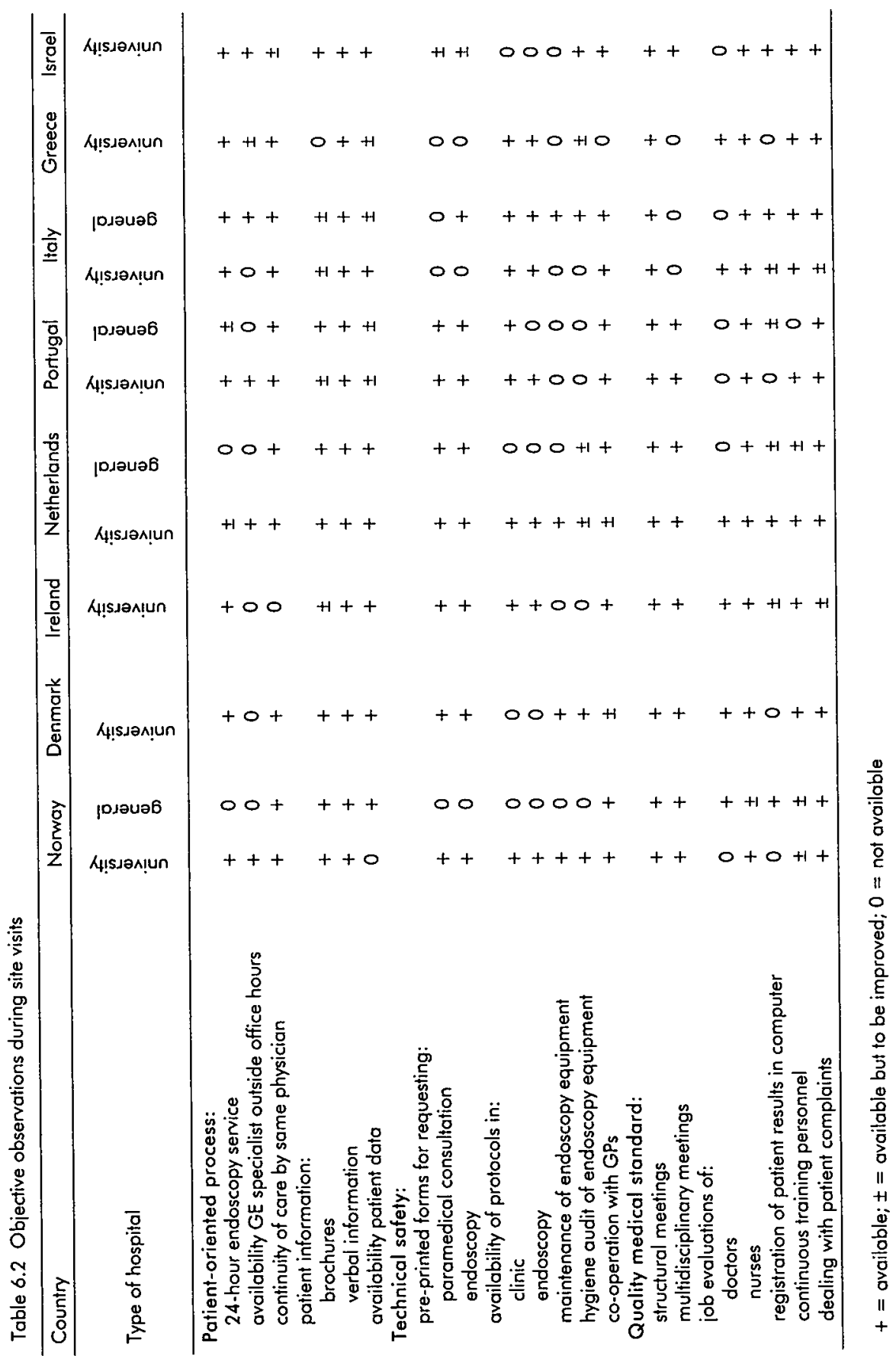


Continuity of care by the same physician was guaranteed in almost all centres within each of the units. Usually, in the general hospitals this was also arranged throughout the three units. Patient information concerning IBD and diagnostic procedures and treatment was provided verbally in all centres, but brochures were not available everywhere, which was particularly true for centres in southern European countries. The availability of diagnostic and therapeutic protocols for doctors and nurses varied over the centres, no consistency concerning general or university hospitals could be observed. In several centres, computer systems were available to register patient data; however, most of these were still subject for improvement and for integration with other in-hospital systems. In most centres, regular maintenance of the endoscopy equipment by the supplying firm was not provided, and also microbiological check-up was not optimal in all centres. For physicians, continuous training with regard to medical management was usually provided, internally by the hospital or externally at conferences, or by medical societies. However, the nursing staff of most hospitals did not have much opportunity for such continuous training.

During the site visits, we were able to note some remarkably positive features in several centres, that can be used as "benchmarks". Benchmarks are positive aspects that are available in a minority of the hospitals and can directly be implemented for improvement in another hospital. These concern accessibility of care, completeness of patient data, provision of diagnostic and therapeutic guidelines, and improving and updating of scientific and clinical knowledge of health care providers. They are shown in Table 6.3.

Table 6.3 Benchmarks of twelve hospitals concerning IBD treatment

Patient-oriented process

1. Multidisciplinary approach: combined gastroenterology/surgery outpatient

2. Triage outpatient department; improves accessibility to specialist care

3. Availability of daily telephone consultation time

4. Availability of a day care hospital, which reduces waiting list for diagnostic procedures and treatment

Technical and patient safety

5. Records of both treating physician and paramedics in the same patient file

6. Regular and frequent update of treating GP concerning patient's status

7. Diagnostic and therapeutic protocols collected in pocket-formatted booklet, provided to all doctors and nurses

Quality medical standard

8. Continuous postgraduate training of both doctors and nurses provided by the hospital

9. Providing wide infegration between treating physicians, nurses and patients

10. Rotation of nurses in outpatient, inpatient, and endoscopy unit 
During a plenary session, 45 physicians collaborating in EC-IBD and an external advisor compiled a set of recommendations for "best practice" in IBD (Table 6.4), using the results shown in Tables 6.2 and 6.3. "Best practice" can be defined as practice guidelines towards optimal quality of care. In addition to the benchmarks mentioned above, they mainly address continuity of care, provision of information to patients, availability and maintenance of diagnostic and therapeutic equipment and facilities.

Table 6.4 Best practice in IBD as it was agreed in the present study

\section{Patient-oriented process}

1. 24-hour endoscopy service

2. continuity of care guaranteed by the same physician in all three care units (inpatient, outpatient, endoscopy)

3. patient privacy

4. complete verbal and written information concerning disease status, disease course, and physical investigations

5. short waiting lists for any service (e.g. by providing a day care hospital)

6. availability and easy accessibility of stoma therapist and dietician

Technical and patient safety

7. excellent facilities (including toilets) \& diagnostic and therapeutic equipment

8. regular update of GPs and other treating physicians concerning patient's condition

9. written diagnostic and therapeutic protocols

10. regular microbiologic check-up and mechanical maintenance of endoscopy equipment

Quality medical standard

11. multidisciplinary and interdisciplinary communication and collaboration (minimum: gastroenterology and surgery)

12. computerised patient data integrated in all hospital departments

13. specific and regular training and education by the hospital authority involved in care for IBD patients

14. rotation of nurses in outpatient, inpatient, and endoscopy unit

\section{Discussion}

In the present study health care provided for IBD patients has been surveyed in eight university and four general hospitals in seven European countries and in Israel. The observations from the twelve site visits can be categorised into: 1) patient-oriented process, 2) technical and patient safety, and 3) quality of the medical standard/continuity of care. The main observations for the patientoriented process were: a) that endoscopy service outside office hours appeared not to be provided in all centres on 24-hour basis (although it seemed that university hospitals had better opportunities for this than general hospitals), b) that continuity of care by the same physician was guaranteed in almost all centres within one of the units, although between the units this was not 
organised everywhere, and c) that verbal information concerning the disease and diagnostic procedures was provided in all centres (however, northern centres appeared to provide information in brochures more often than southern centres).

With regard to technical and patient safety, the availability of protocols concerning diagnostic and therapeutic treatment varied over the hospitals. Moreover, regular mechanical maintenance of the endoscopy equipment was provided more often in northern than southern centres by the equipment supplying companies. Regular checks by the microbiological department on bacterial hygiene appeared not to be common at all in the audited centres.

The quality of the medical standard can be represented by computerisation of patient data and continuous training of health care workers. It was observed that most centres were in some stage of adopting a computerised registration system, although integration of different units/departments was not scheduled in most centres yet. The majority of hospitals provided the possibility for doctors to attend to external postgraduate education; several even arranged this within the hospital. However, nursing staff usually did not at all or not to the same extent have these opportunities.

The approach used in this multi-national survey was unique. It was restricted to survey health care based on peer review for one particular chronic disease, which made detailed auditing possible. Professional peer review, as applied in this study, is based on so-called microsystems of care ${ }^{15}$. A microsystem of care consists of a defined population of patients and the main processes, staff, and technology that work together to meet the needs of that specific population group. This makes it complementary to Donabedian's structure-processoutcome model of health care improvement: an IBD centre should meet patient needs by carrying out health care related processes in an efficient way to achieve desired outcomes" ${ }^{1 !}$.

A limitation of our approach was that only the lead auditor was trained to perform site visits. However, the fact that this auditor was present at all site visits and communicated with the remainder of the group turned the sequence of visits into a learning process for the total group. To simplify and optimise future audits it is recommended to train all auditors and to ensure that they can perform multiple site visits.

The qualitative survey of the health care organisations, as performed with the adapted NIAZ questionnaires to prepare the site visits, cannot be used to describe and analyse differences between the centres. Due to the subjective character of the PDCA cycle, the values assigned to the different results do not have the same meaning for the individual hospitals in the participating countries. In other studies, self-estimated centre compliance has been shown to be consistently higher than actual compliance ${ }^{16}$. Also in the present study, the use of subjective self-reports as a proxy for actual quality of care may be biased upwards to an unknown extent. Hence, comparison between the hospitals was based on the objective findings during the formal audits. 
Most university hospitals were larger in size than general hospitals, meaning that a larger number of health care workers and facilities were available, enabling extended and/or more varied and flexible possibilities to provide health care. They also have more and different tasks than general hospitals, usually being second and third referral centres.

The gastroenterology departments in the participating centres were organised differently within the hospitals. Due to the different criteria in each country used for clinical practice, the numbers of IBD patients admitted to the clinical wards do not represent the same magnitude of the size of the IBD clinics.

Since IBD is a chronic disease and patients usually are frequently in need of health care, in our perception the patient-oriented process is the most important category of our observations with regard to the patients. It appears that it would be optimal to guarantee continuity of care by the same physician throughout the units. In case this cannot be organised, the minimum requirement would be to have one consistent contact person for the patients in whom they can confide. Information about the hours that this person can be contacted would suffice with regard to continuity of care. Furthermore, informing IBD patients both verbally and in writing about their disease has previously been shown to be important ${ }^{17-19}$.

Guidelines for diagnostic and therapeutic management are representative for technical and patient safety, as they can prevent mistakes and support standardisation. Written protocols for both doctors and nurses can provide in this need. In addition, regular mechanical maintenance of endoscopy equipment could prevent defects, which might cause unnecessary costs and increased waiting lists for patients. Besides, microbiological check-ups with regard to hygiene can prevent contamination of other equipment and spread of diseases among patients and health care workers.

The development in computerisation of patient data is important and increases the quality of the medical standard, as it improves accessibility to patient data, reduces time consumption and failures in copying written patient data, and guarantees completeness of data. A hospital-based system that integrates information from all different departments would be ideal for registering health care and health outcomes. Also (obligatory) continuous postgraduate training for both physicians and nursing staff could increase the quality of the medical standard/continuity of care, by updating doctors' and nurses' knowledge both clinically and scientifically. Moreover, rotation of nurses in the outpatient, inpatient, and endoscopy units improves their knowledge of IBD and other gastroenterological diseases as well as their mutual collaboration in providing health care for these patients.

The best features observed during the audits could be used immediately by the auditors themselves (who in fact were colleague physicians treating IBD patients from participating centres in other countries), to improve their care in relation to the observed (benchmarking). The eleven benchmarks in this study concern features of a confidential relationship between health care worker(s) and patient, increasing access to health care for IBD patients, availability of patient data to 
all treating health care workers, and continuous training and updating of health care workers in taking care of IBD patients.

A combination of these benchmarks and other positive findings has resulted in an overview of "best practice" for IBD patients, jointly agreed upon by the organisation EC-IBD. Optimal health care would be provided for IBD patients if a hospital would be able to fulfil these 14 criteria, in addition to the already provided health care. These criteria could be used as guidelines to improve health care provided for IBD patients throughout Europe.

It should be noted that the presented results are a selection of all observations from the audits. The reports of each centre contain a full description of the information collected as well as individual recommendations for optimisation of health care for IBD patients. The participating hospitals are a small sub-sample of all institutions in those eight countries providing health care for IBD patients. Participation was fully voluntarily. An advantage of this is that the observations may be assumed as representative for good standard IBD health care provided in the different centres. However, since the surveyed centres have been collaborating in epidemiological IBD research for years, it might as well be possible that these hospitals provide higher quality care for IBD compared to hospitals that have no specific relationship with IBD.

As the scientific as well as the clinical results satisfy our expectations of this approach, the methodology could be adapted to surveys for other chronic diseases, like diabetes mellitus, renal insufficiency, and rheumatoid arthritis. Moreover, they could be of relevance for EU legislation, regulation and policies concerning health care, particularly for IBD patients. In this way we hope to contribute to the harmonisation of health care in IBD and possibly in other diseases.

The purpose of this survey was the improvement of health care provided for IBD patients in a number of comparable international centres. Further optimisation can be guaranteed if in future years the audits will be repeated, updating for new findings following practice changes conducted in the meantime. Although the site visits of the present study were primarily focused on organisation of care for IBD, we hope to provide a positive contribution to health care for other chronic diseases as well. 
Best practice in IBD

\section{References}

1 van Kemenade YW. Health care in Europe 1997. The finance and reimbursement systems of 18 European countries. Maarssen: Elsevier/De Tijdstroom, 1997.

2 Anell $A$, Willis $M$. International comparison of health care systems using resource profiles. Bull World Health Organ 2000;78:770-8.

3 Perleth $M$, Jakubowski $E$, Busse R. What is 'best practice' in health care? State of the art and perspectives in improving the effectiveness and efficiency of the European health care systems. Health Policy $2001 ; 235-50$.

4 Russel MG, Dorant E, Volovics A, Brummer R-J, Pop P, Muris JW et al. High incidence of inflammatory bowel disease in the Netherlands. Dis Colon Rectum $1998 ; 41: 33-40$.

5 Shivananda S, Lennard-Jones JE, Logan R, Fear N, Price A, Carpenter L ef al. Incidence of inflammatory bowel disease across Europe: is there a difference between north and south? Results of the European Collaborative Study on Inflammatory Bowel Disease (EC-IBD). Gut 1996;39:690-7.

6 Andrews J, Goulston K. Inflammatory bowel disease - its history, current status and outlook. Med J Aust 1994;160:219-23.

7 Stockbrügger RW, Russel MGVM, van Blankenstein M, Shivananda S. EC-IBD: a European effort in inflammatory bowel disease. Eur J Int Med 2000; 11:187-90.

8 van Gennip EMSJ, Sillevis Smitt PAE. The Netherlands Institute for Accreditation of Hospitals. Int J Qual Health Care 2000;12:259-62.

9 Shaw CD. External quality mechanisms for health care: summary of the ExPeRT project on visitatie, accreditation, EFQM and ISO assessment in European Union countries. Int J Qual Health Care 2000;12:169-75.

10 Klazinga N. Re-engineering trust: the adoption and adaptation of four models for external quality assurance of health care services in western European health care systems. Int J Qual Health Care 2000;12:183-9.

11 Donabedian A. Evaluating the quality of medical care. Milbank Mem Fund $Q$ 1966;44 (suppl): 166-206.

12 Heaton C. External peer review in Europe: an overview from the ExPeRT Project. Int J Qual Health Care 2000; 12:177-82.

13 Klazinga N, Lombarts K, van Everdingen J. Quality management in medical specialties: The use of channels and dikes in improving health care in The Netherlands. J Qual impr 1998;24:240-50.

14 van Weert C. Developments in professional quality assurance towards quality improvement: some examples of peer review in the Netherlands and the United Kingdom. Int J Qual Health Care 2000;12:239-42.

15 Weinstein JN, Brown PW, Hanscom B, Walsh T, Nelson EC. Designing an ambulatory clinical practivce for outcomes improvement: from vision to reality - the spine center at Dartmouth-Hitchcock, year one. Qual Man Health Care 2000;8:120. 
16 Saturno PJ, Palmer RH, Gascon JJ. Physician attitudes, self-estimated performance and actual compliance with locally peer-defined quality evaluation criteria. Int J Qual Health Care 1999;1 1:487-96.

17 van der Eijk I, Sixma H, Smeets T, Tavarela Veloso F, Odes S, Montague S et al. Assessing IBD patients' priorities and perceptions on quality of health care: development of the QUOTE-IBD. Am J Gastroenterol, in press.

18 Mayberry JF. The diagnosis of inflammatory bowel disease. What should we tell the patient? Ital J Gastroenterol Hepatol 1997;29:483-6.

19 Smart H, Mayberry JF, Calcraft B, Morris JS, Rhodes J. Effect of information booklet on patients' anxiety levels and consultation rates in Crohn's disease. Public Health 1986;100:184-6. 


\section{Chapter 7}

IBD in Europe: Health care consumption and Quality of Life

I van der Eijk, I Engdahl, J Freitas, M Buckley, Y Mouzas, E Langholz, $R$ Stockbrügger, and M Russel, on behalf of the EC-IBD Study Group Submitted for publication 


\section{Abstract}

\section{Background and aims}

The chronic nature and possible intensive course of inflammatory bowel disease can result in a considerable need for health care and a significantly reduced quality of life. The aims of the present study were to investigate health care consumption in patients with inflammatory bowel disease in a multinational setting, and to examine whether there was a relationship between quality of life and health care consumption.

\section{Patients and methods}

Data from 759 patients with inflammatory bowel disease in seven European countries and Israel were collected. Between six and eight years after diagnosis, data on health care consumption, quality of life, disease activity, and several background variables such as gender and disease localisation, were assessed by means of a patient questionnaire and objective data collection from patient files.

\section{Results}

Crohn's disease patients, patients with extensive disease, and those with active disease had higher health care consumption compared to patients with ulcerative colitis, restricted disease, and inactive disease, respectively. More diagnostic procedures were performed in university compared to general hospitals. In northern centres paramedical health care consumption was higher than in southern centres.

Besides disease activity and female gender, quality of life was negatively influenced by the number of diagnostic procedures.

\section{Conclusions}

This study gives a representative description of hospital health care consumption of patients with inflammatory bowel disease in seven European countries and Israel. We have observed a relationship between health care consumption and cumulative previous disease burden. Furthermore, increasing health care consumption decreases quality of life in inflammatory bowel disease. 


\section{Introduction}

Inflammatory bowel disease (IBD) is an idiopathic inflammatory disorder of the gastrointestinal tract. The two main disease entities are Crohn's disease (CD) and ulcerative colitis (UC). These conditions have a peak incidence in early adulthood', and a combined prevalence of approximately 300 per 100,000 in the Western world ${ }^{2}$. The chronic nature and the sometimes intensive course of IBD can result in a considerable need for health care ${ }^{3}$. Several studies have surveyed health care consumption in single countries (United States ${ }^{4,5}$, Sweden $^{6}$, Netherlands ${ }^{7}$, and France ${ }^{8}$ ). However, to our knowledge, this feature has never been investigated in a multi-national setting, which was the first objective of the present study.

Quality of life (QoL) in IBD patients is known to be significantly inferior to that of healthy controls $s^{4,9-11}$, hence several studies have been conducted to investigate the relationship between QoL and health care consumption in IBD ${ }^{5,7}$. In these national studies it has been found that QoL, amongst other factors, predicts health care consumption. The second objective of the present study was to investigate whether a relationship between $Q$ oL and health care consumption can be shown for IBD patients in a multinational context.

\section{Methods}

\section{Patients and methods}

Between 1991 and 1993 an inception cohort was established of 2201 newly diagnosed IBD patients in 20 clinical centres distributed over twelve countries ${ }^{2}$. In this cohort all patients were registered that were diagnosed with IBD and whose age was between 15 and 65 years of age. The diagnosis of CD or UC was based on endoscopic and/or radiological evidence, confirmed by histology from mucosal biopsies or surgical specimens using uniform criteria ${ }^{12,13}$. Fourteen of these centres in seven European countries and Israel (listed in Table 7.1) participated in the present study, contributing 1177 patients of the original cohort. Of those, 1056 patients could be approached after receiving consent from the treating physicians.

Between six and eight years after diagnosis, data on smoking status, disease activity, QoL, and consultations with paramedics (dietician, social worker, and psychologist) for IBD-related problems were collected by means of a patient questionnaire. QoL was assessed using the Short Inflammatory Bowel Disease Questionnaire $^{14}$. For $C D$ patients disease activity was assessed using the HarveyBradshaw Index $(\mathrm{HBI})^{15}$, as completion of this index does not require a consultation of the patient with a physician, in contrast to the Crohn's Disease Activity Index $(\mathrm{CDAl})^{16}$. Active disease was determined as a $\mathrm{HBI}$ score $\geq 4$, 
corresponding to a CDAl score $\geq 150^{15}$. For UC the Colitis Activity Index (CAI) was selected to assess disease activity ${ }^{17}$. CAl scores $\geq 10$ were considered to indicate active disease.

Patient data were collected from hospital files by local researchers, concerning outpatient consultations, hospital admissions, surgery, and number of performed diagnostic procedures (upper and lower endoscopy (including sigmoidoscopies and colonoscopies), ERCP, X-ray of colon, X-ray of small bowel, abdominal ultrasound, abdominal CT scan) since diagnosis. Also background information regarding age, gender, disease entity (CD or UC), disease location (for $C D$ patients these were small bowel, large bowel, or a combination of both; for UC patients these were proctitis, left-sided colitis, and pancolitis), extraintestinal manifestations, type of hospital (university or general) were assessed.

\section{Statistical analyses}

Chi-square tests were performed to compare $C D$ and $U C$ with regard to gender and smoking status. Unpaired t-tests were used to compare $C D$ and $U C$ patients for age. Differences between groups of patients (CD versus UC, university versus general hospital, north versus south) with regard to patient characteristics and the numbers of hospital admissions, surgical procedures, outpatient consultations, and diagnostic investigations were examined using nonparametric Mann-Whitney tests. Kruskal-Wallis tests were performed to compare subgroups of $C D$ and $U C$ (based on current disease location), as well as different countries for health care consumption.

Multivariate regression analysis was conducted to investigate the relationship of QoL with the number of performed diagnostic procedures during the course of disease and admission to hospital in this period, adjusted for diagnosis, disease activity, country, type of hospital, gender, age, and smoking.

Statistical analyses were performed using SPSS package 8.5 for Windows (SPSS Inc., Chicago, IL). For all analyses p-values less than 0.05 were considered significant.

\section{Results}

The overall response rate to the patient questionnaire was $78 \%(824 / 1056)$. Ten patients were diagnosed with "indeterminate colitis" and were excluded from further analyses. During the year prior to this study, of the remaining 814 patients $220(27 \%)$ did not consult a general practitioner (GP) or a medical specialist for complaints related to IBD, 77 patients (9.5\%) only consulted a GP, 285 patients (35\%) only consulted a medical specialist, and 232 patients $(28.5 \%)$ consulted both a GP and a medical specialist.

Data concerning health care consumption were collected from hospital files of 759 patients (93.2\% of the total group of 814 patients). 


\section{Patient characteristics}

Patient characteristics are presented in Table 7.1. Relatively more males were diagnosed with $U C$ compared to $C D(p=0.001)$, more $C D$ patients smoked $(p<0.001)$, and more UC patients were treated in university hospitals compared to $C D$ patients $(p=0.009)$. UC patients had a significantly higher age than $C D$ patients $(p<0.001)$. The percentage of patients with active disease at the moment of data assessment differed significantly between $C D$ and $U C$ patients $(29.2 \%$ versus $2.2 \% ; p<0.001)$.

Table 7.1 Characteristics of 759 patients participating in the present study

\begin{tabular}{lcc}
\hline & CD & UC \\
\hline Number & 250 & 509 \\
Median age in years $\left(25^{\text {th }}-75^{\text {th }}\right.$ percentile $)$ & $40.5(32.0-51.0)$ & $45(36.0-59.5)^{*}$ \\
Males $(\%)$ & 40.4 & $53.8^{*}$ \\
Smoking (\%) & 39.6 & 23.2 \\
Country & & \\
Northern Europe & 145 & 248 \\
Ireland & 13 & 14 \\
Netherlands & 67 & 107 \\
Norway & 26 & 65 \\
Denmark & 39 & 62 \\
Southern Europe & 105 & 261 \\
Israel & 15 & 31 \\
Greece & 14 & 77 \\
Italy & 57 & 137 \\
Portugal & 19 & 16 \\
Type of hospital (\%) & & \\
University & 54.0 & 65.0 \\
General & 46.0 & 35.0 \\
\hline
\end{tabular}

$* p<0.05$

Health care consumption

Since diagnosis, $17.9 \%(n=136)$ of all patients had consulted a dietician, $5.5 \%$ $(n=42)$ a social worker, and $9.1 \%(n=69)$ a psychologist for IBD-related problems. In northern centres patients consulted both a dietician and a social worker significantly more often than in southern countries $122.7 \%$ and $6.6 \%$ $(p<0.001)$ versus $9.6 \%$ and $3.5 \%(p=0.042)$, respectively). No differences were observed for psychological consultations.

Table 7.2 describes the differences between $C D$ and $U C$ patients concerning health care consumption in all centres. Since diagnosis CD patients had a significantly higher care consumption for almost all parameters; $C D$ patients consulted their specialist more frequently during the last year, more patients had ever been admitted to hospital, more admissions per patient were observed, and more patients underwent surgical procedures. Also more diagnostic investigations were performed in CD patients compared to UC, except for ERCPs 
and lower endoscopies. ERCPs were performed equally seldom in both disease entities; lower endoscopies were performed more often in UC patients.

\section{Disease characteristics}

It was observed that patients with currently active disease had significantly more hospital admissions $(p<0.001)$ and had undergone more surgical procedures since diagnosis $(p<0.001)$. Patients with current disease activity at the time of this study had also more frequently undergone lower $(p=0.014)$ and upper endoscopies $(p=0.001)$, $X$-rays of the small bowel $(p<0.001)$, abdominal ultrasounds $(p<0.001)$ and abdominal CT scans $(p<0.001)$ than inactive patients.

It was found that IBD patients with extensive disease CCD in both small and large bowel, and pancolitis in UC, respectively) had the highest average health care consumption. Of the patients with $C D$ restricted to the colon significantly less underwent surgery at any time during the disease compared to those with disease location in the small bowel. Resection was the most common reason for surgery, followed by fistulae and abscesses.

\section{Centre characteristics}

In Table 7.3 it is shown that university and general hospitals did not differ in number of outpatient consultations, admissions to the hospital and surgical interventions. However, university hospitals performed significantly more diagnostic investigations as mentioned above except for colonic $X$-rays, which were performed more often in general hospitals.

Between countries, no consistent difference in health care consumption could be observed. However, comparison of northern and southern countries $(n=393$ versus $n=366$ ) showed that significantly more patients in northern Europe were ever admitted to hospital for IBD, more patients had ever had surgery, and more $X$-rays of the small bowel were performed per patient. In the south more upper $\mathrm{Gl}$ endoscopies, abdominal ultrasounds, and abdominal CT scans/MRIs were performed per patient (Table 7.4).

\section{Quality of life}

Linear multivariate regression analysis showed that the number of diagnostic investigations $(p=0.049)$ negatively influenced $Q 0 L$, in combination with disease activity $(p<0.001)$ and female gender $(p=0.048)$. The remaining studied variables did not have a significant effect. 
Health care consumption and Quality of Life

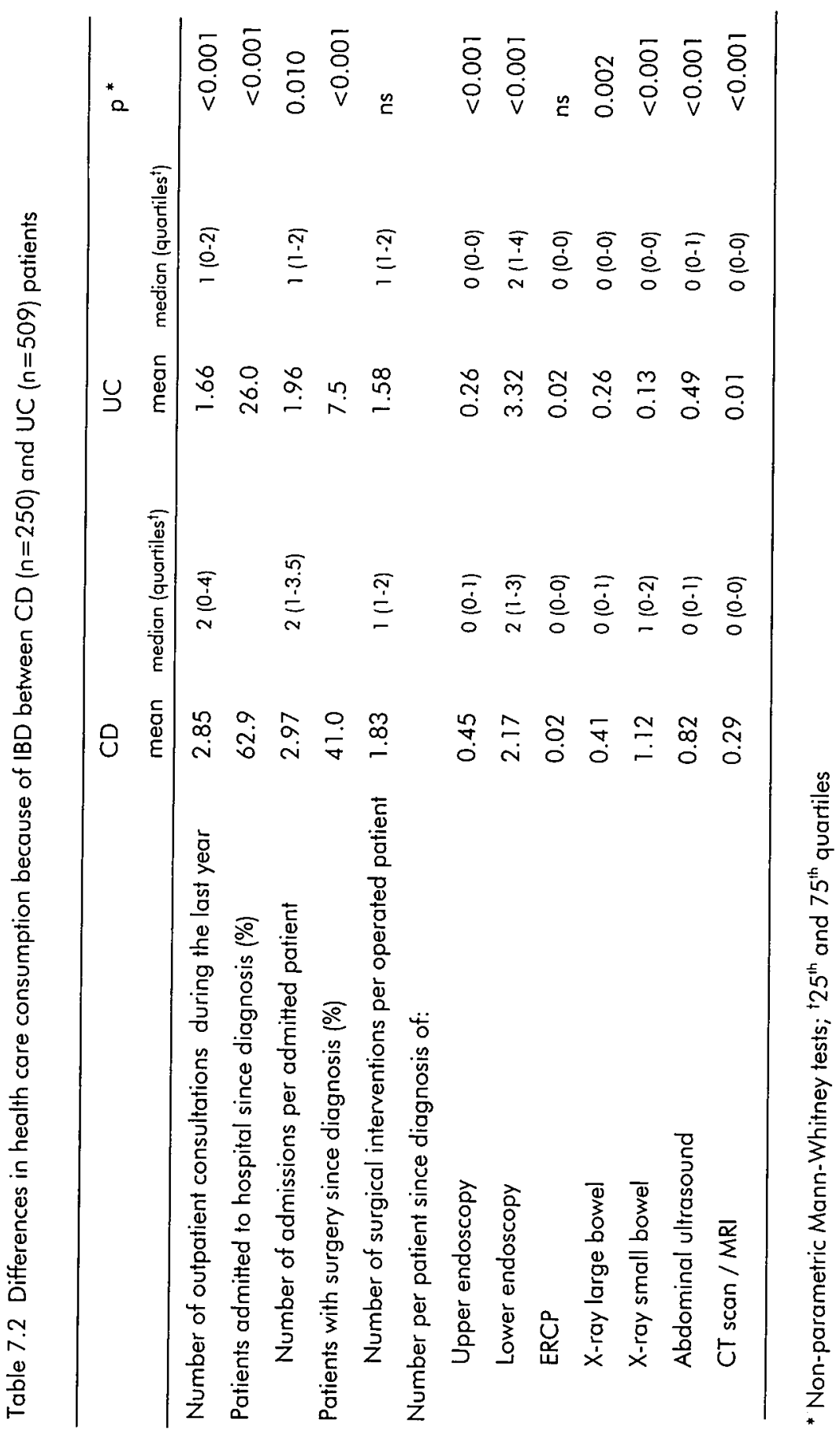


$100 \mid$ Chapter 7

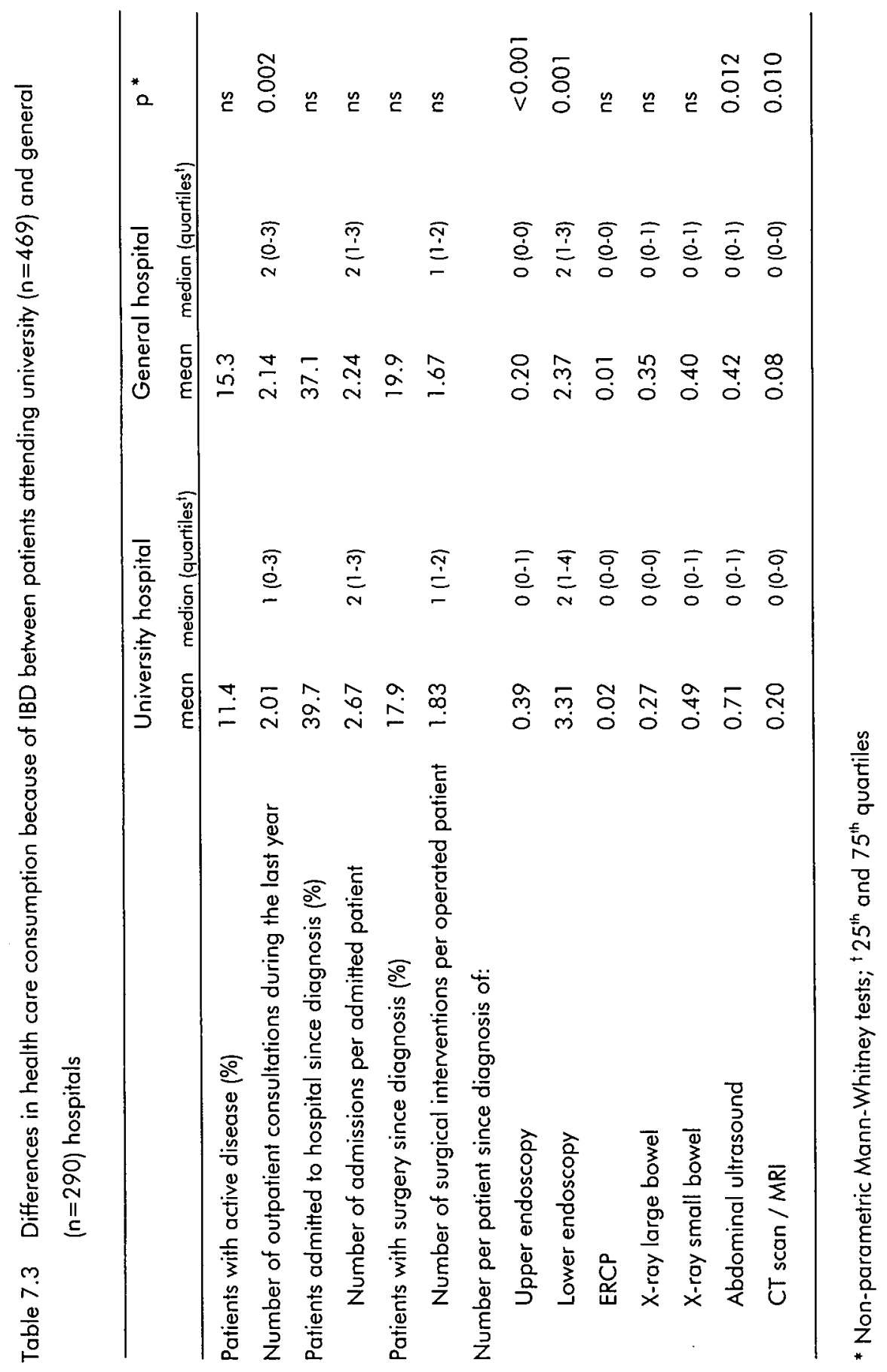


Health care consumption and Quality of Life 101

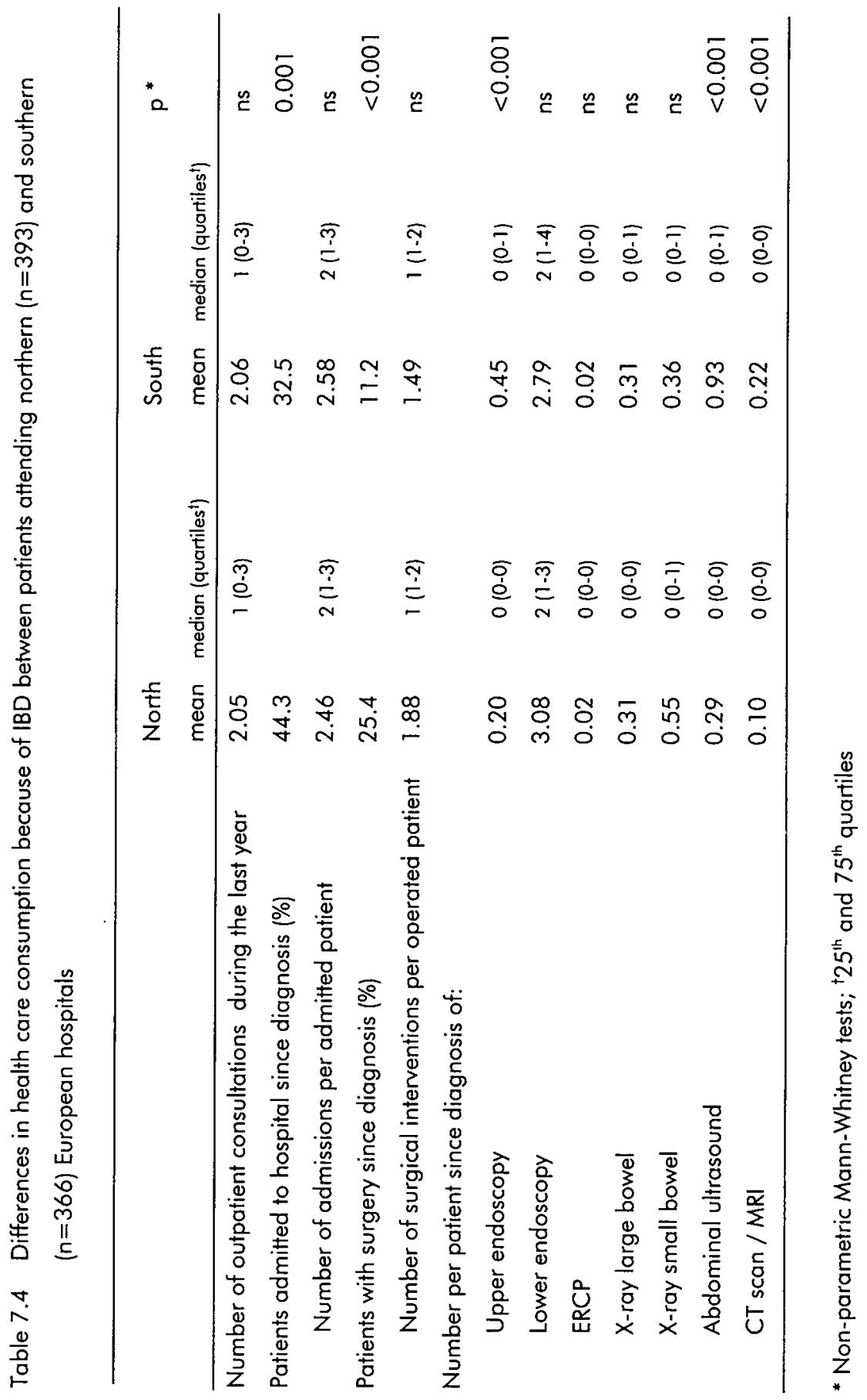




\section{Discussion}

IBD is a chronic disease with an early onset in life, therefore, patients will consume health care for a long period of time. Since incidence figures are rising around the world ${ }^{18}$, it is worthwhile to survey the health care consumption of IBD patients in a multi-national cross-sectional hospital setting, which was the principal objective of the present study.

An important observation was that approximately a quarter of all patients appeared to be in remission, since they did not seek health care for at least one year. It was also found that CD patients had a higher average health care consumption than UC patients. This was also the case in patients with presently active disease compared to those with inactive disease. Similar results were found for both $C D$ and UC patients with extensive disease compared to those whose disease was restricted to smaller areas. Furthermore, it was observed that $C D$ patients with inflammation restricted to the colon underwent fewer surgical procedures compared to those with small bowel disease. Finally, a larger number of diagnostic investigations were performed in university compared to general hospitals.

Treatment of $C D$ may be more complex than $U C$, since the inflammation in $C D$ can affect any part of the gastrointestinal tract and can affect all layers of the gastrointestinal wall, causing abscesses and fistulae, whereas UC affects the large bowel only. This might explain the observed difference in health care consumption between the two disease entities.

Extensive disease usually involves a more serious disease course than restricted disease, resulting in higher health care consumption. The observation that more $C D$ patients with small bowel involvement (both small bowel only and combined localisation) underwent surgery during the course of disease than patients with colonic disease only, is not consistent with previously reported data ${ }^{19}$. However, surgery for small bowel $C D$ is usually necessary for stenotic complications of the disease, in addition to the possible occurrence of fistulae, abscesses, and perforations ${ }^{20-21}$. The latter are characteristic complications both in small bowel and colon of $C D$, in contrast to stenosis that occurs more often in the small bowel.

The majority of patients had inactive disease at the moment of the study, six to eight years after diagnosis. Currently active disease might therefore indicate a more complicated disease course during this period of time, causing higher health care consumption in those patients. However, it should be noted that the definition of active disease, particularly for $C D$, was quite arbitrary in this study, the $\mathrm{HBl}$ had to be used in place of the CDAl. Thus the results might be influenced by the different definitions for active disease in $C D$ and $U C$, represented by the $\mathrm{HBI}$ and $\mathrm{CAl}$. This problem might persist as $\mathrm{CD}$ and $U C$ are distinct entities with their own characteristics.

The higher use of paramedical care in northern countries compared to those in the south, might be explained by the more extended availability of these services in the north. These and other observed differences in health care consumption 
between northern and southern countries might also be explained by diverse health care financing strategies.

The fact that more diagnostic procedures were performed in university compared to general hospitals, might be because more facilities and manpower are available in university hospitals for these investigations. Since the participating university hospitals also serve as second and third referral centres, it could be expected that they treat more difficult cases compared to general hospitals, explaining the necessity of more diagnostic procedures.

Previous data have demonstrated that all features related to the chronic character of IBD negatively influence QoL of the patients ${ }^{4,10,11,22-26}$. The statistical analysis used in this study - multivariate regression analysis - is characterised by adjusting for variables that contribute significantly and uniquely to the relation between the variable of interest (number of diagnostic procedures) and the dependent factor (QoL). In the present study the results showed that having undergone more diagnostic investigations during the course of disease impaired current QoL, in addition to presently active disease and female gender. This suggests that decreased QoL in active disease is caused by the number of performed diagnostic procedures, separate from disease activity and female gender. Therefore, when such an investigation is considered, one should carefully consider whether the procedure is necessary for the patient. A limitation of the study could be that whereas health care consumption was determined over a period of six to eight years, QoL was assessed in a cross-sectional design. It has been shown that females are more prone to admit to depressive symptoms than males ${ }^{27}$. This might be the explanation of the decreased QoL observed in females compared to males in the present study. Alternatively, the dual role of females in society (domestic and professional) may contribute to this finding.

An alternative explanation for our findings might be that more diagnostic investigations are indicative of a more difficult course of disease, which could in turn contribute to the decreased $\mathrm{QoL}^{24}$. This would indicate that the influence of the cumulative effect of the past disease burden on QoL can be measured by health care consumption.

The fact that in this study health care utilisation was assessed by collecting data from hospital files has prevented recall bias that could have occurred if patients were asked to report this information themselves. However, due to the retrospective character of the study, information bias may have inadvertently occurred. The extent of this bias is expected to be small, since all patients attended "trained", attentive hospital departments that have been collaborating in clinical epidemiological IBD research for several years. Moreover, we assume that information bias would have occurred randomly and, therefore, would have no influence on the results of our analyses. The retrospective nature of the study has prevented us from collecting information concerning medication during the course of disease, a parameter that could also have been useful for assessment of health care consumption.

In the present study we also abstained from calculating absolute costs of the different diagnostic procedures, which excludes direct cost-analysis of hospital 
care for IBD during the first six to eight years of the disease. We felt that this would have been difficult in the multi-national setting because of the different health care and insurance systems in the eight participating countries. We have previously shown that $C D$ patients were negatively affected by financial implications of the disease more than UC patients (Chapter 4), probably caused by the generally more difficult disease course of $C D$. Treatment of $C D$ patients is overall more complex, necessitating more expensive medication and nutritional support, some of which may not be refunded by insurance companies or national health care systems in all countries involved in the study. Health care consumption also involves indirect costs following morbidity; these have not been measured because of the divergent socio-economic conditions in the participating countries.

The composition of the present study population is representative of other IBD populations with regard to age and gender distribution', and smoking status ${ }^{28}$. In addition, data were uniformly assessed over a reasonably long period of time (six to eight years), and both university and general hospital care was represented. For these reasons conclusions regarding the relationship between health care consumption and QoL can be considered of general value in the European context.

In future studies assessment of both QoL and health care consumption in a longitudinal design would be of great interest to gain a deeper insight into this relationship.

In conclusion, this study gives a representative description of hospital health care consumption of IBD patients in seven European countries and Israel. It is the first international overview available that has been strictly limited to objective data. Our study has demonstrated previously unknown relationships with regard to health care consumption and QoL in IBD. These findings can be used to further unify health care policies in this chronic disorder, which affects the majority of patients early in life, in a period of social and biological vulnerability. 


\section{References}

1 Russel MG, Dorant E, Volovics $A$, et al. High incidence of inflammatory bowel disease in the Netherlands. Dis Colon Rectum 1998;41:33-40.

2 Shivananda S, Lennard-Jones JE, Logan R, et al. Incidence of inflammatory bowel disease across Europe: is there a difference between north and south? Results of the European Collaborative Study on Inflammatory Bowel Disease (EC-IBD). Gut 1996;39:690-7.

3 Andrews J, Goulston K. Inflammatory bowel disease: its history, current status and outlook. Med J Aust 1994;160:219-23.

4 Drossman DA, Patrick DL, Mitchell $C M$, et al. Health-related quality of life in inflammatory bowel disease. Dig Dis Sci 1989;34:1379-86.

5 Drossman DA, Leserman J, Mitchell $M$, et al. Health status and health care use in persons with inflammatory bowel disease. Dig Dis Sci 1991;36:1746-55.

6 Blomqvist P, Ekbom A. Inflammatory Bowel Disease: Health Care and Costs in Sweden in 1994. Scand J Gastroenterol 1997;32:1134-9.

7 de Boer AGEM, Sprangers MAG, Bartelsman JFW, ef al. Predictors of health care utilization in patients with inflammatory bowel disease: a longitudinal study. Eur $J$ Gastroenter Hepatol 1998;10:783-9.

8 Rolland N, Grandbastien B, Merle V, et al. Cost of early management of chronic inflammatory intestinal disease. Gastroenterol Clin Biol 1999;23:483-8.

9 Guyatt GH, Mitchell A, Irvine EJ, ef al. A new measure of health status for clinical trials in inflammatory bowel disease. Gastroenterology 1989;96:804-10.

10 Mitchell A, Guyatt GH, Singer J, et al. Quality of life in patients with inflammatory bowel disease. J Clin Gastroenterol 1988;10:306-10.

11 Sorensen VZ, Olsen BG, Binder V. Life prospects and quality of life in patients with Crohn's disease. Gut 1987;28:382-5.

12 Lennard-Jones JE. Classification of inflammatory bowel disease. Scand J Gastroenterol 1989;24(Suppl 170):2-6.

13 Lennard-Jones JE, Shivananda S. Clinical uniformity of inflammatory bowel disease at presentation and during the first year of disease in the north and south of Europe. Eur J Gastroenter Hepatol 1997;9:353-9.

14 Irvine EJ, Zhou Q, Thompson AK. The Short Inflammatory Bowel Disease Questionnaire: a quality of life instrument for community physicians managing inflammatory bowel disease. CCRPT Investigators. Canadian Crohn's Relapse Prevention Trial. Am J Gastroenterol 1996;91:1571-8.

15 Harvey RF, Bradshaw JM. A simple index of Crohn's disease activity. Lancet $1980 ; 1: 514$.

16 Best WR, Becktel JM, Singleton JW, et al. Development of a Crohn's disease activity index. Gastroenterology 1976;70:439-44.

17 Lichtiger S, Present DH, Kornbluth A, ef al. Cyclosporine in severe ulcerative colitis refractory to steroid therapy. New Engl J Med 1994;330:1841-5. 
18 Irvine EJ, Farrokhyar F, Swarbrick ET. A critical review of epidemiological studies in inflammatory bowel disease. Scand J Gastroenterol 2001;1:2-15.

19 Farmer RG, Whelan G, Fazio WW. Long-term follow-up of patients with Crohn's disease. Gastroenterology 1985;88:1818-25.

20 Krupnick AS, Morris JB. The long-term results of resection and multiple resections in Crohn's disease. Semin Gastrointest Dis 2000;11:41-51.

21 Kirsner JB, Shorter RG. Inflammatory bowel disease. Williams \& Wilkins: Baltimore, Maryland, 1995.

22 Drossman DA. Measuring quality of life in inflammatory bowel disease. Pharmacoecon 1994;6:578-80.

23 Drossman DA. Quality of life issues in Crohn's disease. In: Crohn's disease. Prantera C \& Korelitz B, eds. Marcel Dekker Inc., New York, 1996.

24 Irvine EJ. Quality of life in inflammatory bowel disease: biases and other factors affecting scores. Scand J Gastroenterol 1995;30:136-40.

25 Love JR, Irvine EJ, Fedorak RN. Quality of life in inflammatory bowel disease. I Clin Gastroenterol 1992;14:15-9.

26 Binder V. Epidemiology, course and socio-economic influence of inflammatory bowel disease. Schweiz Med Wochenschr 1988;1 18:738-42.

27 Streiner DL, Norman GR. Health measurement scales. A practical guide to their development and use. Oxford University Press: New York, 1995.

28 Russel MG, Volovics A, Schoon EJ, et al. Inflammatory bowel disease: is there any relation between smoking status and disease presentation? Inflam Bowel Dis 1998;4:182-6. 
Chapter 8

General discussion and conclusions 
108 Chapter 8 


\section{Introduction}

As a population ages, the prevalence of chronic illnesses will rise resulting in an increasing demand for a health care delivery system that fulfils the needs and resources of this population'. The Quality of Health Care (Q०C) and possibilities for improvement have been subject of many studies during the last few decades. Although the perspective of health care professionals is widely acknowledged to be important and useful, other perspectives on quality have been emphasised in recent years and are elaborated on in Chapter 1 of this thesis. Perhaps the most important change has been a growing recognition that care must be responsive to the preferences and values of the consumers of health care services (the patients), and that their opinions about care are important indicators of its quality ${ }^{2.7}$. Health care professionals have always acknowledged that satisfying patients at some level is essential for providing care of high quality. At the same time, however, health care professionals have often discounted the importance of patients' perspectives in the belief that patients have very limited knowledge of what constitutes technical and administrative quality and because of the difficulty of measuring patients' views accurately and reliably. Scientific, sociological, and political developments have fostered the growing emphasis on the importance and legitimacy of patients' perspectives on the quality of care. Using psychometric techniques, researchers have developed better measures of patients' evaluations of the results of care, thus allowing patients' views to be assessed with scientific accuracy ${ }^{8.13}$. In addition, the view that consumers should have the information and other resources necessary to make judgements about the value of goods and services, eventually created the concept of "patientcentred care ${ }^{\prime 14}$.

In inflammatory bowel disease (IBD) several studies have been performed on limited aspects of $Q_{0} C^{15.18}$, however, we still know relatively little about the total concept of QoC in IBD and the possible relationship between QoC and quality of life $(Q \circ L)^{19,20}$. The main aims of this thesis were to explore QoC in IBD and to relate this to the subjective QoL of patients.

This discussion will first elaborate on the patients' perception of Q०C and its influence on experienced QoL. Subsequently, it will be supported by objective data obtained from treating physicians and care structures. Eventually all perspectives will be combined into a suggestion of "best practice in IBD", concluded from a multi-national, cross-sectional study in patients who have been diagnosed with IBD six to eight years earlier, of their treating physicians and of the hospitals they attended to for medical management.

Assessing quality of health care in IBD

The health care system can be defined as a complex network of relations among individuals and organisations pursuing their respective goals and interests in the delivery or financing of health services and the use of these services. Exchanges 
$110 \mid$ Chapter 8

occur between organisational purchasers and providers, and between providers and patients ${ }^{20}$. Schematically this can be presented by overlapping relational, professional, and organisatory characteristics, as shown in Figure 8.1.

Therefore, in order to obtain a holistic overview and to provide the opportunity to improve QoC accounting for all determinants, it is important to assess QoC from all these three perspectives.

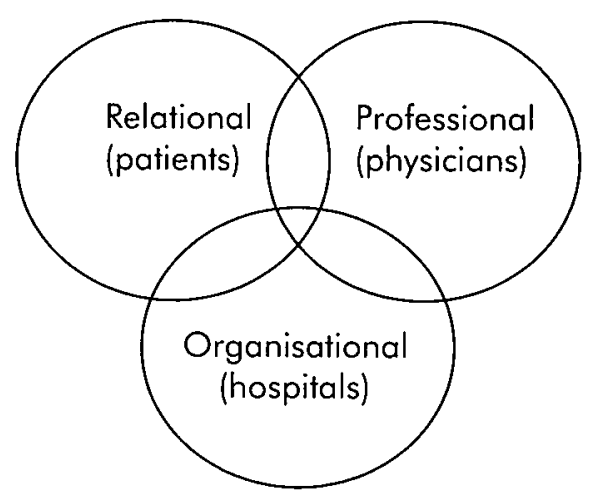

Figure 8.1 Relational, professional, and organisatory characteristics of the health care system

\section{Patients}

In contrast to some other diseases, in IBD a disease-specific questionnaire to assess the patients' perspective on QoC has not been available. To gain insight into what patients regard as important in care and how the provided care is perceived, comparisons should be made across types of care (inpatient or outpatient), facilities, and physicians ${ }^{4}$. However, the relevance and uniformity of patient satisfaction studies with respect to quality management in the health care sector is often questioned because of conceptual and operational problems. A theoretical framework is missing for most instruments developed in this area of health care research ${ }^{2,10}$. In Chapter 2 the development of an IBD-specific questionnaire to assess the patients' perspective on QoC, taking the abovementioned features into account, is described. The methodology used in this multi-national setting was based on involvement of patients ${ }^{10,10,21}$, which was essential for the purpose of this study. Generated items, included in the questionnaire, correspond to the characteristics of the health care system (structure) and the components of the actual encounter between a health care provider and a patient (process). This enables researchers to link components of health care with health outcomes according to Donabedian's structure-processoutcome characterisation ${ }^{22}$.

The scoring system of the questionnaire consists of a combination of importance and performance judgements for different care aspects. In this way it can be measured whether a patient's expectations (importance) are met, in addition to satisfaction (performance). The validity and reproducibility of the instrument was very satisfactory, supporting applicability of the questionnaire. The fact that it is 
an anonymous, self-administered instrument prevents bias that could be expected when patients were interviewed by representatives of a hospital; inaccurate reflection of the patient's perspective can occur due to the fact that the patient is aware of being evaluated ${ }^{4,6,14}$. Furthermore, recall bias might occur as chronically ill patients prefer to describe their care in episodes of time, instead of single visits ${ }^{23}$. Therefore the IBD questionnaire related only to the previous year. In addition, patients might find it difficult to appreciate technical measures of $Q_{\circ}{ }^{24}$, resulting in a more reliable reflection of the patients' real opinion by process aspects of care ${ }^{25}$.

First testing of the questionnaire in one nation (the Netherlands) showed that $C D$ and UC patients gave comparable scores to the different care aspects, suggesting that no distinction between the two disease entities needs to be made when assessing the view of IBD patients on QoC. It was also possible to identify health care areas that might need improvement, in particular the provision of information concerning the disease, supporting the feasibility of the developed instrument to measure the relational determinant of QoC. One of the principal advantages of creating a standardised instrument is the possibility of comparison with data produced in research of other health care areas. When arrangements have been made to improve a certain health care aspect, the assessment should be repeated to confirm whether the improvement has taken place. As good quality of care appears to be essential in chronic diseases, this newly developed patient questionnaire should become an important tool in addition to traditional methods to optimise health care for IBD patients, such as the continuous search for effective medical treatment.

The role of quality of care with regard to quality of life in IBD

QoL is established as an important endpoint in medical care, especially for chronic diseases for which a cure is unlikely. Optimisation of QoC may induce improvement in QoL ${ }^{26}$.

In IBD, QoL has been shown to be depressed compared to that of healthy controls ${ }^{27.34}$. From an ethical as well as a financial point of view it is desirable to minimise the negative effects of IBD on daily life activities and experiences, and thus to maintain or enhance QoL of IBD patients.

It has been shown that quality of life can be defined by a multidimensional concep $^{31,35}$. An extensive literature search produced five variables that have separately been shown to affect quality of life in IBD patients. These were disease activity ${ }^{36,37}$, psychological status ${ }^{38.40}$, coping patterns ${ }^{37,41-43}$, social support ${ }^{44,45}$ and stressful life events ${ }^{46-49}$. However, the quoted studies did not take the other variables into consideration when studying the relation of one of the variables with $Q \circ L$, raising doubts with regard to the significance of the reported associations.

In order to study the possible relationship between QoC and QoL it was necessary to assess data on all variables reported to influence QoL. The major result of this thesis, namely the existence of an association between QoC and QoL, is presented in Chapter 3. Hierarchical multivariate regression analysis showed that in IBD, QoL was indeed influenced by QoC, as well as by disease 
activity, psychological status, type of hospital patients attend to (university versus general), social support, stressful life events, and the way of administration of the questionnaire. In particular the provision of information appeared to contribute to QoL in IBD patients. This supports the statement of Cortis and Lacey that patients who are well-informed are more likely to adjust to hospitalisation, to cope with stressful procedures, to experience less pain and to recover quickly from surgery ${ }^{50}$. Information appears to have an empowering effect, enabling patients to take more control over their health care, and to comply with medical treatment. Therefore, one of the health care policies should be to create optimal conditions for provision and communication of information. $C D$ patients suffered from costs of the disease more than patients with $U C$, which is probably caused by the generally more difficult disease course of $C D$. Treatment of CD patients is more complex and implicates the need for more expensive medication (e.g. anti-TNF $\alpha$ ) and nutritional support, which may not be refunded by insurance companies or national health care systems. For $C D$ patients the continuity of care appeared to be important in QoL, whereas for UC patients the courtesy of attending medical personnel appeared to be crucial. From this particular choice by the patients, it can be concluded that in the care process the combination of medical treatment and psychological approach is needed for improvement of HRQOL in IBD patients. This confirms Blumenthal's hypothesis that patient-centred care is needed when studying the patients' perspective on health care and health outcome ${ }^{14}$.

To date, many health outcome studies have not demonstrated an association between the processes and outcomes of care. For those studies that did show such a relationship, a criticism could be that their conceptual framework did not include sufficient variables that might also significantly influence the outcome measured $^{3,51}$. In the present study, most theoretical considerations were taken into account in the conceptual model. Moreover, the study was conducted in a multi-national setting with uniform diagnostic criteria, and thereby provides results that are representative for a large European area. Nevertheless, repeating this study in different settings, e.g. per country or area, could give additional results in terms of the particular local care aspects that influence QoL. Local health care policies could then be adapted and improved into detail, optimising IBD patients' QoL even further.

\section{Physicians}

The providers' perspective, which is the leading principle in most of the existing instruments, differs markedly from that of the user of health care facilities ${ }^{6,7,10,13,52}$. Changing physicians' practices to optimise health care is not simply providing guidelines, based on the current state of scientific knowledge. Physicians primarily rely on their own experience or colleagues' recommendations in deciding whether to adopt new techniques or interventions ${ }^{53}$. They are partly independent providers by their professional quality, but are also dependent of health care structures for the facilities to provide adequate health care. Therefore, it is important to assess their perspective on the provided QoC before introducing improvement strategies. In an effort to assess the concept of 
QoC as it is considered by specialists treating IBD patients, a questionnaire was developed for doctors, comparable to the patient questionnaire introduced in Chapter 2. The results of the assessment of the doctors' view as well as a comparison of doctors' and patients' perspectives on QoC are presented in Chapter 4. Except for structural dimensions such as cost aspects, physicians treating IBD patients indicated that access to continuous postgraduate clinical and scientific training should be improved by the hospital administrations. Older physicians perceived the quality of the provided care to be higher than younger doctors, probably since they usually have longer clinical experience, which might result in less need for expensive diagnostic procedures and other costly interventions. Our study also showed differences between doctors' and patients' perspectives. An explanation for most of these could be that physicians are restricted to health care policies of the hospital and the national (regional) health care system when providing health care, without the patients being informed about such limitations.

\section{Hospitals}

To provide optimal health care for chronically ill patients, it is essential to identify, develop, and implement a system of care that is locally adapted to that particular population. In order to account for all three determinants of health care (relational, professional, and organisatory), a similar approach to assess data on each determinant is required ${ }^{54}$. Therefore, the methodology to survey local health care systems was restricted to one particular chronic disease, IBD, which made detailed auditing possible (Chapter 5). Professional peer review, as applied in this study, is based on so-called microsystems of care ${ }^{55}$. A microsystem of care consists of a defined population of patients and the main processes, staff, and technology that act together to meet the needs of that specific population group. This makes it complementary to Donabedian's "structure-process-outcome" model of health care improvement: an IBD centre should meet patient needs by carrying out health care related processes in an efficient way to achieve desired outcomes ${ }^{22}$. For the present survey, a uniform structure was developed to assess data on actual resources. Comparisons between different hospitals, based on these features, can be useful for improving health care organisation ${ }^{56}$, resulting in "best practice" for a particular disease, in our case $1 \mathrm{BD}^{57}$. International comparisons of health care systems are difficult for a variety of reasons, such as differences in geographical, demographic and cultural features, political and economic structures, including social care systems. Although the structural characteristics of health care systems differ, every country attempts to provide optimal medical services in a cost-effective manner ${ }^{58}$.

To harmonise health care and to fine-tune the co-operation between care providers within a hospital, but also between hospitals - and probably even between countries - protocols are important instruments. Protocols and guidelines alone offer insufficient guarantees to adequately manage complex care for patients with chronic illnesses and co-morbidity. For those patients, multiple protocols are usually applicable, which are not geared one to another 
and even may conflict with each other. In addition to health care according to protocols, chronically ill patients, who are usually experienced with medical investigations, medication use, and other treatment, should have input in the management of their disease. Besides, protocols should not inhibit the doctor's intuition to deviate from the guidelines in an individual case. A doctor taking these arguments into consideration in clinical practice provides high standard QoC to his patients. In the study presented in Chapter 5 we were able to describe "best practice in IBD" by comparing health care services provided by university and general hospitals in different countries, within the framework of patients' and physicians' perspectives on QoC. "Best practice" concerns features of the patient-oriented process, technical and patient safety, and quality of the medical standard.

Professional peer reviews already exist for answering scientific questions as well as for improving health care and education of physicians. This present study has evidenced that large groups of chronically ill patients can also benefit from this type of research method.

Since IBD incidence figures are rising around the world ${ }^{59}$, it proved worthwhile to survey the health care consumption of IBD patients in a multi-national hospital setting, which was one of the objectives of the study presented in Chapter 6. Data on specialist consultation, admissions to the hospital, need for surgery, and diagnostic procedures were assessed from patients in eight countries covering a period of six to eight years since diagnosis. It was shown that more diagnostic procedures were performed in university hospitals compared to general hospitals. As they are usually second and third referral centres, university clinics are likely to have more diverse and complex tasks than general hospitals. Besides, most university hospitals were larger in size than the general clinics, suggesting that a larger number of health care workers and facilities were available, enabling extended and/or more varied and flexible possibilities to provide health care (Chapter 5). The number of diagnostic procedures performed in southern Europe exceeded that in northern Europe. A reason for this might be a higher concentration and better availability of private clinics in the participating southern countries, partly due to diverse health care financing strategies.

In Chapter 6 a negative association was observed between the number of diagnostic procedures during the course of disease and current QoL, indicating that the influence of the cumulative effect of the past disease burden on QoL can be measured by health care consumption. It also suggests that when a diagnostic procedure is considered, it should be carefully weighed whether it is indeed necessary for the medical management of the disease. These findings can be used to further unify health care policies in this chronic disorder that affects most patients early in life during a period of social and biological vulnerability.

Implications for clinical practice and future research

An ideal and utopian health care system is impossible, not only as medical possibilities, cultural values and environmental conditions are changing, but also 
as the ideal situation presupposes an unlimited supply of resources. Guidelines for the improvement of a health care system can only be developed within the context and culture of a particular population ${ }^{60}$. Our goal should be to ensure that all patients receive care considered to be of high quality on the basis of scientific data and expert judgement. To meet this goal an assessment of quality is required that is largely based on process criteria. However, we should only use process measures with sound scientific evidence or from a formal consensus of experts, telling us that the criteria we are using do indeed lead to an improvement in health ${ }^{25}$.

Unfortunately, many research findings leading to guidelines do not reach the target group, and if they do, they may not be translated into daily clinical practice $^{61,62}$. Regular evaluation of both patients' and doctors' perspectives on the provided QoC could help policy makers in recognising and solving practical bottlenecks in the health care for the chronically ill. Continuous medical training in clinical practice, besides scientific updating, is not only important for high quality care, but also for increased efficiency and cost-effectiveness. If might even help physicians to practice better with fewer means.

The scientific and the clinical results of the study presented in this thesis appear to be relevant for improvement of $Q \circ C$ in IBD, in addition to the identified relation between QoC and QoL. For these reasons, the developed methodology to assess data from patients, physicians and hospitals, could be adapted to survey QoC for other chronic diseases, such as diabetes mellitus, renal insufficiency, and rheumatoid arthritis. Moreover, the results could be of relevance for EU legislation, regulation, and policies concerning health care. In this way we hope to contribute to the European harmonisation of health care in IBD and possibly in other diseases. 


\section{References}

1 Etzwiler DD. Chronic care: a need in search of a system. Diab Educ 1997;23:56973.

2 Meterko M, Nelson EC, Rubin HR, Batalden P, Berwick DM, Hays RD, et al. Patients' judgments of hospital quality: report of a pilot study. Med Care 1990;28:S1-S56.

3 Cleary PD, McNeil BJ. Patient satisfaction as an indicator of quality care. Inquiry 1988;25:25-36.

4 Lebow JL. Consumer assessments of the quality of medical care. Med Care $1974 ; 12: 328-37$.

5 Zastowny TR, Stratmann WC, Adams EH, Fox ML. Patient satisfaction and experience with health services and quality of care. Qual Man Health Care 1995;3:50-61.

6 Borgiel A, O'Neil JJS. Assessing quality in primary care. Can we ask the right questions? Can Fam Phys 1997;43:1699-700.

7 Riggs JE. Assessing quality of care. The limitation imposed by condorcet paradox. Arch Neurol 1997;54:1351-2.

8 Corbella A, Roma J, Martinez-Carretero JM. Continuing education and quality improvement in primary health care. Int J Qual Health Care 1998;10:65-68.

9 Epstein KR, Laine C, Farber NJ, Nelson EC, Davidoff F. Patients' perceptions of office medical practice: judging quality through the patients' eyes. Am J Med Qual $1996 ; 11: 73-80$.

10 Sixma H, Kerssens JJ, van Campen C, Peters L. Quality of care from the patients' perspective: from theoretical concept to a new measuring instrument. Health Expectations 1998;1:82-95.

11 van Campen C, Sixma H, Kerssens JJ, Peters L, Rasker JJ. Assessing patients' priorities and perceptions of the quality of health care: The development of the quote-rheumatic-patients instrument. Brit J Rheumat 1998;37:362-8.

12 Wilde Larsson B, Larsson G, Starrin B. Patients' views on quality of care: a comparison of men and women. J Nurs Manag 1999;7:133-9.

13 Jun M, Peterson RT, Zsidisin GA. The identification and measurement of quality dimensions in health care: focus group interview results. Health Care Manag Rev $1998 ; 23: 81-96$.

14 Blumenthal D. Quality of health care part 1: Quality of care - what is it? New Engl J Med 1996;335:891-4.

15 Mayberry JF. The diagnosis of inflammatory bowel disease - What should we tell the patient? Ital J Gastroenterol Hepatol 1997;29:483-6.

16 Smart H, Mayberry JF, Calcraft B, Morris JS, Rhodes J. Effect of information booklet on patients' anxiety levels and consultation rates in Crohn's disease. Public Health 1986;100:184-6.

17 Moody GA, Mayberry JF. Life insurance and inflammatory bowel disease: is there a discrimination against patients? Int J Colorect Dis 1996;1 1:276-8.

18 Travis SPL. Review article: insurance risks for patients with ulcerative colitis or Crohn's disease. Aliment Pharmacol Ther 1997;1 1:51-9. 
19 Drossman DA, Leserman J, Mitchell M, Li Z, Zagami EA, Patrick DL. Health status and health care use in persons with inflammatory bowel disease. Dig Dis Sci $1991 ; 36: 1746-55$.

20 Patrick DL. Finding health-related quality of life outcomes sensitive to health-care organization and delivery. Med Care 1997;35:NS49-NS57.

21 Trochim WMK. An introduction to concept mapping for planning and evaluation. Eval Progr Plan 1989;12:1-16.

22 Donabedian A. Evaluating the quality of medical care. Milbank Mem Fund Q 1966;44 (suppl): 166-206.

23 Cleary PD, Edgman-Levitan S, Roberts M, Moloney TW, MCMullen W, Walker JD, et al. Patients evaluate their hospital care: a national survey. Health Affairs $1991 ; 10: 254-67$.

24 Meredith P. But was the operation worth it? The limitations of quality of life and patient satisfaction research in health-care outcome assessment. J Qual Clin Pract 1996;16:75-85.

25 Brook RH, McGlynn EA, Cleary PD. Quality of health care part 2: Measuring quality of care. New Engl J Med 1996;335:966-70.

26 de Boer AGEM, Sprangers MAG, Bartelsman JFW, de Haes JCJM. Predictors of health care utilization in patients with inflammatory bowel disease: a longitudinal study. Eur J Gastroenter Hepatol 1998;10:783-9.

27 Andrews J, Goulston K. Inflammatory bowel disease-its history, current status and outlook. Med J Aust 1994;160:219-23.

28 Drossman DA, Patrick DL, Mitchell CM, Zagami EA, Appelbaum MI. Health-related quality of life in inflammatory bowel disease. Dig Dis Sci 1989;34:1379-86.

29 Guyatt GH, Mitchell A, Irvine EJ, Singer J, Williams N, Goodacre R, ef al. A new measure of health status for clinical trials in inflammatory bowel disease. Gastroenterology 1989;96:804-10.

30 Invine EJ. Quality of life in inflammatory bowel disease: biases and other factors affecting scores. Scand J Gastroenterol 1995;30:136-40.

31 Love JR, Irvine EJ, Fedorak RN. Quality of life in inflammatory bowel disease. J Clin Gastroenterol 1992;14:15-9.

32 Mitchell A, Guyatt GH, Singer J, Irvine EJ, Goodacre R, Tompkins C, et al. Quality of life in patients with inflammatory bowel disease. J Clin Gastroenterol 1988;10:30610.

33 Sales DJ, Kirsner JB. The prognosis of inflammatory bowel disease. Arch Intern Med 1983; 143:294-9.

34 Sorensen VZ, OIsen BG, Binder V. Life prospects and quality of life in patients with Crohn's disease. Gut 1987;28:382-5.

35 Ware JE, Sherbourne CD. The MOS 36-item short-form health survey (SF-36). Med Care 1992;30:473-81.

36 Turnbull GK, Vallis TM. Quality of life in inflammatory bowel disease: the interaction of disease activity with psychosocial function. Am J Gastroenterol 1995;90:1450-4.

37 MacPhee $M$, Hoffenberg EJ, Feranchak A. Quality-of-life factors in adolescent inflammatory bowel disease. Inflam Bowel Dis 1998;4:6-11. 
38 Porcelli P, Leoci C, Guerra V. A prospective study of the relationship between disease activity and psychologic distress in patients with inflammatory bowel disease. Scand J Gastroenterol 1996;31:792-6.

39 Helzer JE, Chammas S, Norland CC, Stillings WA, Alpers DH. A study of the association between Crohn's disease and psychiatric illness. Gastroenterology 1984;86:324-30.

40 Moser G, Tillinger W, Sachs G, Genser D, Maier Dobersberger T, Spiess K, et al. Disease-related worries and concerns: a study on out-patients with inflammatory bowel disease. Eur J Gastroenterol Hepatol 1995;7:853-8.

41 Lazarus RS. Coping theory and research: past, present, and future. Psychosom Med 1993;55:234.

42 Wahl A, Hanestad BR, Wiklund I, Moum T. Coping and quality of life in patients with psoriasis. Qual Life Res 1999;8:427-33.

43 Kinash RG, Fischer DG, Lukie BE, Carr TL. Coping patterns and related characteristics in patients with IBD. Rehabil Nurs 1993;18:12-9.

44 McColl MA, Skinner H. Assessing inter-and intrapersonal resources: social support and coping among adults with a disability. Dis Rehab 1995;17:24-34.

45 Sherbourne CD, Meredith LS, Rogers W, Ware JE. Social support and stressful life events: age differences in their effects on health-related quality of life among the chronically ill. Qual Life Res 1992;1:235-46.

46 North CS, Alpers DH, Helzer JE, Spitznagel EL, Clouse RE. Do life events or depression exacerbate inflammatory bowel disease? Ann Int Med 1991;1 14:381-6.

47 Drossman DA. Life stresses and effects on ulcerative colitis, selected summaries. Inflam Bowel Dis 1995; 1:86-9.

48 Porcelli P, Zaka S, Centonze S, Sisto G. Psychological distress and levels of diease activity in inflammatory bowel disease. Ital J Gastroenterol 1994;26:11 1-5.

49 Levenstein S, Prantera C, Varvo V, Scribano ML, Berto E, Andreoli A, et al. Psychological stress and disease activity in ulcerative colitis: a multidimensional cross-sectional study. Am J Gastroenterol 1994;89:1219-25.

50 Cortis JD, Lacey AE. Measuring the quality and quantity of information-giving to inpatients. J Adv Nurs 1996;24:674-81.

51 Coyle YM, Battles JB. Using antecendents of medical care to develop valid quality of care measures. Int J Qual Health Care 1999;1 1:5-12.

52 Fagerstrom L, Bergbom Engberg I, Erikkson K. A comparison between patients' experiences of how their caring needs have been met and the nurses' patient classification - an explorative study. J Nurs Manag 1998;6:369-77.

53 Greco PJ, Eisenberg JM. Changing physicians' practices. New Engl J Med 1993;329:1271-4.

54 Klazinga N. Re-engineering trust: the adoption and adaptation of four models for external quality assurance of health care services in western European health care sysiems. Int J Qual Health Care 2000;12:183-9.

55 Weinstein JN, Brown PW, Hanscom B, Walsh T, Nelson EC. Designing an ambulatory clinical practivce for outcomes improvement: from vision to reality - the spine center at Dartmouth-Hitchcock, year one. Qual Man Health Care 2000;8:120. 
56 Anell A, Willis $M$. International comparison of health care systems using resource profiles. Bull World Health Organ 2000;78:770-8.

57 Perleth $M$, Jakubowski $E$, Busse $R$. What is 'best practice' in health care? State of the art and perspectives in improving the effectiveness and efficiency of the European health care systems. Health Policy $2001 ; 56: 235-50$.

58 van Kemenade $\mathrm{WW}$. Health care in Europe 1997. The finance and reimbursement systems of 18 European countries. Maarssen: Elsevier/De Tijdstroom, 1997.

59 Irvine EJ, Farrokhyar F, Swarbrick ET. A critical review of epidemiological studies in inflammatory bowel disease. Scand J Gastroenterol 2001;1:2-15.

60 Loewy $\mathrm{EH}$. Justice and health care systems: what would an ideal health care system look like? Health Care Anal 1998;6:185-92.

61 Grol R. Implementation of evidence and guidelines in clinical practice: a new field of research? Int J Qual Health Care 2000;12:455-6.

62 Chassin MR. Quality of health care part 3: Improving the quality of care. New Engl J Med 1996;335:1060-3. 
Chapter 9

Summary 
122 Chapter 9 


\section{Summary}

This thesis describes the role of quality of health care $(Q \circ C)$ in patients with Crohn's disease (CD) and ulcerative colitis $(U C)$, collectively referred to as inflammatory bowel disease (IBD). Health care consists of three aspects: relational (patients), professional (physicians), and organisational (hospitals). The aims of the studies addressed in this thesis were: 1) to assess the IBD patients' opinion on QoC in different European countries; 2) to determine the influence of $Q \circ C$ on quality of life $(Q \circ L) ; 3)$ to assess the perspective of the physicians on QoC and to make a comparison with the patients' perspective; 4) to survey the organisational possibilities of hospitals in several European countries; and 5) to survey health care consumption of European IBD patients during the course of their disease and to relate this to subjective QoL.

It is essential to identify, develop, and implement a system of care that is unique to those with specific, long-term health concerns and requirements. Chapter 1 critically reviews the current knowledge about methods to study the QoC in the chronically ill, concentrating on those with IBD. In summary, several different general measures regarding quality of care assessment in chronic diseases exist. However, in the specific case of IBD no instrument is available to assess total QoC.

In health care, exchanges occur between organisational providers and physicians, and between physicians and patients. It has been shown in chronic diseases that the perspectives of patients and physicians differ with regard to QoC. Relatively little research exists on the ideal combination of health care aspects, organisation, and orientation of physicians to effectively satisfy the needs of the chronically ill patient. Comparisons should be made across types of care (inpatient and outpatient), facilities, patients, and physicians to gain insight into the optimal QoC possible. Patients, physicians, and organisations must be able to integrate, access, respond to, and modify health and health care mechanisms, stressing the need to assess the perspectives of these three groups of health care partners. To develop instruments for these assessments, it is important to involve the target populations from the very start.

Since it has been shown that QoL is impaired in IBD patients, the relationship between $Q O C$ and QOL in IBD is one that is certainly worth studying. If there is an association between these parameters, optimisation of Q०C might improve QoL in IBD.

The development of a questionnaire to assess quality of care through the patients' eyes (QUOTE-IBD) is described in Chapter 2. It was conducted in a multinational setting (seven countries) in co-operation with 380 IBD patients. The result is an easy-to-complete, anonymous, self-administered instrument that was shown to be valid and reliable. The QUOTE-IBD consists of ten generic and 13 
IBD-specific items and combines both importance and performance evaluations. The 23 items are in agreement with the literature, since eight generally accepted care dimensions - accessibility, costs, accommodation, continuity of care, courtesy, information, competence, and autonomy - are represented by at least one item in the concept. These care dimensions represent both structure and process features of the health care system, which enables researchers to relate QoC to health outcome measures such as QoL.

Initial testing of the QUOTE-IBD in the Netherlands showed that the questionnaire was applicable to identify targets for improvement both in hospital settings and in general practices. When arrangements have been made to improve a certain health care aspect, the QUOTE-IBD measurement should be repeated to confirm whether the improvement has been established.

In Chapter 3 the role of QoC in relation to QoL is described. Since literature reported several variables to possibly influence $Q O L$ in IBD (i.e. disease activity, psychological status, coping, stressful life events, and social support), a conceptual model was constructed taking these into account. Data were assessed from IBD patients in eight countries (Norway, Denmark, Ireland, Netherlands, Portugal, ltaly, Greece, and Israel), by using existing questionnaires to assess data on QoL and the reported influencing variables, and the QUOTE-IBD for QoC. The patients participated in an inception cohort of newly diagnosed patients, created between 1991 and 1993. At the moment of data assessment for this study the patients were diagnosed with IBD for six to eight years, suggesting they were experienced with regard to the receipt of health care to their IBD.

Hierarchical multivariate regression analysis showed that in IBD, QoL was indeed influenced by QoC, in particular by the provision of information, as well as by disease activity, psychological status, type of hospital patients attend to (university versus general), social support, stressful life events, and the way of administration of the questionnaire. $C D$ patients suffered from costs of the disease more than patients with UC. For CD patients the continuity of care appeared to be important in QoL, whereas for UC patients the courtesy of attending medical personnel appeared to be crucial.

The physicians' perspective on the QOC provided for IBD patients, and the comparison with the perception of the care-receiving patient, in the same multinational setting as described above, are reported in Chapter 4. A questionnaire to assess the perspective of physicians was developed involving Dutch physicians treating IBD patients. The scoring system was similar to that of the QUOTE-IBD, combining importance and performance ratings. Both questionnaires were administered simultaneously to the respective target populations. It was observed that physicians believed that several care aspects should be improved, in particular the health care costs in IBD. This may be due to the fact that in order to stay within the budget, physicians might be forced to use less expensive, but also less efficient diagnostic procedures or treatments. 
The perspectives of patients and physicians differed markedly, particularly with regard to the provision of information, which was perceived worse by patients than by physicians. It might be that specifically patients with chronic diseases have a growing demand for more detailed information about the nature of their disease, its clinical management, social consequences and prognosis. Other differences might be due to the fact that physicians are restricted to working in predetermined health care structures unknown by the patients.

The available health care facilities and policies for IBD, as observed in the participating twelve European hospitals (eight university and four general hospitals), are presented in Chapter 5. They are used to define "best practice" with regard to IBD. "Best practice" can be summarised as practical guidelines towards optimal quality of care in IBD.

Existing quality norms, developed for total hospital care by a specified organisation, were restricted to IBD-specific care and adapted to the frame of reference of the study group. In each centre these norms were surveyed by means of questionnaires. The data collected were used as a basis for professional peer reviews in all participating centres. Two auditors visited each centre, using a uniform approach. The observations in each centre can be categorised into patient-oriented processes, technical and patient safety, and quality of the medical standard. Several findings can be considered as "benchmarks" (positive care aspects that can directly be implemented for improvement of IBD care in another hospital). In combination with other important positive observations, "best practice" in IBD could be created.

These guidelines for optimal health care for IBD concern a confidential relationship between health care worker(s) and patient, good accessibility to health care, availability of patient data, continuous training and updating of health care workers with regard to care for IBD patients, continuity of care, provision of information to patients, and availability and maintenance of diagnostic and therapeutic equipment and facilities.

Chapter 6 focuses on the health care consumption of IBD patients in eight countries during the first six to eight years of their disease, and the possible relationship of this feature with QoL. Data on health care consumption, QoL, disease activity, and several background variables such as gender and disease localisation, were assessed by means of a patient questionnaire and objective data collection from patient files. Data of $250 \mathrm{CD}$ and 509 UC patients were available for statistical analyses. CD patients, patients with extensive disease, and those with active disease had higher health care consumption during the course of disease compared to patients with ulcerative colitis, restricted disease, and inactive disease, respectively. This might be explained by a more difficult or more serious disease course.

More diagnostic procedures were performed in university compared to general hospitals, probably due to the referral characteristics of university hospitals and the usually greater availability of health care facilities. In northern centres 
126 Chapter 9

paramedical health care consumption was higher than in southern centres, possibly since these services are more extendedly available in the north.

With regard to QoL, it was observed that besides disease activity and female gender, the number of diagnostic procedures negatively influenced QoL. Confirmation of these results by longitudinal studies is required in order to provide practical recommendations for health care policies with regard to invasive diagnostic procedures in IBD.

In conclusion, this thesis presents the development of methods to accurately assess data on QoC from patients, physicians, and health care organisations. Moreover, it shows that a relationship between QoC and QoL exists. Improvement and regular evaluation of QOC in IBD may play a beneficial role in the QoL of IBD patients. Future studies employing these means for data assessment could expand the research population within and between countries in order to facilitate European harmonisation of providing good QoC in IBD. 
Chapter 10

Samenvatting 
128 Chapter 10 


\section{Samenvatting}

Dit proefschrift beschriiff de rol van kwaliteit van gezondheidszorg (QoC) bii patiënten met de ziekte van Crohn (CD) en colitis ulcerosa (UC), ziekłes die ook wel omschreven worden als chronische inflammatoire darmziekten (IBD). Gezondheidszorg bestaat vit relationele (patiënten), professionele (artsen), en organisatorische (ziekenhuizen) aspecten.

De viif doelen van de studies zoals beschreven in dit proefschrift ziin: 1) het in kaart brengen van het patiëntenperspectief met betrekking tot QoC in verschillende Europese landen; 2) het bepalen van de invloed QoC op kwaliteif van leven (QoL) heeft bij IBD; 3) het meten van de opinie van artsen omtrent QoC en deze vergelijken met die van patiënten; 4) het beschrijven van de organisatorische mogelijkheden met betrekking tot zorg voor IBD in ziekenhuizen in een aantal Europese landen; en 5) het in kaart brengen van de zorgconsumptie van Europese IBD-patiënten gedurende het beloop van de ziekte en dit relateren aan de subjectieve QoL.

Het is essentieel om een zorgsysteem te identificeren, ontwikkelen, en implementeren dat uniek is voor patiënten met specifieke, lange termijn behoefte aan gezondheidszorg. In Hoofdstuk 1 wordt een kritisch overzicht gegeven van de huidige wetenschap omtrent methoden waarmee QoC bij chronisch zieken bestudeerd kan worden, toegespitst op IBD. Samenvattend bestaan er verschillende generische methoden om QoC bij chronisch zieken te bepalen. Voor het specifieke geval van IBD bestaat er echter geen instrument om een totaalbeeld van de geboden QoC te geven.

In de gezondheidszorg treden er interacties op tussen zorgmanagers en artsen, alsmede tussen artsen en patiënten. Het is eerder aangetoond dat bij chronische ziekten de visie van artsen en patiënten substantieel kan verschillen wat betreft QoC. Er zijn relatief weinig studies gerapporteerd over de ideale combinatie van zorgaspecten, organisatie, en oriëntatie van artsen om aan de behoeften van chronisch zieke patiënten te voldoen. Er zouden vergelijkingen gemaakt moeten worden binnen zowel klinische als poliklinische zorg, aanwezige faciliteiten, patiënten, en artsen om inzicht te kriigen in de best mogelijke QoC. Patiënten, artsen, en ziekenhuizen moeten in staat zijn gezondheids(zorg)mechanismen te integreren, toegang hiertoe te verlenen en deze aan te passen. Hierbii zou de nadruk gelegd moeten worden op de noodzaak om de visies van deze drie partners op de geboden gezondheidszorg te verkrijgen. Om methoden voor dit doel te ontwikkelen is het van belang om de doelgroepen van begin af aan bii het proces te betrekken.

Daar het aangetoond is dat IBD-patiënten een verlaagde QoL hebben ten opzichte van gezonde personen, is het de moeite waard om de mogelijke relatie tussen $Q_{0} C$ en $Q o L$ te bestuderen. Als er een relatie tussen deze twee 
parameters bestaat, zou dat betekenen dat een hogere mate van QoC de QoL bij IBD-patiënten zou kunnen verbeteren.

De ontwikkeling van een vragenlijst om het perspectief van IBD-patiënten op QoC te bepalen (de QUOTE-IBD) wordt beschreven in Hoofdstuk 2. Dit onderzoek is uitgevoerd in een multinationale setting (zeven landen) in samenwerking met 380 IBD-patiënten. Het resultaat is een eenvoudig zelf in te vullen, anonieme vragenlijst waarvan de validiteit en betrouwbaarheid zijn aangetoond. De QUOTE-IBD bestaat vit tien generische en 13 IBD-specifieke vragen, en combineert zowel de mate van belang die de patiënt aan bepaalde zorgaspecten hecht als de ervaring van de patiënt met deze aspecten. De 23 vragen zijn in overeenstemming met de literatuur gezien het feit dat acht algemeen geaccepteerde dimensies van QoC - toegankelijkheid, kosten, accommodatie, continuïteit van zorg, bejegening, informatievoorziening, competentie, en autonomie - worden gerepresenteerd door tenminste één vraag in het concept. Deze zorgdimensies representeren zowel structuur- als proceskenmerken van het gezondheidszorgsysteem, waardoor onderzoekers in staat zijn om QoC aan vitkomstmaten zoals QoL te relateren.

Het initieel testen van de QUOTE-IBD in Nederland heeft aangetoond dat de vragenlijst toegepast kan worden om aspecten te identificeren die verbetering behoeven, in zowel ziekenhuizen als huisartsenpraktiiken. Als er regelingen getroffen worden om een zorgaspect te verbeteren, zou de meting met de QUOTE-IBD herhaald moeten worden om te bevestigen dat de verbetering daadwerkelijk heeft plaatsgevonden.

In Hoofdstuk 3 wordt QoC in relatie tot QoL beschreven. Aangezien in de literatuur verscheidene variabelen zijn gerapporteerd die QoL bij IBD-patiënten kunnen beïnvloeden (ziekteactiviteit, psychologische status, omgaan met de ziekte, stressvolle gebeurtenissen, en sociale steun), werd er een conceptueel model ontwikkeld dat rekening houdt met deze factoren. Vervolgens zijn hier gegevens over verzameld van IBD-patiënten in acht landen (Noorwegen, Denemarken, lerland, Nederland, Portugal, Italië, Griekenland en Israël), door middel van bestaande vragenlijsten voor $Q$ oL en voor de in de literatuur gerapporteerde variabelen, alsmede de QUOTE-IBD voor QoC. Bii de deelnemende patiënten was IBD gediagnosticeerd tussen 1991 en 1993. Dit betekent dat op het moment van dataverzameling voor de huidige studie de patiënten reeds zes tot acht jaar bekend waren met deze ziekte en gedurende deze periode ervaring hebben opgedaan met gezondheidszorg voor IBD.

Met hiërarchische multivariate regressie-analyse is aangetoond dat bij patiënten met IBD de QoL inderdaad werd beïnvloed door QoC, en dat met name informatievoorziening over de ziekte een rol bleek te spelen. Ook ziekteactiviteit, psychologische status, het soort ziekenhuis dat de patiënten bezochten (academisch of perifeer), sociale steun, stressvolle gebeurtenissen en de manier waarop de vragenlijst afgenomen werd (interview of zelfrapportage), beïnvloedden de QoL. Patiënten met CD bleken grotere problemen te hebben met de kosten die met hun ziekte gepaard gaan dan patiënten met UC. 
Bovendien bleek de continuïteit van de zorg van belang te zijn voor QoL bij patiënten met $C D$, terwiil voor patiënten met $U C$ de bejegening van behandelend medisch personeel, zoals ervaren door de patiënten, cruciaal was.

De visie van de arts op de QoC die aan IBD-patiënten geboden wordt, alsmede het vergelijk met de mening van de patiënt die de zorg ontvangen heeft in dezelfde multinationale setting als boven beschreven, worden in Hoofdstuk 4 beschreven. Nederlandse artsen die IBD-patiënten behandelen zijn betrokken bii de ontwikkeling van een vragenlijst om de opinie van artsen te peilen. Het scoresysteem was gelijk aan dat van de QUOTE-IBD, waarbii belang- en ervaringsevaluaties worden gecombineerd. Beide vragenlijsten zijn tegelijkertijd ingevuld door de respectievelijke doelgroepen. Het bleek dat artsen van mening waren dat verscheidene zorgaspecten verbeterd zouden kunnen worden, met name de kosten voor gezondheidszorg voor IBD. Deze bevinding zou toegeschreven kunnen worden aan de mogelijkheid dat artsen, om binnen het budget te blijven, gedwongen kunnen zijn om minder dure, maar ook minder efficiënte diagnostische procedures of behandelingen toe te passen dan optimaal zou ziin.

De visies van artsen en patiënten met betrekking tot QoC verschilden substantieel, met name ten aanzien van de informatievoorziening, welke slechter werd beoordeeld door patiënten dan door hun artsen. Een verklaring hiervoor zou kunnen zijn dat patiënten met een chronische ziekte een toenemende behoefte aan gedetailleerde informatie omtrent de aard van hun ziekte, de klinische behandeling, sociale consequenties en prognose hebben. Andere verschillen kunnen zijn ontstaan doordat artsen beperkt worden in hun behandelingsstrategieën door bepaalde gezondheidszorgstructuren die onbekend zijn bii de patiënt.

De beschikbare gezondheidszorgfaciliteiten en strategieën om IBD te behandelen, zoals geobserveerd in de twaalf deelnemende Europese ziekenhuizen (acht academische en vier perifere ziekenhuizen), worden gepresenteerd in Hoofdstuk 5. Deze observaties zijn gebruikt om "best practice" voor IBD te definiëren. "Best practice" kan omschreven worden als een set praktische richtlijnen voor optimale QoC voor een bepaalde ziekte.

Bestaande kwaliteitsnormen, zoals ontwikkeld door een professionele organisatie voor ziekenhuisbrede zorg, werden beperkt tof IBD-specifieke zorg en aangepast aan het referentiekader van de studiegroep. In elk centrum zijn deze normen in kaart gebracht door middel van vragenlijsten. De verzamelde data zijn vervolgens gebruikt als basis voor professionele "peer reviews" in alle deelnemende centra. leder ziekenhuis werd bezocht door twee auditoren, waarbii gebruik werd gemaakt van een uniforme aanpak. De observaties in de centra kunnen gecategoriseerd worden in patiëntgeoriënteerde processen, technische en patiëntgebonden veiligheid, en kwaliteit van de medische standaard. Verscheidene bevindingen kunnen gezien worden als "benchmarks" voor IBD (dit zijn positieve zorgaspecten die direct in een ander ziekenhuis geïmplementeerd kunnen worden ter verbetering van zorg). In combinatie met 
andere positieve bevindingen kon "best practice" voor IBD ontwikkeld worden. Deze richtlijnen voor optimale gezondheidszorg voor IBD hebben betrekking op een vertrouwensband tussen zorgverlener(s) en patiënt, een goede toegankelijkheid van de zorg, de beschikbaarheid van patiëntgegevens, continue training en bijscholing in zorg voor IBD van zorgverleners, continuitteit van zorg, informatievoorziening aan patiënten, en beschikbaarheid en onderhoud van diagnostische en therapeutische faciliteiten.

Hoofdstuk 6 richt zich op de zorgconsumptie van IBD-patiënten in acht landen gedurende de eerste zes tot acht jaar van hun ziekte, en de mogelijke relatie hiervan met subjectieve QoL. Gegevens over zorgconsumptie, ziekteactiviteit en verscheidene achtergrondvariabelen zoals geslacht en ziektelokalisatie, werden verkregen door middel van een patiëntenvragenlijst alsmede door objectieve dataverzameling vit medische patiëntendossiers. Gegevens van 250 patiënten met CD en 509 met UC konden worden geïncludeerd in de statistische analyses. Patiënten met CD, met uitgebreide ziektelokalisatie en met actieve ziekte, bleken een grotere zorgconsumptie gedurende het beloop van hun ziekte te hebben dan patiënten met respectievelijk UC, beperkte ziektelokalisatie en inactieve ziekte. Dit zou verklaard kunnen worden door een complexer en ernstiger ziektebeloop van de eerstgenoemde groep.

In academische ziekenhuizen werden meer diagnostische procedures vitgevoerd dan in perifere ziekenhuizen. Waarschijnlijk is dit veroorzaakt door verwijzingen naar academische ziekenhuizen en de gewoonlijk grotere beschikbaarheid van zorgfaciliteiten aldaar. In noordelijke centra werd er een grotere consumptie van paramedische zorg geobserveerd dan in zuidelijke centra, mogelijk doordat deze diensten in grotere mate beschikbaar zijn in het noorden.

Met betrekking tot QoL bleek dat het aantal vitgevoerde diagnostische procedures, naast ziekteactiviteit en vrouwelijk geslacht, de QoL negatief beïnvloedde. Bevestiging van deze resultaten door middel van longitudinale studies is noodzakelijk om praktische aanbevelingen te kunnen doen voor gezondheidszorgstrategieën met betrekking tot het vitvoeren van invasieve diagnostische procedures bii IBD-patiënten.

Samengevat presenteert dit proefschrift de ontwikkeling van methoden om nauwkeurige gegevens te verzamelen over QoC van patiënten, artsen en gezondheidszorgorganisaties. Het beschreven onderzoek heeft aangetoond dat er een relatie bestaat tussen QoC en QoL. Verbetering en regelmatige evaluatie van QoC voor IBD zou een gunstige rol kunnen spelen voor de QoL van IBDpatiënten. Toekomstig onderzoek waarin de ontwikkelde methoden voor dataverzameling gebruikt worden, zou de onderzoekspopulaties binnen en tussen landen kunnen vergroten om Europese harmonisering ten aanzien van hef verstrekken van goede QoC voor IBD-patiënten te faciliteren. 
Dankwoord 

134 


\section{Dankwoord}

Gedurende het onderzoek dat beschreven wordt in dit proefschrift ben ik veel mensen tegengekomen die mij op verschillende manieren geholpen hebben een stapie verder te komen in de wetenschap en in het leven in het algemeen. Zonder woord van dank is de afsluiting van vier jaar onderzoek dan ook niet compleet.

Mijn begeleider Maurice Russel had zelf een duidelijk idee over hoe het onderzoek zou moeten verlopen, maar liet mij wel de vrije hand om mijn eigen ideeën vit te werken. Maurice, ik waardeer het enorm dat je altijd tijd voor me vriimaakte, ondanks je eigen drukke agenda. Je haalde zelf al aan tijdens de laatste EC*IBD meeting dat we tijdens onze vele reizen naar congressen en dergelijke behalve hard gewerkt ook veel gelachen en leuke dingen gedaan hebben. Dank je wel, en ook voor het feit dat je altijd een rotsvast vertrouwen in mij had!

Natuurlijk zou dit proefschrift ook niet geworden zijn wat het nu is zonder mijn promotor Reinhold Stockbrügger. Vooral in de latere fasen hadden wii steeds vaker met elkaar te maken en heeft hij me gericht gestuurd. Hij was de bron van deze studie en geloofde in mijn capaciteiten, stimuleerde me iedere keer weer om net een beetje hoger te grijpen. En Reinhold, ondanks mijn eigen bedenkingen hierover wist je dat het me zou lukken... dank je wel!

The participation of so many patients from eight different countries has been indispensable for the final results. I would like to express my gratitude for their confidence in the project and their willingness to share so much personal information. In particular I would like to thank the European Federation of Crohn's and Colitis Associations (EFCCA) for their contribution.

Professor Spreeuwenberg, professor Baeten en professor Grol wil ik bedanken voor hun bereidwilligheid om dit proefschrift te lezen en te beoordelen. I am grateful to professor O'Morain and professor Irvine for their contribution to the evaluation of this thesis.

The participants of the EC*IBD study group accepted me from the beginning as a full member of the group. I really enjoyed working with them and they will stay in my memory as a very fine group of people, sharing great scientific and social ideas (I will never forget the famous dinner songs!). Great hospitality was displayed wherever we met for congresses or else, which I noticed on a personal basis during the site visits. I can only mention a few of them: Pia Munkholm, Patrizia Politi, Kostas Katsanos, Ingemar Engdahl, Martin Buckley, Selwyn Odes, João Freitas, Yannis Mouzas, and loannis Vlachonikolis. I hope all the others 
know that I am just as grateful to them for this accomplishment, which is something we did together!

Alle gegevens die ik verzamelde in de verschillende landen werden minutieus ingevoerd in de computer door de dames van data-entry bij het MEMIC. Wat ben ik blii dat zii dat wilden doen! Het efficiënt in goede banen leiden hiervan en de hulp bij de statistiek van eerst Eric van Wijlick en later Judy Nijman heb ik altijd zeer gewaardeerd. Alle andere medewerkers van het MEMIC wil ik graag bedanken voor de gezellige tijden toen mijn werkplek nog bij hen op de afdeling was, en ik wil met name noemen dat de koffie van Jacqueline Khalifa nog altijd onovertroffen is. Specifiekere statistische ondersteuning kreeg ik van Petra Koken en later van Reini Bretveld. De professionele relatie met Petra liep vit op een dierbare persoonlijke vriendschap, die standhoudt ondanks dat ze nu al enige jaren in Amerika woont. Onlangs heb ik haar nog opgezocht en is weer gebleken dat we iets heel bijzonders delen. Daarom ben ik dankbaar dat zii mijn paranimf wil zijn.

Zonder de inzet van Herman Sixma zou een groot gedeelte van dit proefschrift er heel anders hebben uitgezien. Dankzii zijn sturing en ongelofelijke geduld in het beantwoorden van mijn ontelbare vragen is het gelukt een internationale vragenlijst te maken waarmee we de mening van de IBD-patiënt over de geboden zorg kunnen peilen. Tamara Smeets heeft deze lijst gevalideerd in Nederland.

Ook Frank Verheggen verdient een aparte vermelding. Hii liet me kennismaken met voor mij onbekende terreinen in de zorg. Ik heb veel van hem geleerd. Tevens bracht hij me in contact met het $\mathrm{CBO}$, waar ik de nodige sturing kreeg zowel wat betreft theoretische achtergronden als de praktiik. Jan Fossen begeleidde me tijdens de eerste site visit.

Marie-Noëlle Janssen en Barbara Ryan ben ik zeer dankbaar voor het snel en nauwkeurig corrigeren van de Engelse taal van mijn manuscripten. Tiny Wouters dank ik voor haar kantooruren-overschrijdende enthousiasme om een mooi verzorgde lay-out van dit proefschrift af te leveren.

Dank ook aan Laurent Paulussen voor zijn inzet om mij het boekhouden aan te leren. Gedurende de afgelopen vier jaar ben ik er zelfs een zeker plezier aan gaan beleven!

Voorts heb ik goede herinneringen aan mijn (oud-)collega's van de afdeling gastroenterologie, ik heb er altiid met veel plezier gewerkt. Daarom wil ik Dominique Goossens, Silvia Sanduleanu, Edith Maes, Anita Feleus, Erik Schoon, Ger Koek, Robert-Jan Brummer, Annemarie Wensing, Wim Hameeteman, Mariëlle Romberg, Lilian Wishaupt, Elly Mores, Marc de Bièvre en Jan Kamphuis bedanken voor de prettige werksfeer en de meeste onder hen natuurlijk ook voor hun bijdrage aan het onderzoek door patiënten te benaderen en mij van gegevens te voorzien. Aan Frank Wolters draag ik de EC*IBD-toorts over, waardoor hii een veeleisende maar plezierige taak krijgt. Ik wens hem veel succes met zijn eigen promotieonderzoek. Noël Jaegers heeft mij heel wat werk 
vit handen genomen bij de organisatie van verschillende meetings. Mijn dank is groot!

Ardi Oberndorff was vaak mijn redding in nood, als ik er zelf geen tijd voor had loste zii de nodige problemen voor me op. Dank je wel! Michiel van Nieuwenhoven heeft me regelmatig de meest verrukkelijke maaltijden voorgezet, aangenaam vergezeld door een goede wijn. En natuurlijk is onze fantastische reis door Californië een onvergetelijke herinnering.

Het onderzoek dat mij vier jaar heeft beziggehouden was eerst in handen van Martine Hesselink, maar zii heeft het aan mii afgestaan om meer tijd aan haar kinderen te kunnen besteden. In al die jaren is zij wel mijn kamergenote geweest en hebben we heel wat onderwerpen de revue laten passeren, onder andere tijdens het voorbereiden van grote mailings. Ook hebben we een aantal gezellige "meidenavonden" gehad met Gaby Scheepers, Bertine Philipsen, Daisy Jonkers en Anita Ruiigers. Gaby is zelfs één van mijn beste vriendinnen geworden, ook al heeft zij het azM kort na mijn aanstelling verlaten. Maar we bellen elkaar iedere dag eventies, en onze vriendschap heeft ons door een paar moeilijke perioden in ons leven heen geholpen. Ik ben blij dat ook zij mijn paranimf wil zijn.

De nodige ontspanning werd op feesties, skivakanties, sportuurties en andere gezellige activiteiten verzorgd door mijn vrienden en familie. Met name wil ik hier noemen: Saskia en Philip, Luuk en Anique, Harm en Chantal, Monique en Hans, Stephan, Edwin en Nicole, Smol en Delian, Nicole, Leo en Astrid. En natuurliik Jeroen, met wie ik erg gelukkige jaren heb gedeeld.

Als laatste wil ik mijn grootouders noemen. Zii zijn mijn uitlaatklep voor alles, daarom draag ik met liefde dit proefschrift aan hen op. Zii weten hoe het leven in elkaar zit en wat belangrijk is. Zij zijn mijn voorbeeld van hoe ik de wereld in wil kijken. Bedankt lieve opa en oma, jullie onvoorwaardelijke steun kent geen grenzen! 
138 
Curriculum Vitae 

140 


\section{Curriculum Vitae}

Ingrid van der Eijk werd op 7 februari 1972 geboren te Eindhoven. In 1990 behaalde zii het VWO diploma aan het Bernardinus College te Heerlen. Datzelfde jaar startte zij met de studie Gezondheidswetenschappen aan de Universiteit Maastricht, met als afstudeerrichting Biologische Gezondheidkunde. $\mathrm{Na}$ een stage en een jaar vrijwilligerswerk op de afdeling Diëtetiek van het academisch ziekenhuis Maastricht, gevolgd door een extra stage aan de University of Sydney, Australia, werd het doctoraal examen gehaald in 1996. In 1997 begon zii bii de vakgroep Interne Geneeskunde van de Universiteit Maastricht aan het in dit proefschrift beschreven promotieonderzoek, onder leiding van Prof. dr. R.W. Stockbrügger en Dr. M.G. Russel. 